\title{
NEW ZEALAND CONTRIBUTIONS TO THE INTERNATIONAL WORKSHOP on the SEISMIC DESIGN AND RETROFITTING Of REINFORCED CONCRETE BRIDGES BORMIO, ITALY, APRIL 2-5, 1991
}

\author{
R. Park1, H.E. Chapman'2, L.G. Cormack ${ }^{3}$, and \\ P.J. North 4
}

\section{BACKGROUND TO THE WORKSHOP}

The Loma Prieta earthquake in California in 1989 again emphasized the vulnerability of bridge structures to seismic damage. At an informal discussion between some engineers at the Fourth United states National Conference on Earthquake Engineering in Palm springs, California, in May 1990, it was considered that an interchange of information on design philosophies and procedures used in Europe, the United States, Japan and New Zealand would be invaluable. This would lead to a definitive comparison of the current state of the art and of practice in reinforced concrete bridge seismic design and retrofitting in major seismically active regions.

A workshop was organised by Professor $G$ Michele Calvi of the Universita di Pavia, Italy, and Professor M J Nigel Priestley of the University of California, San Diego, and held at Bormio in the Italian Alps during 25 April 1991.

The Workshop was attended by a total of eleven engineers from the European countries of Austria, Greece, Italy, Portugal and Switzerland, five engineers from the United States, three engineers from Japan and four engineers from New Zealand. The New Zealand engineers who attended are the authors of this report.

The names of all 23 participants at the Workshop are 1 isted in Appendix 1.

The Workshop was sponsored by the following organisations:

National center for Earthquake
Engineering Research (USA)
National Research Council (Italy)
Earthquake and War Damage Commission (NZ)
VSL International LTD (Switzerland)
Universita Degli Studi Di Pavla (Italy)
Banca Del Monte Di Lombardla (Italy)
NZ National Society for Earthquake
Engineering

\section{OBJECTIVE AND SCORE OF THE WORKSHOP}

The main objective of the workshop was to provide a critical comparison of the current state-of-the-art and of the practice in reinforced concrete bridge seismic design and retrofitting between the main seismically active regions. A secondary objective was to produce a clear statement of research needs and to propose possible international research cooperation. Four points of view were to be considered and compared, according to a geographical base which also corresponds to different design philosophies: the European, American, Japanese and New Zealand approaches were to be discussed. Emphasis was to be put on discussion of unresolved differences between different design and research practices. The workshop was organised in four sections, dealing with (1) basic concepts, (2) detailing, (3) examples of application, and (4) retrofitting. Each section was to consist of a presentation from each of the groups involved and an in-depth discussion session.

\section{THE MORRBHOP BESSIONB}

The workshop was organised into four main sessions with contents as described below:

\section{Session 1: Basic design concepts}

This section of the workshop was to deal with design philosophy and requirements (limit states), definition of seismic design loading and related assumptions, procedures of analysis, definition of ductility levels and accepted force reduction factors. The suggested list of contents was as follows:

1. Design Philosophy

1.1 Evaluation of the importance of the bridge

1.2 Definition of limit states and their probability of occurrence (Fellow and Group Leader)

2 Works consultancy Services Ltd, Wellington (Fellow)

3 Beca, Carter, Hollings and Ferner, Auckland (Member)

Murray North and Partners, Auckland (Fellow and NZNSEE President) 
1.3 Basic design choices: structural systems, bridge types, isolation or dissipation devices

2. Seismic action

2.1 Definition of ground motion (ground acceleration and frequency content)

2.2 Effects of local soil conditions

2.3 Assumptions on the ground motion at the base of different piers

2.4 Treatment of vertical acceleration

3. Procedures of analysis
3.1 Linear static
3.2 Linear dynamic
3.3 Nonlinear
3.4 Foundations (abutments) and soil- structure interaction

4. Ductility levels

4.1 Bridge types

4.2 Curvature ductility

4.3 Displacement ductility

4.4 Force reduction factors

4.5 Maximum displacements

4.6 Second order effects ( $p$ delta)

\section{Session 2: Design details}

The discussion was to be centred on typical member proportions and reinforcement details, addressing the problem of the typical capacity design principles adopted in each design approach, of their relevance and of their mutual consistency. The suggested list of contents was as follows:

1. Member proportioning and details

1.1 Basic parameters and choices for member proportioning

1.2 Foundations

1.3 Isolation and dissipation devices

1.4 Provisions for deck joint seismic movement

2. Reinforcement details

2.1 Typical reinforcement grade and percentage

2.2 Critical regions

2.3 Anchorage, splices, confinement

3. Capacity design principles

3.1 Soil-foundation

3.2 piers

3.3 Connections between deck and piers (abutments)

3.4 Deck

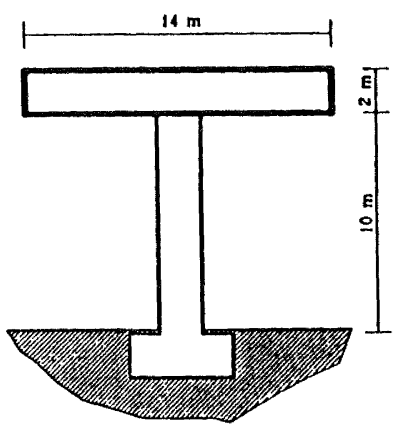

FIGURE 1 BASIC GEOMETRY OF THE VIADUCT

\section{Session 3: Examples of application}

The objective of this session was to facilitate the comparison of design approaches used in different countries and to discuss the differences resulting from state-of-the-art and a code approach. For this purpose, each of the participant groups was to prepare a few design examples, according to the structural and seismicity constraints given in what follows. Comments on possible design alternatives were recommended.

\section{Case 1}

A portion of an infinitely long viaduct with identical spans and vertical structures was to be considered. The span length was $40 \mathrm{~m}$ with a clear height of $10 \mathrm{~m}$ (Figure 1). The viaduct was supposed to be part of a threelane freeway, with a total dead weight of the structure of $200 \mathrm{kN} / \mathrm{m}$. The soil behaviour was assumed to be elastic-plastic bilinear, with the plastic hardening portion represented as a straight line of slope $1 / 4$ of the initial elastic slope $k$. The elastic limit was to occur at a deflection $w^{*}$ which was constant with depth. $w^{*}$ was assumed equal to $25 \mathrm{~mm}$. The elastic slope $k$ was assumed to vary linearly with the depth $z$ according to the relation:

$$
k=z / 100
$$

where $k$ was in $\mathrm{N} / \mathrm{mm}_{2}$ and $z$ in $\mathrm{m}$. This is illustrated in Figure 2. Four possible variations were to be examined: the maximum ground acceleration was to be set to 0.25 and $0.40 \mathrm{~g} ;$ a single circular pier and a frame with two rectangular piers were to be designed as a vertical structure. Only a transverse analysis of one bent was required.

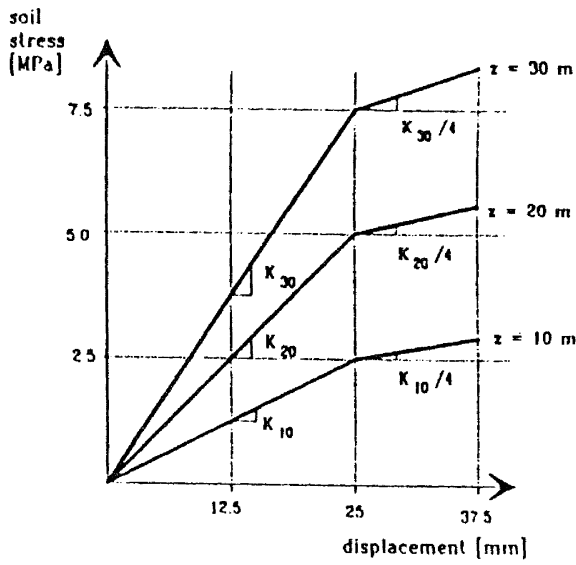

FIGURE 2 BOIL BEHAVIOUR

Case 2

A whole bridge was to be considered, both in the transverse and longitudinal directions. Function of the bridge, mass per unit length, seismicity and soil were the same as in case 1. The geometrical constraints are given in Figure 3. 


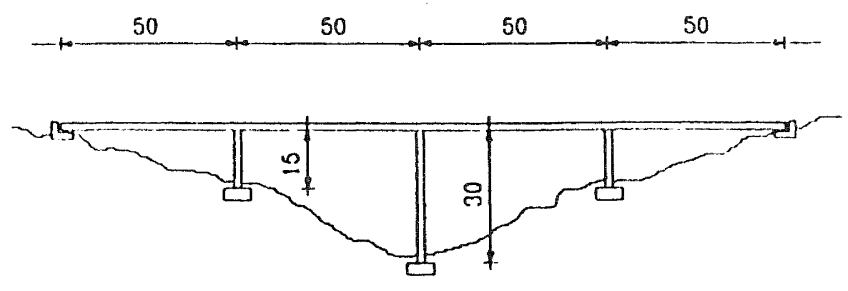

FIGURE 3 ELEVATION OF THE WHOLE BRIDGE

\section{Session 4: Retrofitting}

This session was to deal with the main inadequacies encountered in the bridges constructed in the recent past in each of the geographical areas represented in the workshop, and with possible retrofitting strategies adopted or suggested in the various regions. A revision of the concepts discussed in sessions 1 and 2 when applied to retrofitting was to be addressed together with the effectiveness of the different retrofitting techniques. It was suggested that the following items be addressed in each paper:

1. Assessment of existing structures

1.1 Flexural strength

1.2 Flexural ductility

1.3 Shear strength

1.4 Beam/column joint shear strength

1.5 Foundation capacity

2. Observed behaviour of existing bridges

3. Methods of retrofit, including design methods

3.1 Flexural strength

3.2 Shear strength

3.3 Joint shear strength

3.4 Foundation capacity

3.5 Capacity design requirements

4. Methods for prioritizing retrofit needs between different structures

5. Examples of retrofit implemented at time of writing papers

\section{WORKSHOP PROGRAMME}

Tuesday, 2 April

Foreword

Session 1A: Basic design concepts presentations (USA, New Zealand, Japan, Europe) Chairman: Professor PE Pinto

Session 1B: Basic design discussion

Wednesday, 3 April

Session 1C: Basic design concepts Session 2A: discussion Design details presentations (Japan, USA, Europe, New Zealand) Chairman: Professor GM Calvi Design details - discussion Session 2C: Design details - discussion
Thursday, 4 April

$\begin{array}{ll}\text { Session 3A: } & \begin{array}{l}\text { Examples of application - } \\ \text { presentations (New Zealand, } \\ \text { Europe, USA, Japan) } \\ \text { Chairman: Professor R Flesch } \\ \text { Examples of application - } \\ \text { discussion }\end{array} \\ \text { Session 3B: } & \begin{array}{l}\text { Examples of application - } \\ \text { discussion } \\ \text { Retrofitting - presentations } \\ \text { (Europe, Japan, New Zealand, } \\ \text { USA) } \\ \text { Chairman: Professor IG Buckle }\end{array}\end{array}$

Friday, 5 April

$\begin{array}{ll}\text { Session 4B: } & \text { Retrofitting - discussion } \\ \text { Session 4C: } & \text { Retrofitting - discussion } \\ \text { Session 5A: } & \text { Summary } \\ \text { Session 5B: } & \begin{array}{l}\text { Researman Professor R Park } \\ \text { cooperation programs and }\end{array}\end{array}$

\section{PROCEEDINGS OF THE WORKSHOP}

The papers prepared by the participants and the written reports of the discussion session chairmen will constitute part of a volume which is to be published as the proceedings of the workshop.

The four New Zealand papers presented at the workshop are published as sections of the paper that follows. The principal authors of the four sections are:

Section 1 - R. Park and H.E. Chapman Section 2 - P.J. North and R. Park Section 3 - L.G. Cormack Section 4 - H.E. Chapman

A written summary of the Workshop discussions and the summary of the findings of the Workshop will be published in a subsequent issue of the Bulletin.

\section{PARTICIPANTS}

$\begin{array}{lll}\text { Franco } & \text { BRAGA } & \text { Italy } \\ \text { G Michele } & \text { CALVI } & \text { Italy } \\ \text { Eduardo C CARVALHO } & \text { Portugal } \\ \text { Muaro } & \text { DOLCE } & \text { Italy } \\ \text { Ricardo } & \text { DUARTE } & \text { Portugal } \\ \text { Rainer } & \text { FLESCH } & \text { Austria } \\ \text { Basil C } & \text { KOLIAS } & \text { Greece } \\ \text { Camillo } & \text { NUTI } & \text { Italy } \\ \text { Paolo E } & \text { PINTO } & \text { Italy } \\ \text { Thomas } & \text { WENK } & \text { Switzerland } \\ \text { Franz A } & \text { ZAHN } & \text { Switzerland } \\ & & \\ \text { Hisanobu } & \text { ICHIMASU } & \text { Japan } \\ \text { Juro } & \text { KODERA } & \text { Japan } \\ \text { Hajime } & \text { OHUCHI } & \text { Japan } \\ & & \\ \text { Howard E } & \text { CHAPMAN } & \text { New Zealand } \\ \text { Gavin } & \text { CORMACK } & \text { New Zealand } \\ \text { Peter J } & \text { NORTH } & \text { New Zealand } \\ \text { Robert } & \text { PARK } & \text { New Zealand } \\ \text { Ian G } & \text { BUCKLE } & \text { USA } \\ \text { James H } & \text { GATES } & \text { USA } \\ \text { Stephen A MAHIN } & \text { USA } \\ \text { MJ Nigel } & \text { PRIESTLEY } & \text { USA } \\ \text { Frieder } & \text { SEIBLE } & \text { USA } \\ & & \end{array}$




\section{SECTION 1 \\ BASIC DESIGN CONCEPTS FOR HIGHWAY BRIDGES}

(Principal Authors: R Park and HE Chapman)

\subsection{BRIDGE DESIGN BPECIFICATIONB}

In New Zealand in recent years the design of highway bridges on public roads, which were financed wholly or partly from funds provided by the former New Zealand National Roads Board, was conducted using the Highway Bridge Design Brief [1.1] issued by the former Ministry of Works and Development which specified general design requirements and design loadings. The design of concrete bridges was also required to be in accordance with the Concrete Design code [1.2] issued by the Standards Association of New Zealand in 1982 which specifies design requirements for reinforced and prestressed concrete.

The Highway Bridge Design Brief has more recently been replaced by a Bridge Manual which was published as a provisional document by the former National Roads Board (NRB) in september 1989 [1.3]. The NRB Bridge Manual has been republished by its successor, Transit New Zealand (TNZ), as a draft for comment entitled Bridge Manual : Design and Evaluation [1.4]. The TNZ Bridge Manual [1.4] was prepared by Works and Development Services Corporation (NZ) Ltd.

A great many of the changes made to the earthquake design provisions in the Bridge Manuals $[1.3,1,4]$ are based on the recommendations of the discussion group on the seismic design of bridges which was convened by the New Zealand National Society for Earthquake Engineering and published in a Bulletin of the Society in September 1980 [1.5]. The design loadings for bridges in the Bridge Manuals $[1.3,1.4]$ have been based on the latest published draft recommendations of the committee of the Standards Association of New zealand which is revising the code for the general structural design and design loadings for buildings [1.6].

Significant information on the seismic design of bridges has also been published in recent years in New Zealand in other papers in the Bulletin of the New Zealand National Society for Earthquake Engineering, and in the papers and summary volumes prepared for Bridge Design and Research Seminars organized by the Road Research Unit of the National Roads Board in Auckland in 1978 and 1984, and more recently by Transit New Zealand in Christchurch in $1990[1.7$ to $1.11]$.

This paper summarizes the current design philosophy for concrete bridges in New zealand with emphasis on the seismic resistance. The seismic design provisions from the TNZ Bridge Manual [1.4] were reproduced as Appendix 1 to the original paper (but are not reproduced herein) and some of the background to those provisions will be discussed.

\subsection{BRIDGE BTROCTURAL BYBTEMS}

A range of highway bridge types are in use in New Zealand.

Most bridge superstructures constructed in New Zealand in recent years utilize standard precast prestressed concrete units in the form of $I$ or $T$ sections, or hollow core or $U$ or $W$ sections, or solid rectangular sections, depending on the span. Pretensioned or post-tensioned, or combined pre and post-tensioned, units have been used. Generally the precast units act compositely with cast in situ concrete slab or topping. Precast segmental construction has also been used. Totally cast in situ concrete bridge superstructures are more economical and appropriate for long spans, usually continuous, especially where shallow construction depths are necessary, or where the geometric shape of the structure is complicated. Superstructure spans are always connected at intermediate supports, either by continuity, by deck linkage slab or by linkage bolts.

The substructures of bridges tend to be constructed of reinforced concrete and to be relatively simple structures, involving few structural members. A typical bridge substructure may consist of one or more columns, or a wall, supported by either a spread footing or a pile cap connected to driven or cast in situ piles. At the top of the columns or wall is a cap which supports the superstructure. Sometimes the cap is a diaphragm within a box girder.

Recently constructed highway bridge substructures frequently consist of single or multiple steel encased cast in situ concrete piles beneath ground level with a reinforced concrete column and column cap above supporting the bridge superstructure (see Figure 1.1).

The end of the bridge superstructure can be designed to be free to rotate and translate relative to the substructure, or designed with integral or semi-integral abutments.

According to the Bridge Manual [1.4], an integral abutment is defined as one which is built integrally with the end of the bridge superstructure and with the supporting piles. The abutment therefore forms the end diaphragm of the superstructure and the retaining wall for the approach filling. The supporting piles are restrained against rotation relative to the superstructure, but are free to conform to superstructure length changes by pile flexure. A semi-integral abutment is defined [1.4] as an integral abutment which contains provision for relative rotation, but not translation, between the superstructure and the supporting piles. 


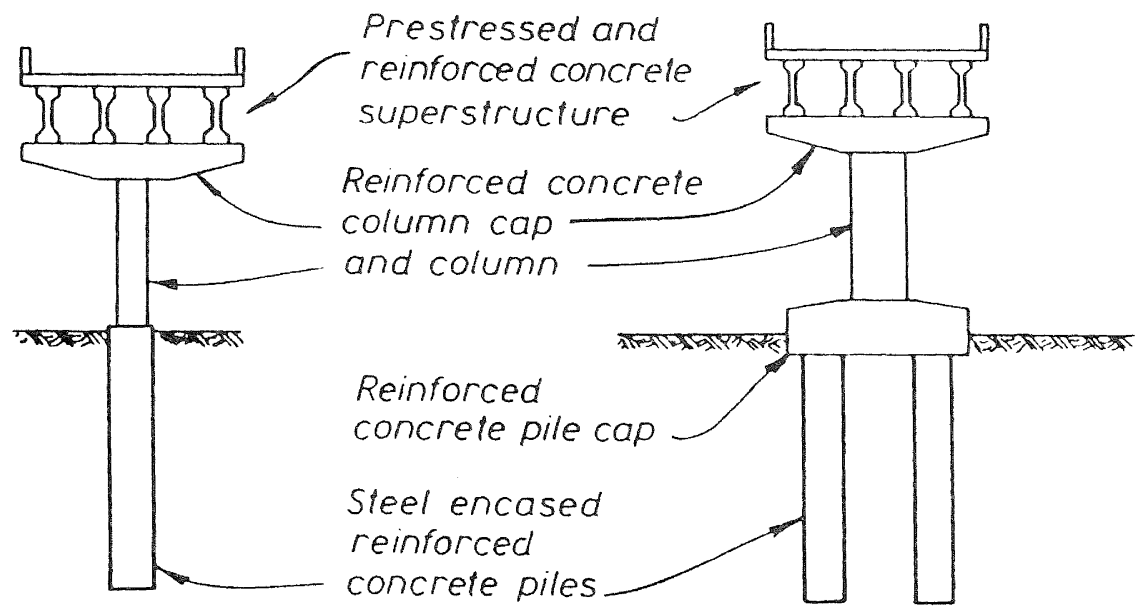

(a) Single Pile Substructures

(b) Multi-pile Substruclures

FIGURE 1.1 TYPICAL RECENTLY CON8TRUCTED HIGHWAY BRIDGE STRUCTURES IN NEW ZEALAND

\subsection{DESIGN PHILOBOPHY}

\subsubsection{Evaluation of Importance of Bridges}

Section 5.2 .3 of the Bridge Manual [1.4] defines importance categories for bridges based on the average number of vehicles per day at the time of design (see Table 5.2). A risk factor $R$ is allocated to each importance category. In effect the risk factor $R$ indicates the return period of the design earthquake which is used for each importance category.

\subsubsection{Definition of seismic linit states and Their Probability of occurrence}

Section 5.1 .1 of the Bridge Manual [1.4] sets out seismic limit states in terms of the required performance standards for the earthquake resistance of the bridge. The acceptable frequency and degree of loss of serviceability of the bridge after seismic events of various intensities (which is related to probability of occurrence) is specified. Economics do not justify design for damage free behaviour in all likely earthquakes.

\subsubsection{8tructural Action}

Section 5.1 .2 of the Bridge Manual [1.4] defines categories of structures depending on the manner in which the structure will respond to earthquake shaking.

A bridge substructure may be designed for a horizontal earthquake loading which is somewhat less than the elastic response inertia force induced by a major earthquake, providing that the substructure is designed so as to be capable of dissipating energy by ductile plastic deformations in regions of the structure chosen by the designer. sufficient strength capacity is provided elsewhere in the structure to ensure that the chosen energy dissipating mechanism does develop in the event of a major earthquake. A key aspect of the design approach is the choice of an intended mode of structural behaviour during strong earthquakes, and then to design and detail members to ensure that the structure behaves as intended.

When the chosen energy dissipating mechanism for single or multiple column substructures involves plastic hinges in the substructure, the plastic hinges should preferably form in the columns rather than in the foundations (footing or pile cap or piles), because of the greater accessibility for inspection and repair of the columns. Generally during an earthquake, horizontal shears and axial or eccentric vertical forces are transmitted from the bridge superstructure to the supporting columns and foundations.

In the case of single column substructures, with the bridge superstructure on bearings, the plastic hinge regions will primarily be only at the column bases regardless of the direction of the seismic actions (see Figure 1.2), although torsion of the superstructure may induce a secondary moment at the top of the column. In the case of multiple columns bents, with the bridge superstructure on bearings, plastic hinging may occur at the top and bottom of the columns when the seismic forces act at right angles to the longitudinal axis of the bridge, but only at the bottom of the columns when the seismic forces act along the longitudinal axis of the bridge (see Figure 1.3).

The ductility demand of plastic hinge regions can be reduced by the use of higher seismic design loads. Hence, depending on the level of design seismic loading, design for limited ductility, or even elastic response, is possible.

Base isolation and energy dissipating devices have been incorporated in bridges in New zealand since 1973. They are normally used to lengthen the natural period of the structure and to increase the damping, thereby modifying the seismic response. The resulting benefits generally include the 


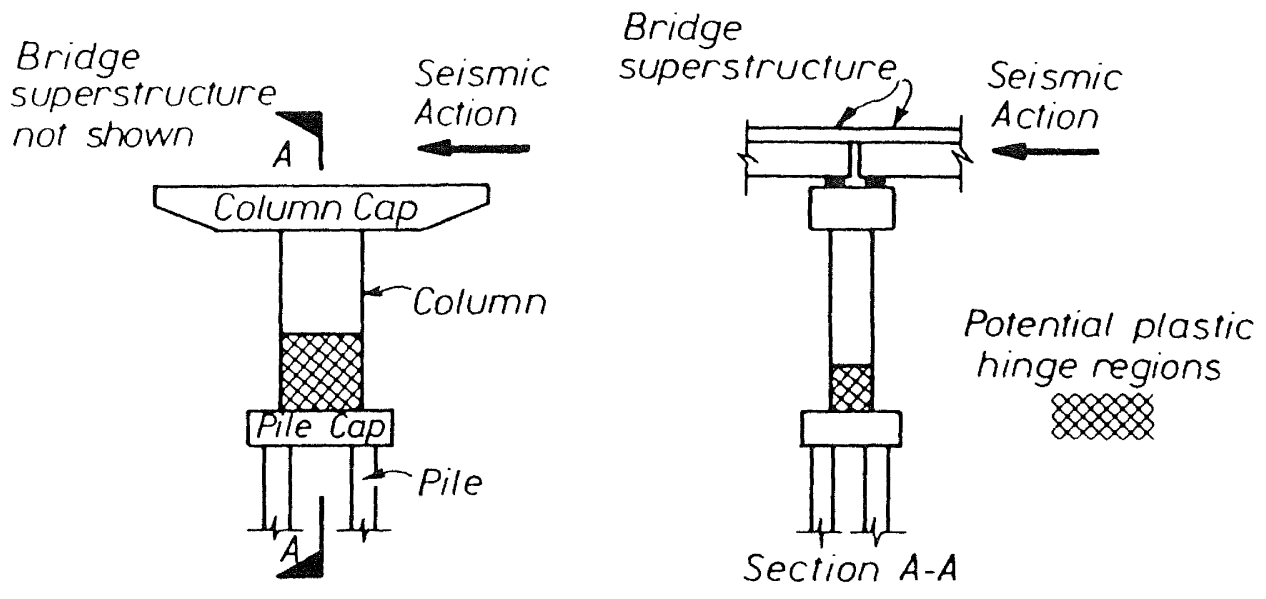

FIGURE 1.2 SINGLE COLUMN BENT AND POTENTIAL PLABTIC HINGE REGIONS FOR BEIBMIC ACTION AT RIGHT ANGLES TO AND ALONG LONGITUDINAL AXIS OF BRIDGE.

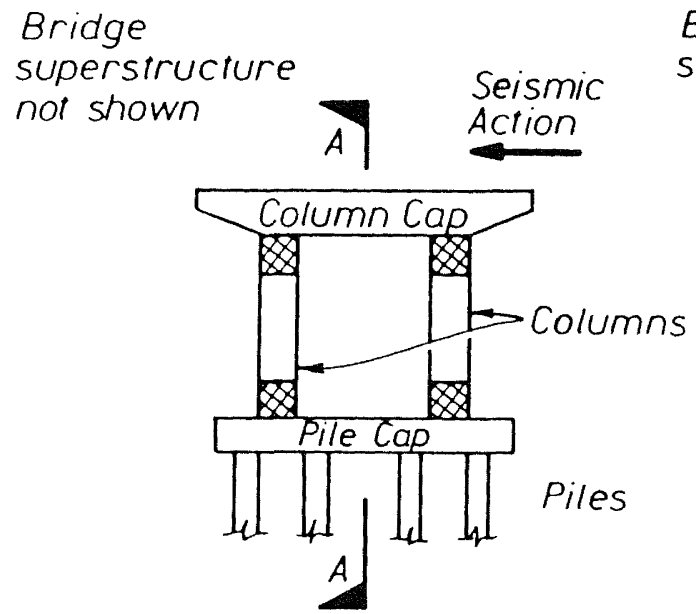

Bridge

superstructure

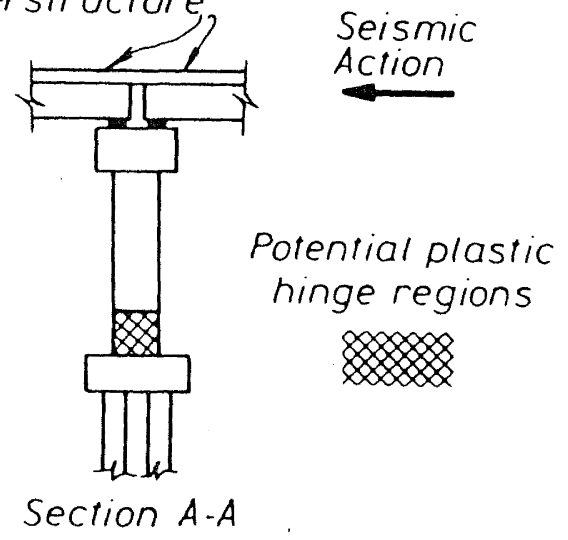

FIGURE 1.3 DOUBLE COLUMN BENT AND POTENTIAL PLABTIC HINGE REGIONS FOR BEIBMIC ACTION AT RIGHT ANGLE TO AND ALONG LONGITUDINAL AXIB OF BRIDGE. feasibility of designing the structure to remain elastic to a higher level of seismic shaking (even up to the design earthquake) and reduction of response displacements, thereby limiting secondary damage in strong and moderate earthquakes. The requirements as set out in section 5.4.9 of the Bridge Manual [1.4] are that energy dissipating devices should be treated similarly to plastic hinges. Reference 1.9 describes the use of this technique in New zealand, which to date has been applied to 47 bridges.

\subsection{SEISMIC ACTIONB}

\subsubsection{Seismic Design Loads}

The specification for horizontal seismic loading in the Bridge Manual [1.4] follows the approach adopted by the NZNSEE Study Group [1.5] and adopted by the draft New zealand loadings code for buildings [1.6]. The procedure for determining the design seismic loading is given in section 5.2.1 of the Bridge Manual [1.4].
To determine the equivalent static design seismic loading, the design earthquake is defined by the response spectrum appropriate to the site conditions and the structure displacement ductility factor. The structure displacement ductility factor is defined as $\mu=\Delta / \Delta_{y}$, where $\Delta$ is the maximum horizontal displacement and $\Delta_{y}$ is the horizontal displacement at first yield, both measured at the centre of mass of the superstructure.

The design seismic load curves in Fig. 5.2 of the Bridge Manual [1.4] are presented for a range of values of the structure displacement ductility factor, which enables the designer to select the basic design acceleration coefficient $c_{k}$ corresponding to the required ductility. "The lower the design seismic load the greater the required ductility. Ductility values presented range from $\mu=1$ (elastic response) to $\mu=6$ (the maximum allowable design value). For some structures the maximum value of $\mu$ is limited to less than 6 , depending on the structural action (see Fig. 5.4 of the Bridge Manual [1.4]). The curves are normalised for application throughout the country, since 
analytical work showed insufficient variation of curve shape to justify the use of zone related curves. Two sets of curves are, however, presented for use on normal and flexible soils. The variation of seismicity throughout the country is taken into account by the zone factor $z$, which ranges from 0.4 to 0.8 (see Fig. 5.3 of the Bridge Manual [1.4]) which is taken from the draft loadings code for buildings [1.6].

The elastic $(\mu=1)$ response spectrum curve for normal soils in Fig. 5.2 of the Bridge Manual [1.4] is a 5\% damped spectrum. The ordinates of the inelastic $(\mu>1)$ spectra were obtained from the corresponding elastic curves by considering the yield levels of single degree of freedom oscillators required to obtain various displacement ductility factors as a ratio to the maximum elastic response values for each elastic period. The single degree of freedom oscillators were subjected to three United States records (El Centro 1940 north-south, Parkfield 1966 N65E and Orion 1971 eastwest) and three Japanese records (Hachinohe 1968 north-south, Tohoku 1978 north-south and Sendai basement 1978 north-south) and smoothed curves for various ductilities drawn through the individual curves for the various records which showed considerable scatter. For short periods, the inelastic design spectra show a plateau from 0 to 0.2 seconds for normal soils, to reflect the increase in the response acceleration for short-period structures on yielding because of their increased effective periods. The spectra for flexible soils were obtained from the spectra for normal soils [1.6].

For most of the country the zone factor $z$ corresponds closely to the $5 \%$ damped spectral acceleration at the peak of the 150 year return period uniform risk spectra for normal soils [1.6].

The requirements of the Bridge Manual [1.4] for vertical earthquake response are given in its section 5.2.4.

\subsubsection{Combination of Load Effects}

Load combinations and load factors for strength requirements involving seismic loading specified by the Bridge Manual [1.4] are

$\mathrm{U}-1.00\{\mathrm{kDL}+1.35(\mathrm{EP}+\mathrm{OW})$ $+\mathrm{SG}+\mathrm{ST}+\mathrm{EQ}+0.33 \mathrm{TP}$

$U=1.35(\mathrm{DL}+\mathrm{EP}+\mathrm{OW}+\mathrm{SG}+0.33 \mathrm{EQ}+1.1 \mathrm{CN})(1.2)$

where $\mathrm{CN}=$ Construction loads, including loads on an incomplete structure $\mathrm{DL}=$ Dead load, including superimposed dead load

$\mathrm{EP}=$ Earth pressure

$\mathrm{EQ}=$ Earthquake effects

OW = Ordinary water pressure and buoyancy

SG $=$ shortening effects

$\mathrm{ST}=$ settlement

$\mathrm{TP}=$ Temperature effects, overall and differential

$\mathrm{U}=$ Design load for strength design method

$k=1.3$ or 0.8 , whichever is more severe, to allow for vertical acceleration.

The required seismic resistance of structures during construction is difficult to specify in a general manner. Designers are required to take account of the duration of the construction stage, vulnerability of the structure and surrounds, and cost of temporarily improving the seismic resistance, and to ensure that the load combination given by Eq. 1.2 results in adequate protection for the circumstances being considered.

\subsection{PROCEDURES OF ANALYSIS}

The procedures for analysis (equivalent static force and dynamic) are given in section 5.3 of the Bridge Manual [1.4]. Included in that section are recommendations for member properties for analysis and the manner of calculating displacements of bridge structures due to earthquake shaking.

\subsection{DUCTILITY LEVELS}

\section{6 .1 Bridgo Types}

In the ductile design procedure, the preferred mechanisms involve plastic hinges in the columns and in regions which are accessible for inspection and repair. For less ductile mechanisms, or where the plastic hinge positions are not readily accessible for inspection and repair, a reduced structure displacement ductility factor $\mu$ and hence an increased design seismic load is used in design. Table 5.1 and Fig. 5.4 of the Bridge Manual [1.4] show examples of the maximum allowable values for the structure displacement ductility factor 1. for use in design, for various types of substructures and plastic hinge positions. In all cases the designer should check that the substructure is capable of sustaining the design value of $\mu$.

\subsubsection{Relationship Between Displacement and Curvature Ductility Factor}

When ductility is to be achieved by plastic hinging, the potential plastic hinge regions need to be carefully detailed for adequate ductility in order to ensure that the shaking from large earthquakes does not cause collapse. The most important design consideration for ductility in plastic hinge regions is the provision of adequate transverse reinforcement in the form of rectangular arrangements of steel, or circular spirals or hoops. Anchorage failure of all reinforcement must also be prevented.

The local ductility required at a plastic hinge in a yielding structure may be expressed by the curvature ductility factor $\phi_{u} / \phi_{y}$, where $\phi_{u}$ is the maximum curvature (rotation per unit length) at the section and $\phi_{y}$ is the curvature at the section at yield? 


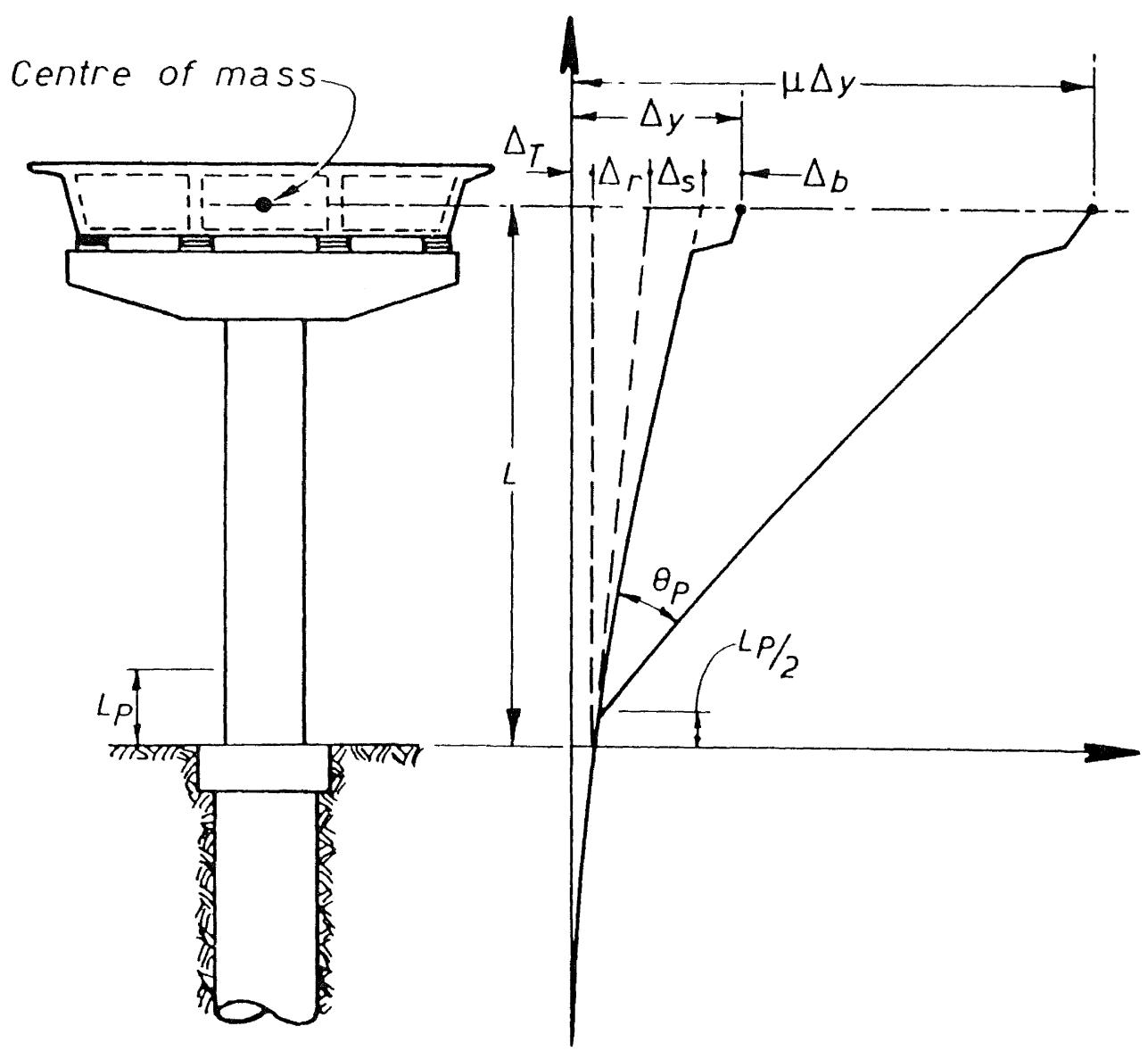

FIGURE 1.4 HORIZONTAL DISPLACEMENT AT FIRST YIELD AND AT MAXIMUM DUCTILITY DEMAND OF A BRIDGE 8TRUCTURE.

It can be shown $[1.12,1.13]$ that the required curvature ductility factor $\phi_{u} / \phi_{y}$ at the plastic hinge sections will generally be much greater than the required structure displacement ductility factor $\mu$ for the structure, since once yielding commences further displacement occurs mainly by rotation at the plastic hinges. The relationship between the curvature ductility factor demand at the plastic hinges and the imposed displacement ductility factor can be determined by considering the geometry of the deformations of the bridge structure.

As an example, the bridge structure shown in Figure 1.4 will be considered [1.12]. The horizontal seismic force is assumed to act at the centre of mass of the superstructure. The horizontal displacement at the centre of mass will be due to deformations of the column, foundation and bearings. Assuming linear-elastic behaviour up to the stage of first yield, and a triangular bending moment diagram in the column due to the horizontal seismic load, the horizontal displacement at the centre of mass of the superstructure due to deformation of the column when yield is first reached at the base of the columns is

$$
\Delta_{s}-\frac{M_{\gamma} L^{2}}{3 E I}
$$

where $M_{y}=$ column moment at base at yield EI = flexural rigidity of column section, and

$\mathrm{L}=$ distance from column base to centre of mass (see Figure 1.4).

Now the curvature at yield at the column base is given by $\phi_{y}=M_{y} / E I$. Therefore

$$
A_{s}-\frac{\phi_{y} L^{2}}{3}
$$

Because of foundation flexibility and bearing deformations, the yield displacement is increased by $\Delta_{r}$ and $\Delta_{r}$ due to translation and rotation of the pile cap and by $\Delta_{b}$ due to shear deformations of the bearing. In that case the horizontal displacement at the centre of mass of the superstructure when yield is first reached at the base of the column (see Fig. 1.4) is

$$
\Delta_{\gamma}-\Delta_{s}+\Delta_{T}+\Delta_{T}+\Delta_{b}-c \Delta_{s}
$$

where $C$ is a coefficient representing the increase in elastic flexibility of the system due to the foundation and bearings. From Eqs. 1.4 and 1.5 . 


$$
4-\frac{C \phi_{y} L^{2}}{3}
$$

Further horizontal displacement at the centre of mass of the superstructure can occur during the acceleration pulse of the earthquake by plastic rotation which occurs over an equivalent plastic hinge length $L_{p}$ $[1.12,1.13]$. Assuming that the plastic rotation $\theta_{p}$ is concentrated at the centre of the plastic hinge, the total horizontal displacement at the centre of mass of the superstructure can be written as

$$
A_{L}-A_{p}+\theta_{p}\left(L-0.5 I_{p}\right)
$$

$$
\text { where } \theta_{p}-\left(\phi_{u}-\phi_{y}\right) I_{p}
$$

and $\phi_{u}$ is the maximum curvature reached at the column base. Therefore

$$
\Delta_{u}-\Delta_{y}+\left(\phi_{u}-\phi_{y}\right) L_{p}\left(L-0.5 I_{p}\right)
$$

Hence the displacement ductility factor $\mu=$ $\theta / \Delta_{y}$ can be written as

$$
\mu=1+\frac{\left(\phi_{u}-\phi_{y}\right)}{\phi_{y}} I_{p}\left(I-0.5 L_{p}\right)
$$

On substituting $\Delta_{y}$ from $\mathrm{Eq} \cdot 1.6$

$$
\mu-1+\frac{3}{\mathrm{C}}\left[\frac{\phi_{u}}{\phi_{y}}-1\right] \frac{\mathrm{L}_{\mathrm{p}}}{\mathrm{L}}\left[1-0.5 \frac{\mathrm{L}_{\mathrm{p}}}{\mathrm{L}}\right]
$$

or

$$
\frac{\phi_{u}}{\phi_{y}}-1+\frac{C(\mu-1)}{3 \frac{L_{p}}{L}\left[1-0.5 \frac{L_{p}}{L}\right]}
$$

For stiff columns the value of $c$ may be as high as 5 or more and the effect on the curvature ductility demand may be substantial. Typically $L_{p}=0.5 \mathrm{D}$, where $\mathrm{D}=$ column overall depth $[1.12,1.13]$. Some values of $\phi_{u} / \phi_{y}$ for when $\mu=6, C=1$ or 2 , and for a range of column aspect rations $L / D$ obtained from Eq. 1.11 assuming $L_{p}=0.5 D$, are

\begin{tabular}{||c|c|c|c|}
\hline & \multicolumn{3}{|c|}{ L/D } \\
\cline { 2 - 4 } & 2.5 & 5 & 10 \\
\hline$\phi_{u} / \phi_{Y}$ when $C=1$ & 10.3 & 18.5 & 35.2 \\
$\phi_{u} / \phi_{Y}$ when $C=2$ & 19.5 & 36.1 & 69.5 \\
\hline
\end{tabular}

It is evident that the required $\phi_{u} / \phi_{y}$ can be considerably larger than $\mu$, particularly when the plastic hinge length is a small proportion of the column length and when the foundation and bearing flexibility is significant.

In summary, the trends demonstrated by Eq. 1.11 are that the required curvature ductility factor at plastic hinge sections of bridge columns increases when the ratio of column height to column lateral dimension increases, when the flexibility of the foundation and bearing increases, and when the imposed displacement ductility factor $\mu$ increases. Equations 1.10 and 1.11 may be used in two ways in design, either to determine the required $\phi_{\mu} / \phi_{y}$ for a chosen $\mu$ or to determine the available $\mu$ for a given $\phi_{u} / \phi_{y}$ capacity.

A refined design procedure for determining the amount of transverse reinforcement required to achieve a given curvature ductility factor has recently been derived for reinforced concrete columns $[1.14,1.15,1.17]$. This enables the bridge structure to be designed for the seismic load associated with the chosen displacement ductility factor, and then transverse confining reinforcement can be provided for the associated curvature ductility factor. That is, in a refined design procedure the quantity of confining steel placed will depend on the calculated curvature ductility factor demand.

\subsubsection{Maximum Displacements}

Section 5.3.5 of the Bridge Manual [1.4] gives methods for estimating seismic displacements. A very important design criterion is that the bridge superstructure must be adequately supported so not to become dislodged during a major earthquake when significant displacement of the bridge substructure occurs. Section 5.3 .5 also requires that allowance should be made at superstructure movement joints for out-ofphase response of two adjacent sections of the structure. Section 5.5 gives design provisions for relative displacements.

\subsection{MEMBER DESIGN CRITERIA AND FOUNDATION DEEIGN}

Section 5.4 of the Bridge Manual [1.4] sets out the acceptable values of member capacities (or relative capacities) to be provided in order to meet capacity design principles. The aim is to ensure that the required yielding behaviour of the structure is achieved, by designing members and joints to have sufficient strength to confine yielding to the intended plastic hinge positions. The strengths specified are chosen to provide sufficient margins to satisfy this criterion, while avoiding excessive strength and consequent cost.

The capacity design approach requires consideration of three levels of member strength, namely dependable strength, ideal strength and overstrength. These terms are defined as follows. 
Capacity design: The design method in which elements of the primary lateral earthquake load resisting system are chosen and suitably designed and detailed for energy dissipation under severe deformations. All other structural elements are then provided with sufficient strength so that the chosen means of energy dissipation can be maintained.

Dependable strength: The ideal strength multiplied by the strength reduction factor as given in the appropriate materials code.

Ideal strength: The theoretical strength of a member section, calculated using section dimensions as detailed and the lower 5 percentile characteristic material strengths.

overstrength: The maximum strength of a member section, taking into account the main factors that may contribute to an increase in strength beyond the ideal value. These factors include a steel yield strength higher than specified, strain hardening of steel at large deformations, a concrete strength higher than specified and additional reinforcement placed for construction proposes.

In ductile structures the dependable flexural strength of plastic hinges should be at least equal to the moments obtained from analysis for the load combinations given by Eqs. 1.1 and 1.2 . Capacity design requirements will be considered satisfied if the overstrength flexural capacities of the plastic hinges are matched by (a) their own ideal shear strengths, and (b) the ideal shear and ideal flexural strengths of resisting members.

The scope of section 5.4 [1.4] includes consideration of the ability of soils to resist forces from foundation members. It also deals with structures anchored by friction slabs, structures on rocking foundations and structures with energy dissipating devices.

\subsection{EARTH RETAINING STRUCTUREB}

Section 5.6 of the Bridge Manual [1.4] covers both bridge abutments and free standing retaining walls which are associated with bridges. A feature of these provisions is the acceptance that free standing walls, but not bridge abutments, may be designed for limited outward movements during the design earthquake event.

\subsection{CONCLUSIONS}

Seismic design procedures for bridges in New zealand provide designers with criteria for all aspects of design. Successful implementation of the procedures (and, it is believed, of other seismic design specifications) greatly depends on the designers understanding of its intent, and on the choice of the most appropriate practical structural form for good seismic performance. There are still some unresolved issues concerning the methods by which the design criteria should be met.

\subsection{ACKNOWLEDGEMENT}

The agreement of the General Manager Transit New zealand, to the inclusion of Reference 1.4 as an Appendix to the original paper is acknowledged with thanks.

Note: The Appendix has been omitted from the paper as published herein.

\subsection{REFERENCES}

1.1 "Highway Bridge Design Brief" CDP $701 / \mathrm{D}$, Ministry of Works and Development, Wellington, 1978 .

1.2 "Code of Practice for the Design of Concrete structures, NZS 3101 Part $1: 1982 "$ " "Commentary on the Design of Concrete structures NZS 3101 Part $2: 1982$ ", and "Amendment No. 1 to NZS 3101 : Parts 1 and 2, 1989" Standards Association of New Zealand, Wellington.

1.3 "Bridge Manual", (Provisional) National Roads Board, Wellington, 1989 .

1.4 "Bridge Manual : Design and Evaluation", (Draft for Comment), Transit New Zealand, Wellington, 1991.

1.5 "Papers Resulting from the Deliberations of the study Group on the Seismic Design of Bridges" Bulletin of the New Zealand National Society for Earthquake Engineering, Vo1. 13, No. 3, September 1980, pp.226-309.

1.6 "Code of Practice for General Structural Design and Design Loadings for Buildings", 2/DZ 4203/2 Draft for Comment, standards Association of New Zealand, Wellington, 1991.

1.7 PARK, $\mathrm{R}$ and PAULAY, T, "Strength and Ductility of Concrete Substructures of Bridges", Vol. 1 : RRU Bulletin 84, Bridge Design and Research Seminar, Transit New Zealand, 1990, p. 170 .

1.8 WOOD, J H and ELMS, D G, "Seismic Design of Bridge Abutments and Retaining Walls", Vol. 2 : RRU Bulletin 84, Bridge Design and Research Seminar, Transit New Zealand 1990 , p. 90

1.9 CHAPMAN, $\mathrm{H} \mathrm{E}$ and KIRKCALDIE, $\mathrm{D} \mathrm{K}$ "Seismic Design of Base Isolated Bridges Incorporating Mechanical Energy Dissipating Dissipators", Vol. 3 : RRU Bulletin 84, Bridge Design and Research Seminar, Transit New Zealand, 1990, p.44.

1.10 JENNINGS, D N, READ, S A L, MILLAR, P $J$, HUPPERT, F, BLACK, P M, PARTON, I $M$ AND OLSEN, A J, "Road Engineering in Soft Rock Materials", Vol. 4 : RRU 
Bulletin 84, Bridge Design and Research Seminar, Transit New Zealand, 1990, p.78.

1.11 "Summary Papers and other Technical Papers", Vol. 5: RRU Bulletin 84, Bridge Design and Research Seminar, Transit New Zealand, 1990, p.266.

1.12 PRIESTLEY, $M J N$, and PARK, R, "Strength and Ductility of Bridge Substructures", RRU Bullet in, No. 71, National Roads Board, Wellington, 1984, p.120. (See also" "Strength and Ductility of Concrete Bridge Columns Under Seismic Loading", Structural Journal of American Concrete Institute, Vol. 84, No. 1, Jan-Feb 1987, pp.61-76.)
1.13. PARK, $R$ and PAULAY, $T$, "Reinforced Concrete structures", John wiley and Sons, New York, 1975, p.769.

1.14 ZAHN, F A, PARK, $R$ and PRIESTLEY, M J $N$, "Design of Reinforced Concrete Bridge Columns for strength and Ductility", Research Report 86-7, Department of Civil Engineering, University of Canterbury, March 1986, p. 402 .

1.15 ZAHN, F A, PARK, R, PRIESTLEY, M J N and CHAPMAN, $H$ E, "Development of Design Procedures for the Flexural Strength and Ductility of Reinforced Concrete Bridge Columns". Bulletin of the New zealand National Society for Earthquake Engineering, Vol. 19, No. 3. September 1986, pp.200-212.

\title{
SECTION 2 DESIGN DETALS FOR HIGHWAY BRIDGES
}

\author{
(Princlpal Authors: PJ North and $R$ Park)
}

\subsection{DESIGN PRINCIPLES}

\subsubsection{General}

The seismic design of bridges in New Zealand is based on the philosophy that bridges should be usable after the design earthquake and that repairs to reinstate the original strength should be achievable. A minor earthquake should cause no disruption to traffic. An earthquake larger than the design case should not cause collapse and temporary repairs should enable the bridge to be passable by emergency vehicles. Permanent repair should still be possible [2.1].

To achieve these objectives, the New Zealand codes encourage designers to provide ductility for seismic resistance for the reasons set out in section 1 . This is not always achieved easily.

In this section, methods of providing ductility in structures and detailing for seismic resistance are discussed. Illustrations are taken from bridges that have been built in New Zealand in accordance with the principles expressed in section 1.

Appendices are also given which summarise the New zealand concrete design code provisions for transverse reinforcement required in columns and piers for ductility, and which summarise more recent developments in seismic design procedures for bridge substructures.

\subsection{2 structural 8ystom}

If the overall concept of the bridge structure is chosen with the requirements of seismic resistance in mind from the beginning, the additional cost of seismic resistance is small. If, on the other hand, seismic resistance is applied to a structural concept developed with only vertical loads in mind, the additional cost can be quite high.

Unlike building structures where plastic hinges are encouraged to form in beams before columns, the ductility of bridge structures is provided in the substructure elements rather than the deck. Hinge zones should be located in places that are accessible for inspection and repair.

It is economic to share lateral loads to as many supports as possible but that can be in conflict with requirements to provide release for environmental movements. Thus the design of substructures to provide for all requirements can be something of a compromise.

Bridges on tall piers are inherently flexible and can readily be designed to incorporate seismic ductility in a flexural yielding mode. Long low bridges with shorter stiff piers need release from some supports to allow for superstructure shortening. In this case, sharing seismic loads to piers requires the application of special hardware. Sometimes it is sufficient to release one end of the pier with a hinge (usually at the top). In New Zealand single stem circular reinforced concrete piers cantilevered from the base are very common. The ductile hinge is provided at the base of the column where it is visible and repairable as shown in Figure 2.1a. Other less ductile and less desirable systems are also illustrated in the figure.

If a bridge is very low and the piers are too stiff, the hinge zone could be forced into the piles where deflection and repair 

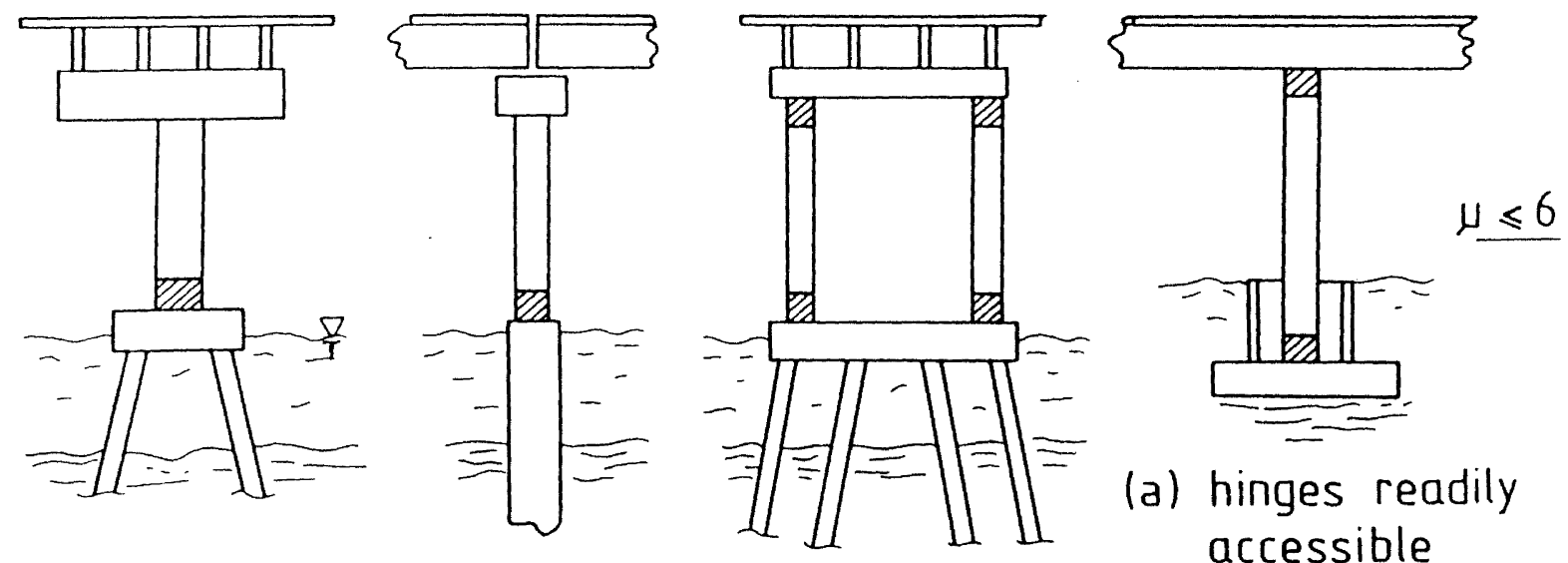

(a) hinges readily accessible

(b) hinges reasonably accessible
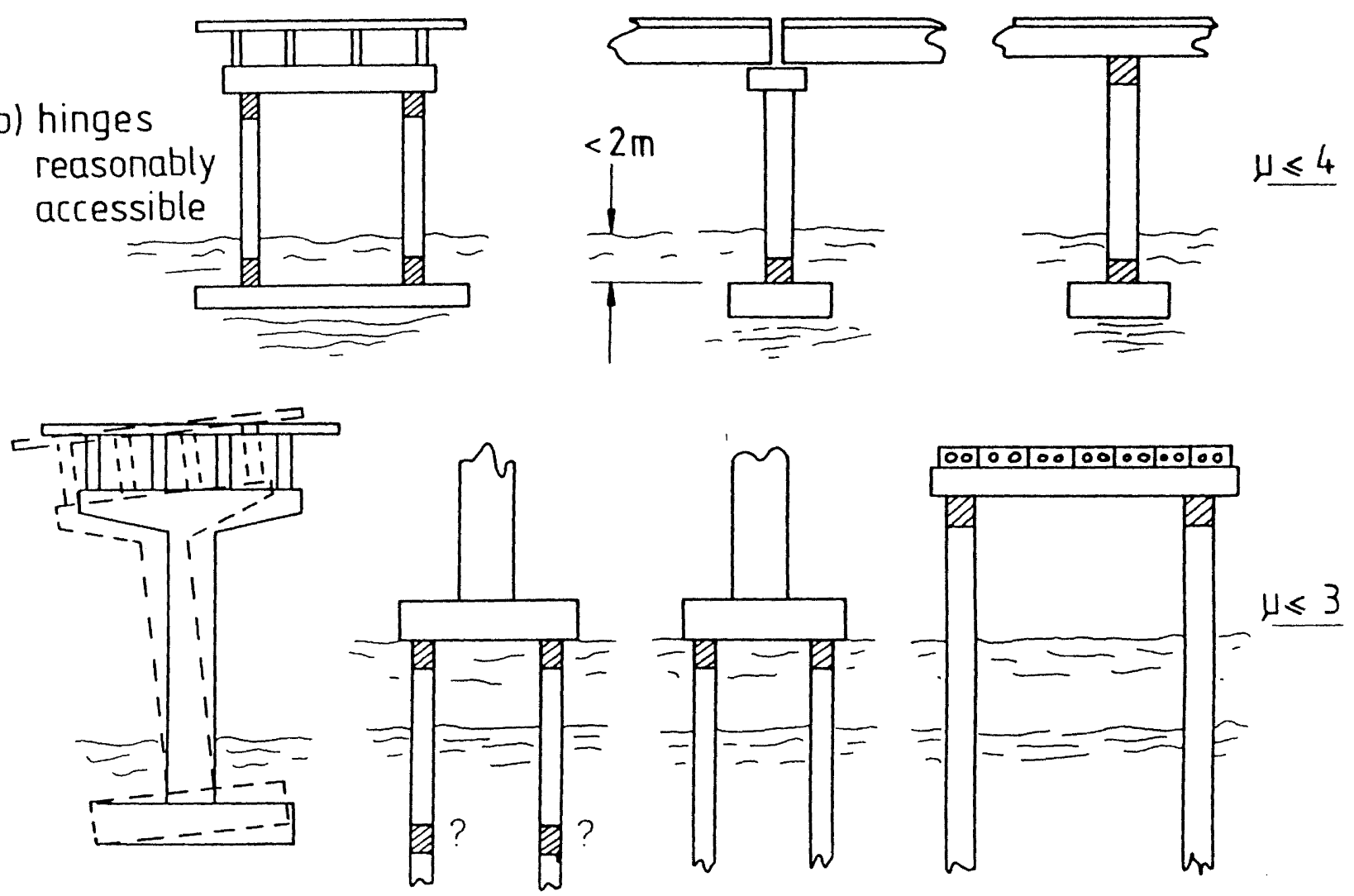

(c) rocking

(d) inaccessible hinges

(e) hinging in raised piles with large axial forces

plastic hinge

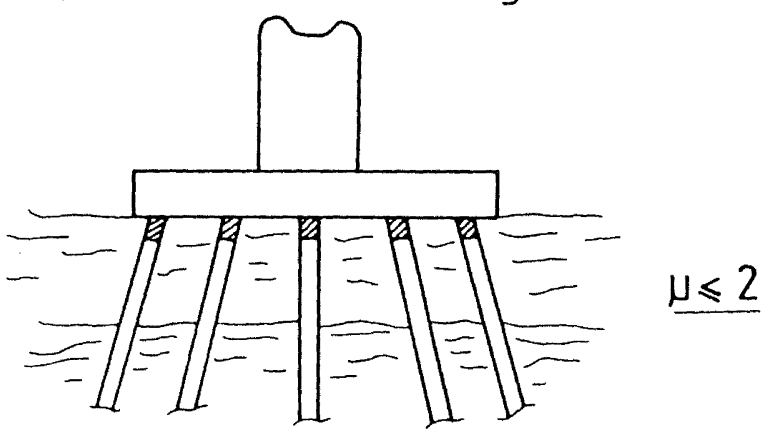


are more difficult. in such cases an alternative way of providing ductility is to install isolation/dissipation devices between the superstructure and the foundation.

Abutments tend to be much stiffer than piers and can attract a large proportion of the horizontal loads. Furthermore, it is very difficult to provide structural ductility at abutments with satisfactory details. It is therefore common practice to provide mechanical hardware which provides isolation (sliding bearings) with or without ductile inkages.

\subsubsection{Capacity Dasion Principlos}

The rules for ensuring adequate strength outside ductile zones, and ductility within those zones are codified [2.1, 2.2]. Dependable member resistance is the section strength allowing for partial factors for calculation, material, and construction variations. For flexure a strength reduction factor of 0.9 is used while for shear 0.85. Member ideal strength is the resistance before this factor is applied, but includes using the lower characteristic yield strength of reinforcement. Member overstrength takes into account all possible factors that may give a greater member resistance such as strain hardening, higher material strength than specified and any extra steel placed beyond the minimum required.

A study group of the New Zealand National Society for Earthquake Engineering has published a summary of capacity design principles for bridges [2.3].

Ductility is generally achieved by allowing the structure to yield and deform plastically in the design earthquake event. This involves nominating the plastic hinge zones in the structure and detalling them to be ductile. The remainder of the structure may be detailed to be brittle provided that there is no chance that the strength of brittle sections will be exceeded. The overall structural analysis is carried out using capacity design principles to ensure that the various elements are provided with the right hierarchy of strength to ensure that the structure yields in the manner chosen and provided for $[2.1,2.2]$.

Plastic hinge regions are designed to have a minimum dependable strength which limits damage in minor earthquakes. However, the upper bound strength of hinge regions also needs to be calculated so that adjacent zones of members designed to remain elastic do, in fact, remain so under all circumstances. The upper bound or overstrength of a section is calculated using the upper characteristic (5\%) strengths of reinforcement and concrete and additionally enhanced to allow for strain hardening. Section overstrengths are typically 1.25 times the ideal section strengths. For shear in a plastic hinge, the concrete is assumed to make no contribution to shear resistance.

With all plastic hinges developing their overstrength, the distribution of shear and moment is determined and all other areas designed to these actions.

The principles of capacity design also apply to what could be considered secondary items, for example the frictional forces generated at PTFE sliding bearings. The frictional force should be estimated assuming a coefficient of friction of at least 0.15 .

Friction slabs intended to act as anchorages for abutments, etc, should be designed so that the connection reinforcement at its lower characteristic yield strength has enough strength to resist the ideal friction.

\subsection{4 soll-8tructure Interaction}

Bridge designers in New Zealand generally model the substructure of piled bridges as a flexible pile with horizontal winkler springs modelling the soil compliance. Upper bound spring forces are determined by the passive soil capacity. The sensitivity of the design is tested by using a range of soil stiffnesses, including absence of springs in some zones to model liquefaction. The pier response is therefore an iterative procedure if an elastic analysis program is used; non-linear computer programs are not in wide use.

Including the effect of soil compliance in the overall bridge response is generally favourable in increasing the period of the system and hence reducing the seismic load. The effects of increased displacements needs to be carefully considered.

However, there are cases when increased curvature ductility demand occurs if the structure period is already short [2.4].

\subsubsection{Isolation and Dissipation Devices}

Decks are designed to remain elastic under seismic action. If the deck is supported on bearings, advantage can be taken of this element of flexibility and seismic isolation systems can be incorporated which reduce the load attracted by the bridge $[2.5]$. The number of railway and highway bridges fitted with seismic isolation devices is now thought to number over 60 . These devices range from lead-rubber bearings to hydraulic systems and steel flexural yielding elements. A particularly large railway bridge is designed so that the twin column piers rock on the pilecaps [2.6].

The most common isolation method is leadrubber elastomeric bearings between deck and piers. Figure 2.2 depicts an example. These bearings can readily replace a conventional elastomeric bearing, but they have been found to be economical only in regions of higher seismic risk in New Zealand and where substructures are stiff. Their wider use is hindered by the complexities of analytical modelling, although guidelines such as the AASHTO provisions [2.7] have introduced methods using equivalent damping and period values for the structure.

Isolation and dissipation devices should be detailed to be easily inspected so that any 


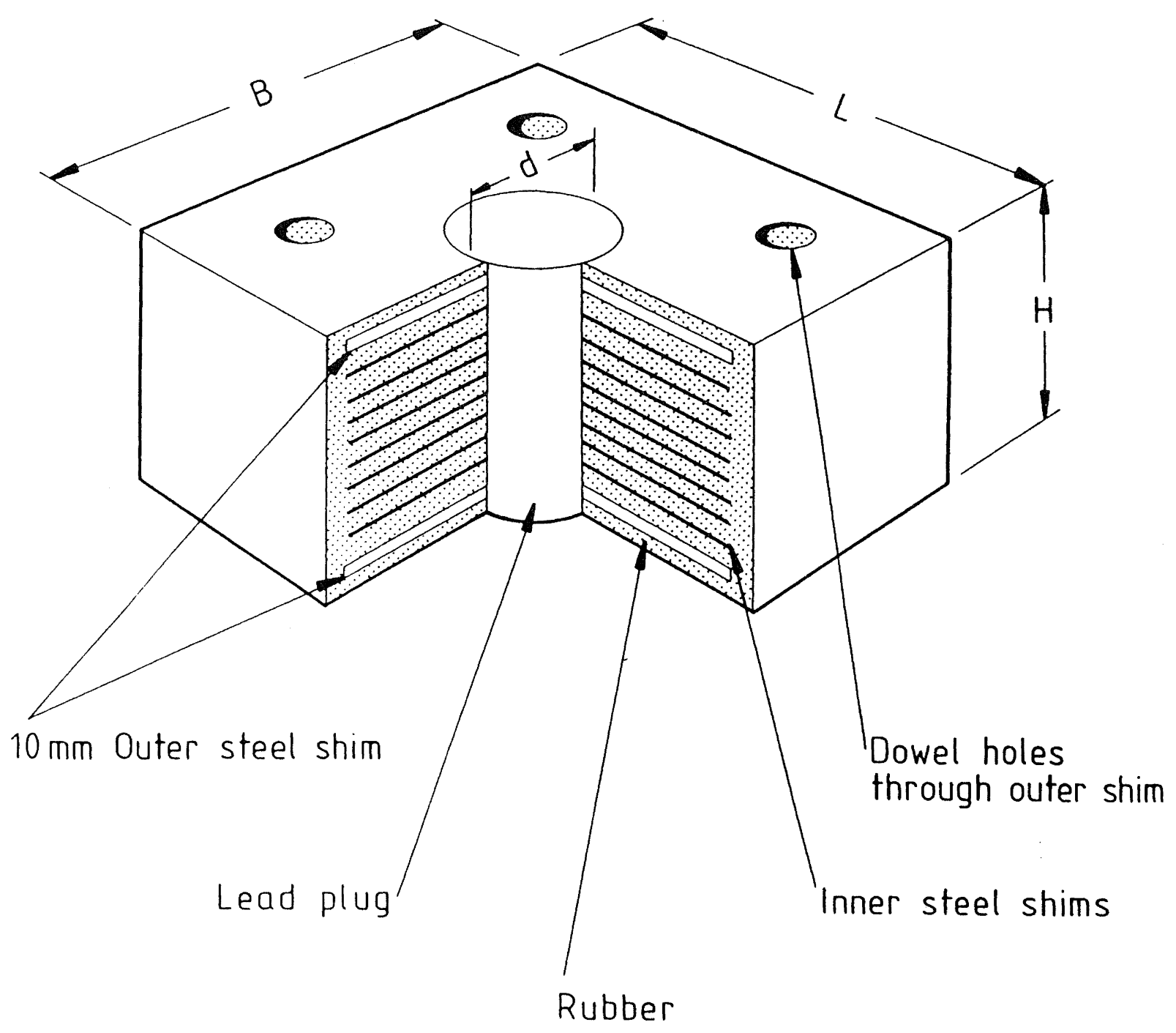

FIGURE 2.2 TYPICAL LEAD-RUBBER BEARING.

necessary maintenance can be determined and carried out. They should also be readily replaceable in case of damage from seismic attack.

The method of fixing bearings to decks and supporting members needs to be carefully considered in the light of the shear force transmitted through the bearings.

\subsubsection{Provisions for Deck Movement}

The calculated seismic movement is generally found to exceed thermal, creep and shrinkage deformation of bridge decks restrained by piers. It is not practical or justifiable to provide expansion joints to cope with the full seismic movement and the New zealand Code requires only one quarter of the design seismic deformation plus long term shortening and one third of the temperature effects to be provided for within the joints. It is also likely that transverse deck movements at abutments could destroy any joints, so various measures are adopted to control seismic effects in these cases. In simple cases it is accepted that seal elements may have to be replaced.

sufficient clearance should be provided between major elements of the deck and abutments to prevent severe damage under the design earthquake. A small sacrificial area of slab or abutment wall may be provided, bridging most of the clearance space, but which under seismic motion is damaged and can subsequently be easily repaired. A detail of such a "knock-off" area is given in section 2.2.5.

Short span decks are commonly restrained with a number of linkage bolts and rubber buffers as shown in Figure 2.3. The top of the back wall of the abutment is, in this case, designed to "knock-off" when impacted by the deck. The expansion joint would require replacement but the bridge should still be negotiable by 4-wheel-drive vehicles. A settlement slab is provided, which can act as a ramp to the bridge should 


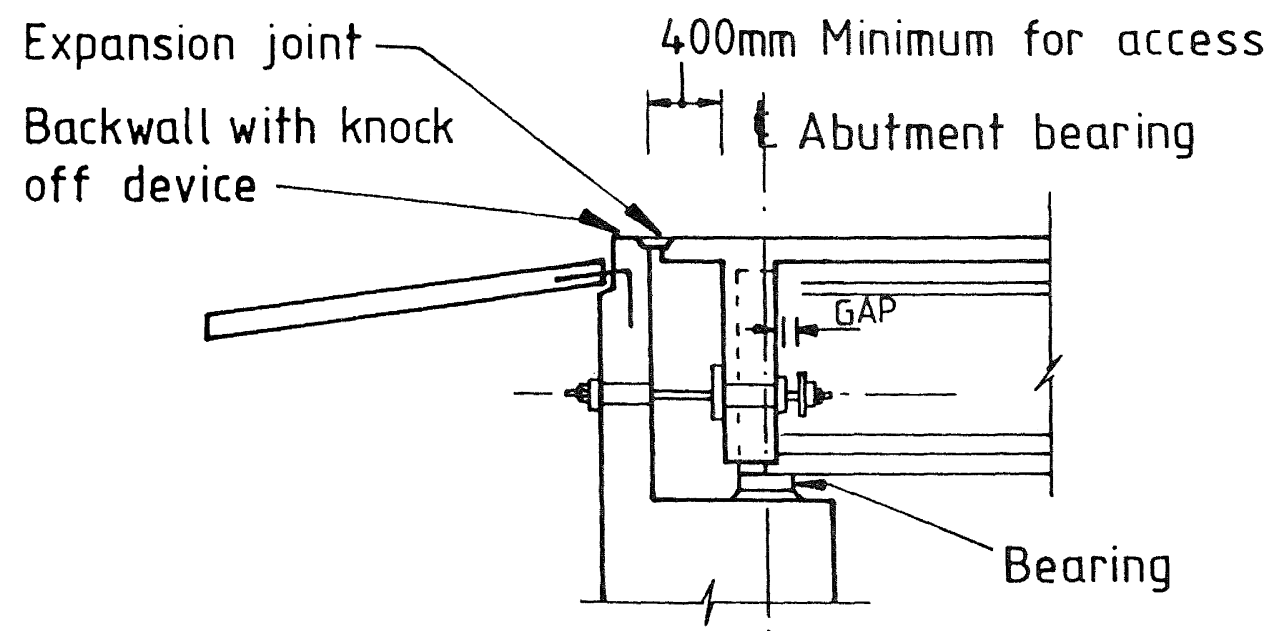

(a) SECTIONAL ELEVATION THROUGH LINKAGE BOLT

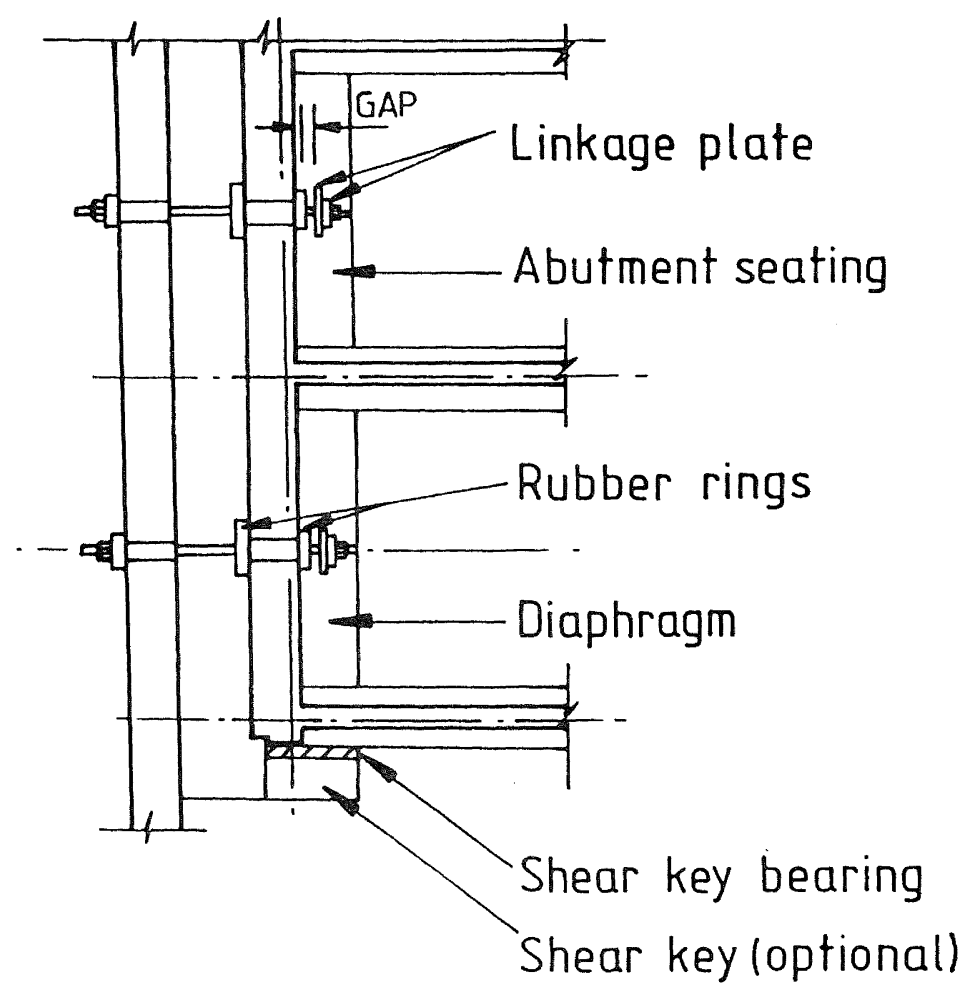

(b) SECTIONAL PLAN THROUGH LINKAGE BOLTS

FIGURE 2.3 SEIBMIC LINRAGE BOLTS TYPICAL OF BHORT SPAN BRIDGES. 


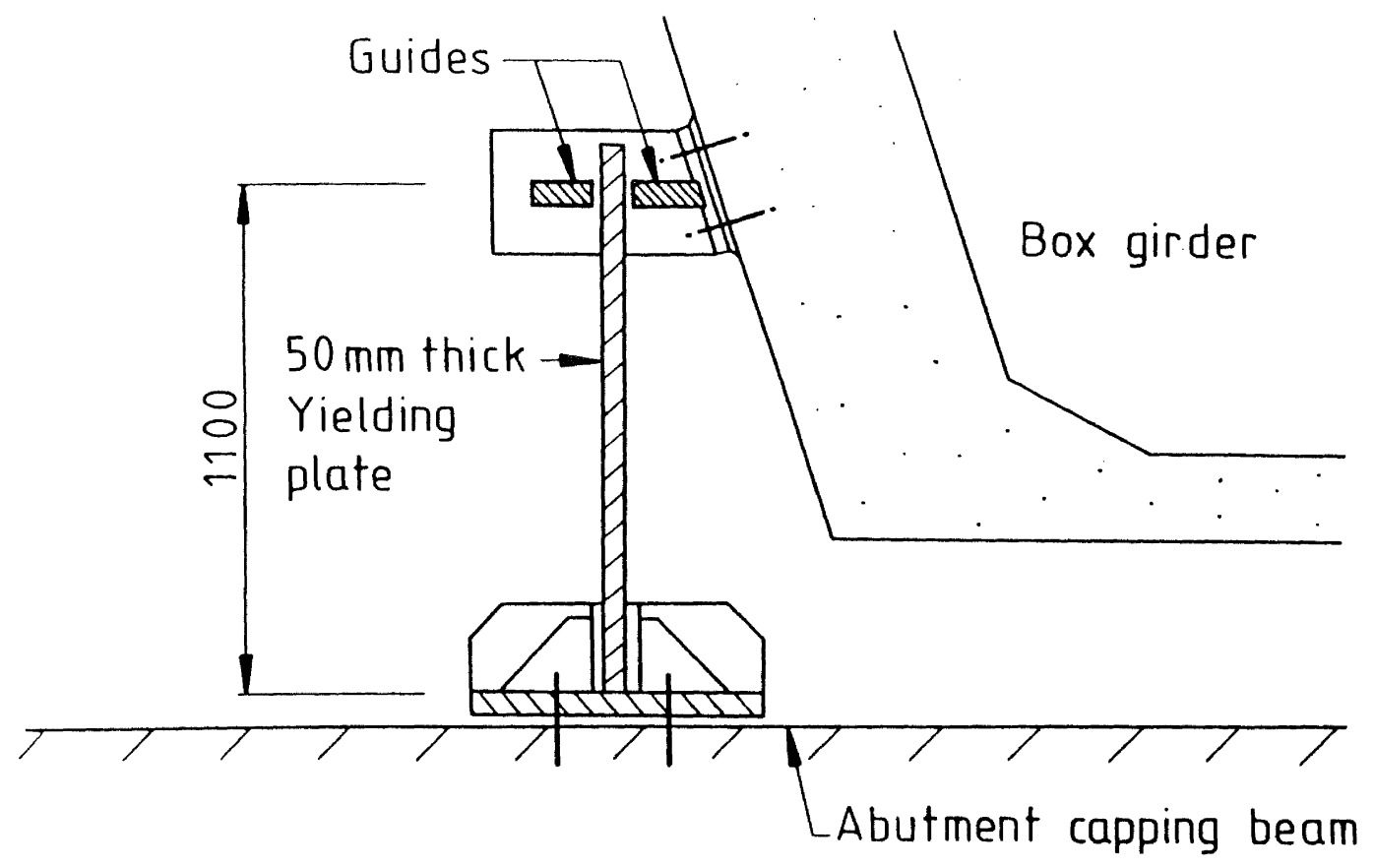

(a) SECTION

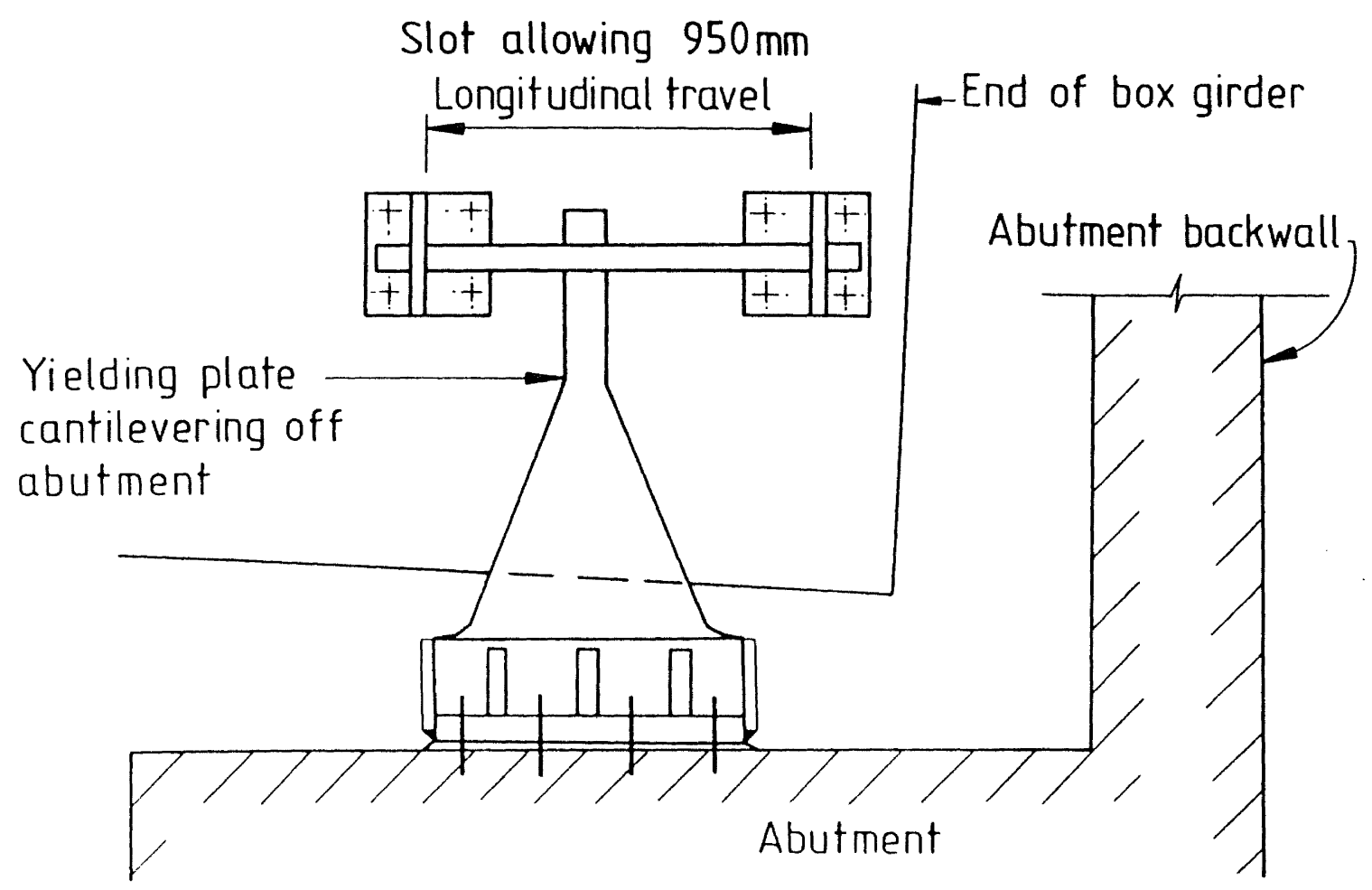

(b) ELEVATION 


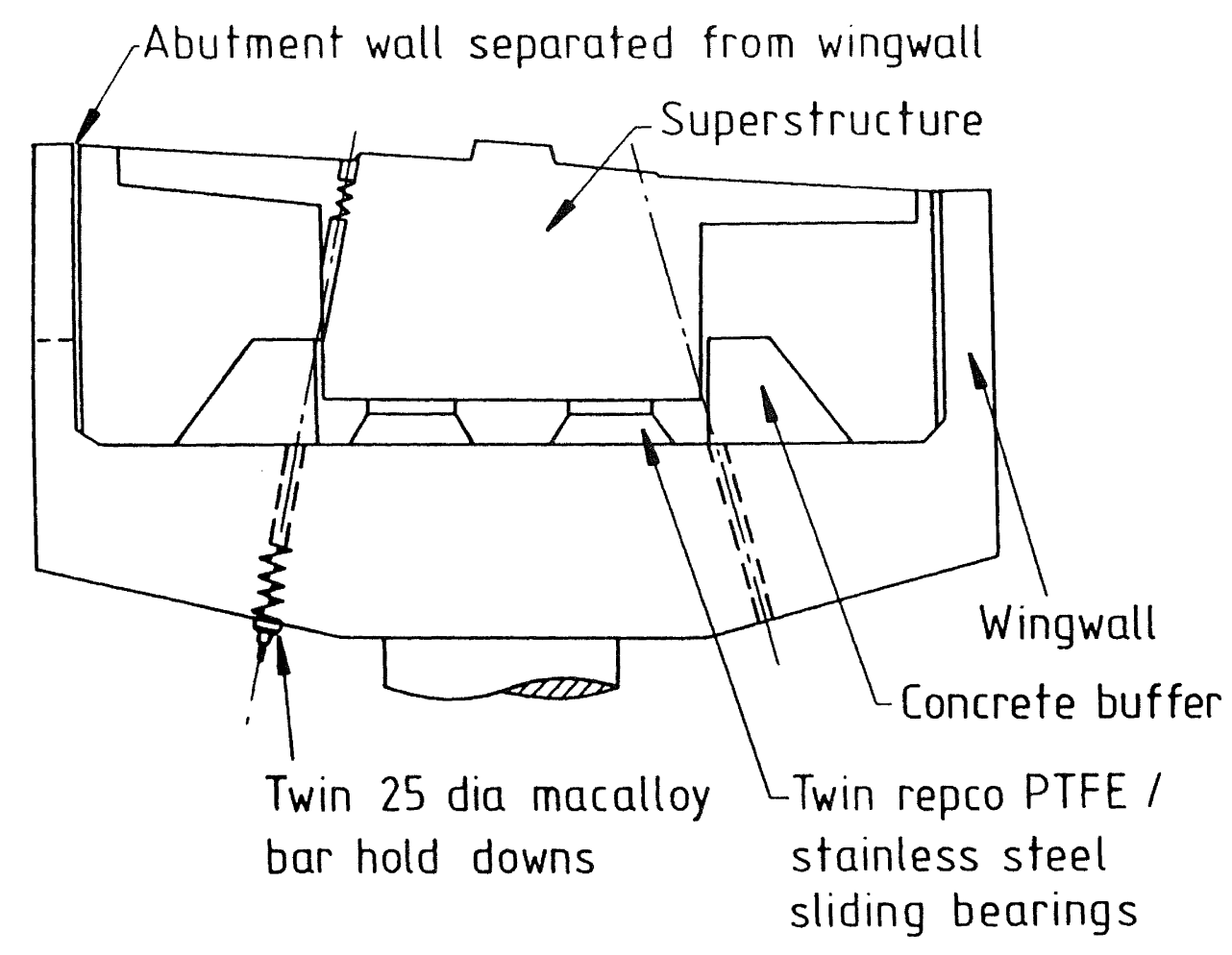

(a) CROSS - SECTION

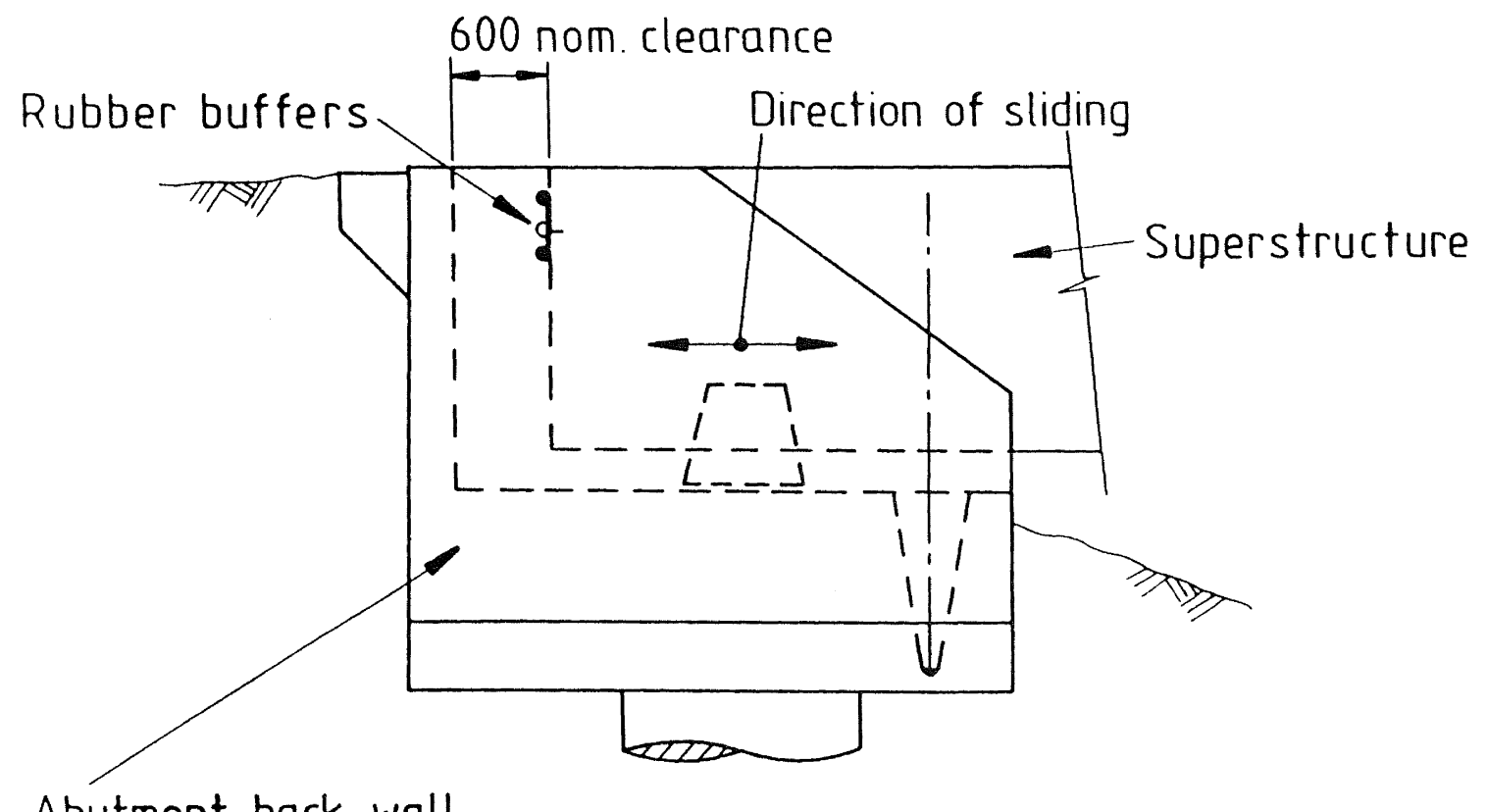

Abutment back wall

(b) ELEVATION

FIGURE 2.5 TYPICAL ABUTMENT ARRANGEMENT, BRIDGE C. 
the approach embankment subside during an earthquake. When the deck moves away from the abutment the rubber rings and linkage bars stop the deck exceeding the movement range of the bearings. Restraining buffers are commonly provided to the sides of the deck at the piers and abutments.

Figure 2.4 illustrates the type of seismic restraint that was employed at the abutments of the Bridge $A$ described in section 2.3 . It was designed to control the transverse deck movement and limit bending in the box girder. The triangular vertical plate yields gradually and provides a known force to the deck countering the seismic stresses. In the longitudinal direction a slot allows the deck to move freely. The device was developed in New Zealand some years ago [2.8].

Figure 2.5 illustrates the seismic restraint systems employed in Railway Bridge $C$. The deck cross-section is held in transverse position by concrete buffers while remaining free to slide longitudinally on PTFE bearings. Overturning of the deck is controlled by high-strength tie bars into the abutment. The bar into the abutment passes through a tapered duct, shown on the elevation Fig. $2.5 \mathrm{~b}$ which, in conjunction with a rubber pad under the anchor plate, allows up to $500 \mathrm{~mm}$ longitudinal movement before the tie bar takes up significant load.

The end of the deck has $600 \mathrm{~mm}$ clearance to the abutment back wall, and in the unlikely event that this gap closes in an earthquake, rubber buffers are provided to cushion the impact. Each rail is provided with a special joint which accommodates movement.

\subsection{REINFORCEMENT DETAILS}

\subsubsection{Introduction}

For the sake of illustration the reinforcement details described in this section are taken from a number of actual bridge designs, as outlined in section 2.3.

The reinforcement ratios referred to in the following sections are defined as follows:-

Longitudinal reinforcement ratio is the total area of longitudinal (axial) reinforcement divided by the gross section area.

Transverse reinforcement ratio, in the case of hoops or helical reinforcement, is the ratio of the volume of hoop steel to the total volume of the concrete core. The concrete core is within the circumscribing cylinder over the hoops and has a diameter equal to the hoop outside diameter.

\subsubsection{Piles}

The New Zealand Code [2.2] requires that the tops of all piles in structures designed for ductile seismic resistance shall be considered as potential plastic hinge regions unless it can be shown that the earthquake effects cause no moment in the pile. A distinction is made between potential plastic hinge regions and plastic hinge regions. The latter are where the designer intends to allow the plasticity while the former are regions in which plasticity may inadvertently develop under adverse circumstances. Maximum and minimum reinforcement ratios are specified and transverse steel shall be as for a column (see Appendix 2.1 and 2.2).

Figure 2.6 illustrates a typical pile in the substructure of Bridge A. These piles and the associated piers provide longitudinal and transverse seismic restraint. The top one diameter length of each pile is reinforced with closely spaced hoops, being the area of potential plastic hinging. The quantity of hoops decreases down the pile. In large diameter piles the shear and confinement reinforcement is generally fabricated as single hoops, sometimes with lapped and butt welded splices as depicted in Figure 2.7 (c), while in smaller piles the transverse reinforcement is typically helical.

Table 2.1 shows the quantities of reinforcement in piles for Bridges $A$ and $B$. The grades of reinforcement used in this case had minimum yield strengths of $275 \mathrm{MPa}$ for hoops (plain round bars for both bridges), and $380 \mathrm{MPa}$ and $275 \mathrm{MPa}$ for deformed longitudinal bars in Bridge $A$ and Bridge $B$ respectively.

A relatively low ratio of longitudinal reinforcement occurs in Bridge $B$ piles. The code minimum ratio in this case is 0.0029 , much lower than the allowable limit for columns. This relaxation of requirements is due to the generally larger cross-section of piles. Small piles (less than 800 diameter) must follow the same rules as columns.

Table 2.1 - Typical pile Reinforcement

\begin{tabular}{||l|c|c|c||}
\hline & \multicolumn{2}{|c|}{ Bridge A } & $\begin{array}{c}\text { Bridge } \\
\text { B }\end{array}$ \\
\cline { 2 - 4 } & $\begin{array}{c}\text { Typical } \\
\text { Pier }\end{array}$ & $\begin{array}{c}\text { Anchor } \\
\text { Pier }\end{array}$ & $\begin{array}{c}\text { Typical } \\
\text { Pier }\end{array}$ \\
\hline $\begin{array}{l}\text { Pile Diameter } \\
\text { mm }\end{array}$ & 1500 & 1800 & 1800 \\
\hline $\begin{array}{l}\text { Number of } \\
\text { Piles }\end{array}$ & $\begin{array}{c}2 \\
\text { Vertical }\end{array}$ & $\begin{array}{c}4 \\
\text { Raking }\end{array}$ & 2 \\
\hline $\begin{array}{l}\text { Pile } \\
\text { Longitudinal } \\
\text { Reinforcement } \\
\text { Ratio }\end{array}$ & 0.0146 & 0.0082 & 0.0064 \\
\hline $\begin{array}{l}\text { Pile } \\
\text { Transverse } \\
\text { Reinforcement } \\
\text { Ratio:- } \\
\text { - Top 1 diam } \\
\text { - Next 1 diam } \\
\text { - Remainder }\end{array}$ & $\begin{array}{l}0.0098 \\
0.0049\end{array}$ & $\begin{array}{l}0.0081 \\
0.0040 \\
0.0018\end{array}$ & $\begin{array}{l}0.0073 \\
0.0036\end{array}$ \\
\hline
\end{tabular}

\subsubsection{Plex columns}

The New Zealand Code [2.2] requires that the longitudinal reinforcement ratio should not be less than 0.008 . Also, the longitudinal 


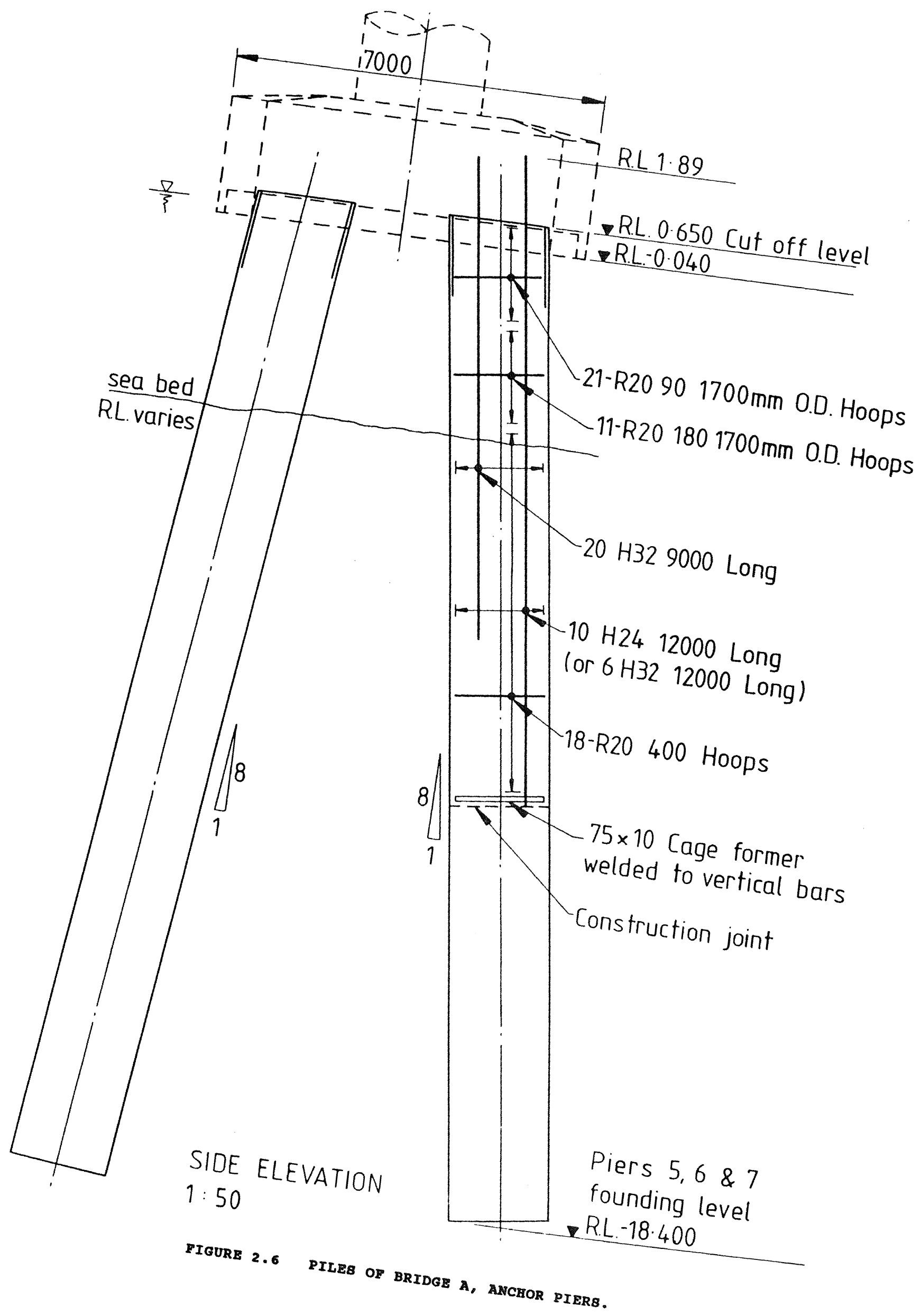




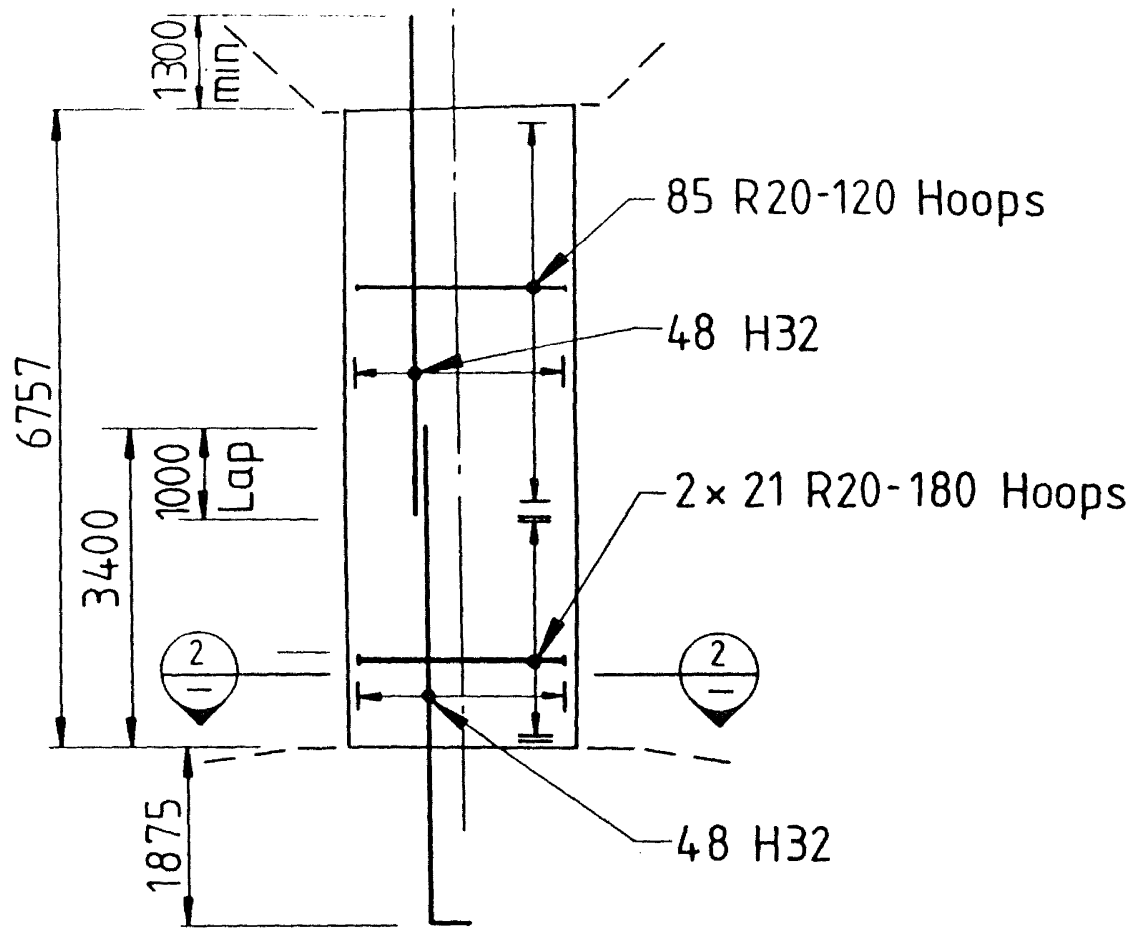

(a) ELEVATION PIER 6

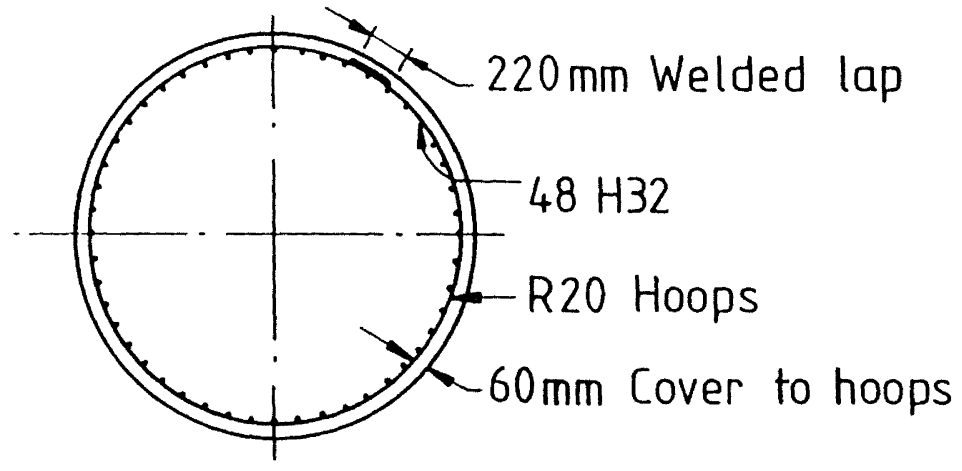

(b) SECTION 2

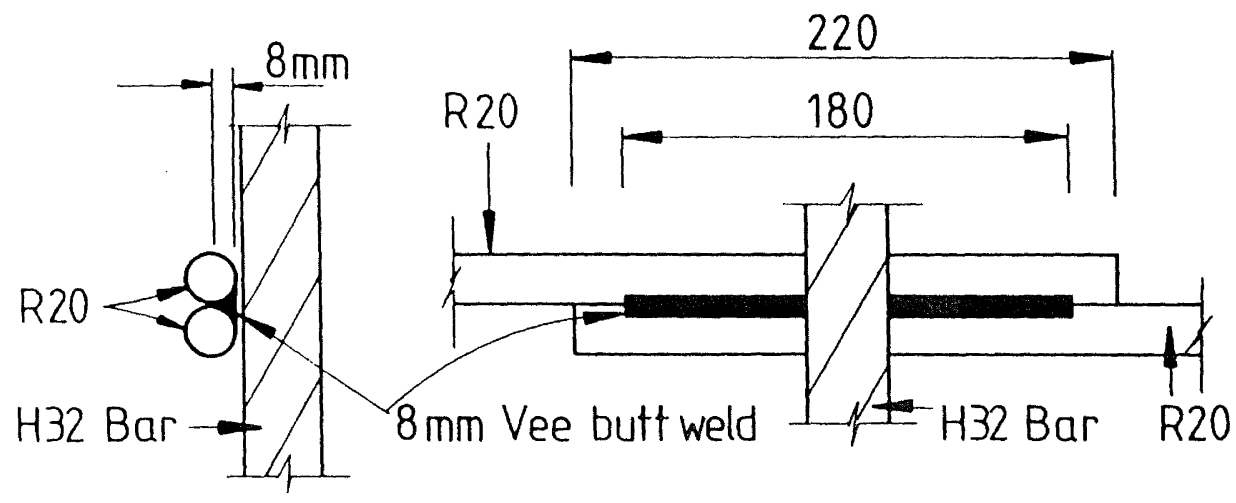

(c) HOOP SPLICE DETAIL

FIGURE 2.7 TYPICAL PIER REINFORCEMENT DETAILS, BRIDGE A. 


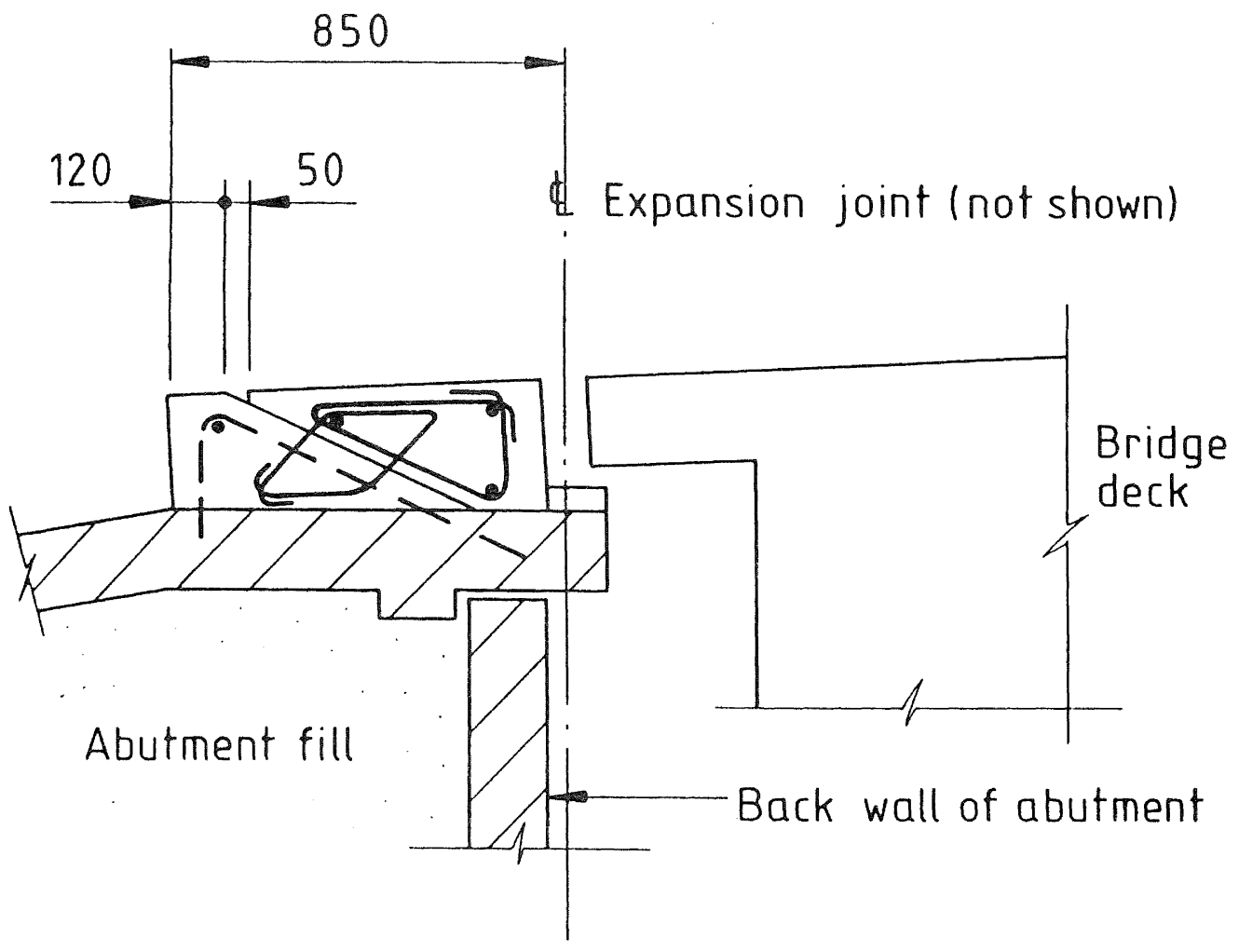

FIGURE 2.8 RNOCK-OFY DETAIL AT ABUTMENT.

reinforcement ratio should not exceed $18 / f$ except that in lap splices the total should not exceed $24 / f_{y}$, where $f_{y}$ is the yield strength of the steel. The longitudinal bars in plastic hinge regions must not be spaced further apart than $200 \mathrm{~mm}$.

The transverse confining reinforcement required is a function of axial load, concrete strength and ratio of the confined core area to the gross section area. The maximum spacing of confining steel is limited to $200 \mathrm{~mm}$, six longitudinal bar diameters, or one-fifth of the smallest section dimension. Adjacent to the hinge region these spacings double and the minimum confining steel requirements halve, for a length equal to the hinge region (see Appendices 2.1 and 2.2 ).

The length of plastic hinge regions is related to the axial load level and moment gradient. A typical length is one diameter of the column for piers with low axial loads (see Appendices 2.1 and 2.2).

The pier columns are designed to plastically deform under the design seismic load. The details of reinforcing in an anchor pier of Bridge $A$ are shown in Figure 2.7. Note that the longitudinal bars are detailed to lap outside the plastic hinge regions and welded hoops are used as shown in Figure 2.7. The transverse steel is closely spaced for the lower one diameter of the column corresponding to the inferred extent of plasticity. High grade bars can be used for hoops to reduce congestion and facilitate construction.

Table 2.2 sets out the typical reinforcement ratios in the piers.
Table 2.2 - Typical Pier Reinforcement

\begin{tabular}{|c|c|c|c|}
\hline & \multicolumn{2}{|c|}{ Bridge A } & \multirow{2}{*}{$\begin{array}{c}\begin{array}{c}\text { Bridge } \\
\text { B }\end{array} \\
\begin{array}{c}\text { Typical } \\
\text { Pier }\end{array} \\
\end{array}$} \\
\hline & $\begin{array}{c}\text { Typical } \\
\text { pier }\end{array}$ & $\begin{array}{c}\text { Anchor } \\
\text { Pler }\end{array}$ & \\
\hline $\begin{array}{l}\text { Pier Diameter } \\
\text { min }\end{array}$ & 1800 & 2400 & 1000 \\
\hline $\begin{array}{l}\text { Number of } \\
\text { Columns }\end{array}$ & 1 & 1 & 2 \\
\hline $\begin{array}{l}\text { Pile } \\
\text { Longitudinal } \\
\text { Reinforcement } \\
\text { Ratio }\end{array}$ & 0.0095 & 0.0085 & 0.0266 \\
\hline $\begin{array}{l}\text { Transverse } \\
\text { Reinforcement } \\
\text { Ratio:- } \\
\text { - Hinge } \\
\text { Region } \\
\text { - Elsewhere }\end{array}$ & $\begin{array}{l}0.0122 \\
0.0061\end{array}$ & $\begin{array}{l}0.0091 \\
0.0046\end{array}$ & $\begin{array}{l}0.0125 \\
0.0070\end{array}$ \\
\hline
\end{tabular}

\subsubsection{Splices}

Where longitudinal bars are lap spliced, the normal lap length requirements apply. Earthquake resistant design prescribes that in piers, the splice must be located away from plastic hinges. Confinement is required around bars lapping in terision zones or in areas of reversing stress. 


\subsubsection{Abutment Details}

A detail of a knock-off zone at an abutment is depicted in Figure 2.8. Under longitudinal seismic loads the cantilever slab will impact on the triangular block which will shear off up the inclined construction joint. Damage will be limited to the expansion joint and this repairable element and the remainder of the deck and abutment will remain undamaged.

\subsection{EXAMPLE BRIDGE8}

\subsubsection{Bridge A}

Bridge $A[2.9]$ is an incrementally launched prestressed concrete box girder of 12 spans $478 \mathrm{~m}$ long shown in Figures 2.9 and 2.10 . The superstructure is a single cell with a deck width of $11.3 \mathrm{~m}$ carrying 2 lanes and a footpath. The three central piers of this bridge are anchor piers providing longitudinal restraint for seismic, thermal, traffic and shrinkage and creep effects.

other piers provide only transverse restraint. The abutments provide a reduced and designed level of transverse seismic restraint through a special yielding device described earlier. All piers were designed to yield at the base of the pier columns, with the capping beams, pile caps and piles all remaining elastic.

\subsubsection{Bridge B}

Bridge $B$ is a twin spine beam bridge with a $1400 \mathrm{~mm}$ deep and $13 \mathrm{~m}$ wide deck (see Fig 2.11). It is supported on twin column piers founded on bored piles. The columns rise straight off the piles which are connected at ground level by a substantial tie beam. The bridge has 5 spans of around $28 \mathrm{~m}$ and is on $11.5^{\circ}$ skew.

\subsubsection{Bridge C}

Figure 2.12 illustrates Bridge $C[2.10]$ a $414 \mathrm{~m}$ long single track railway bridge of $20 \mathrm{~m}$ typical span. The deck is generally solid and of the section shown in Figure $2.13 \mathrm{a}$, though the haunched areas are hollow. The deck is continuous and monolithic with all but the shortest piers near the ends. This improves seismic performance but adversely affects relief of thermal. shrinkage and creep effects. The designers compromised by adopting the following measures:-

(a) a stiff anchor pier to minimise the required stiffness of all other piers;

(b) unguided sliding bearings at piers 2 and 21 and transversely guided abutments (Fig 2.5);

(c) pinned connections between the deck and piers $3,4,18,19,20$ as depicted in Figure 2.13b;

(d) pier cross-sections which are constant over the upper $30 \mathrm{~m}$ and larger below. Under longitudinal seismic loads this forces pier plastic hinges to form at base of the upper section and results in roughly similar seismic shear to most columns despite the overall pier heights varying significantly. The lower thicker pier areas were subject to capacity design to ensure that plasticity only occurs in the intended areas.

(e) Tapering the anchor pier to reduce moments induced in the deck.

\subsection{RECENT DEVELOPMENTS IN DEGIGN PROCEDUREB}

Since the publication of the current New Zealand Code $[2.2]$ in 1982 , research at the University of Canterbury has resulted in refined seismic design procedures for bridge columns and piers. These procedures enable more accurate determination of the quantities of longitudinal reinforcement required for flexural strength and transverse reinforcement required to achieve specified ductility levels. A summary of that research work is given in References 2.11 and 2.12 and in the attached Appendices 2.3 and 2.4 .

\subsection{ACKNOWLEDGEMENTE}

The authors acknowledge the assistance of $\mathrm{Dr}$ $J \mathrm{~T}$ Dale of Murray-North Limited in the preparation of this section and thank MurrayNorth Limited and Beca Carter Hollings and Ferner Limited (both Auckland, New Zealand) for their co-operation in providing data on the bridges used as examples.

\subsection{REFERENCEB}

2.1 "Bridge Manual: Design and Evaluation", (Draft for Comment), Transit New Zealand, Wellington, 1991.

2.2 "Code of Practice for the Design of Concrete structures, NZS 3101 Part 1 : 1982", "Commentary on the Design of Concrete structures NZS 3101 Part 2: 1982 " and "Amendment No. 1 to NZS 3101 Parts 1 and 2, 1989", standards Association of New Zealand, Wellington.

2.3 CHAPMAN H E, NORTH P J, PARK R, "section 3: Capacity Design Principles and Practice", papers resulting from deliberations of the Society's discussion group on the seismic design of bridges. Bulletin, $\mathrm{NZ}$ National Society for Earthquake Engineering, Vol. 13 , No. 3, September 1980 , pp $242-247$.

2.4 PRIESTLEY $M J \mathrm{~N}$, PARK $\mathrm{R}$, HENG $\mathrm{N} \mathrm{K}$, "Influence of Foundation Compliance on the Seismic Response of Bridge Piers", Bulletin, Nz National Society for Earthquake Engineering, Vol. 12, No. 1, March 1979, pp $22-34$

2.5 TURKINGTON D M, CARR A J, COOKE N, and MOSS P J, "Seismic Design of Bridges on Lead-Rubber Bearings", J of structural Engineering, Vol. 115, No. 2, ASCE, DeC 1989 , pp $3,000-3,016$.

2.6 CORMACK L G, "The Design and Construction of the Major Bridges on the Mangaweka Rail Deviation", IPENZ 


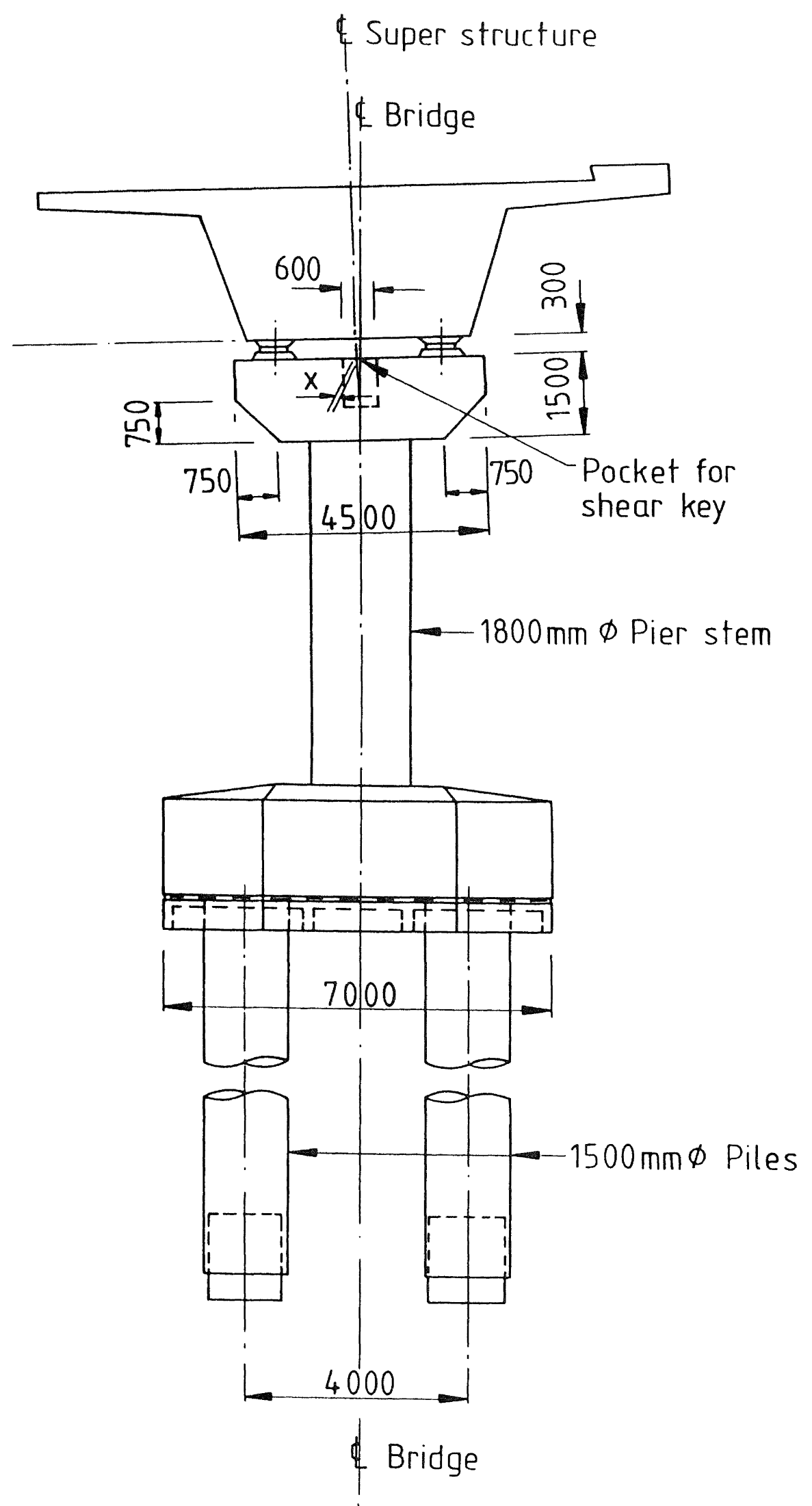

FIGURE 2.9 BOX GIRDER BRIDGE A, CROSB SECTION AT A STANDARD PIER. 


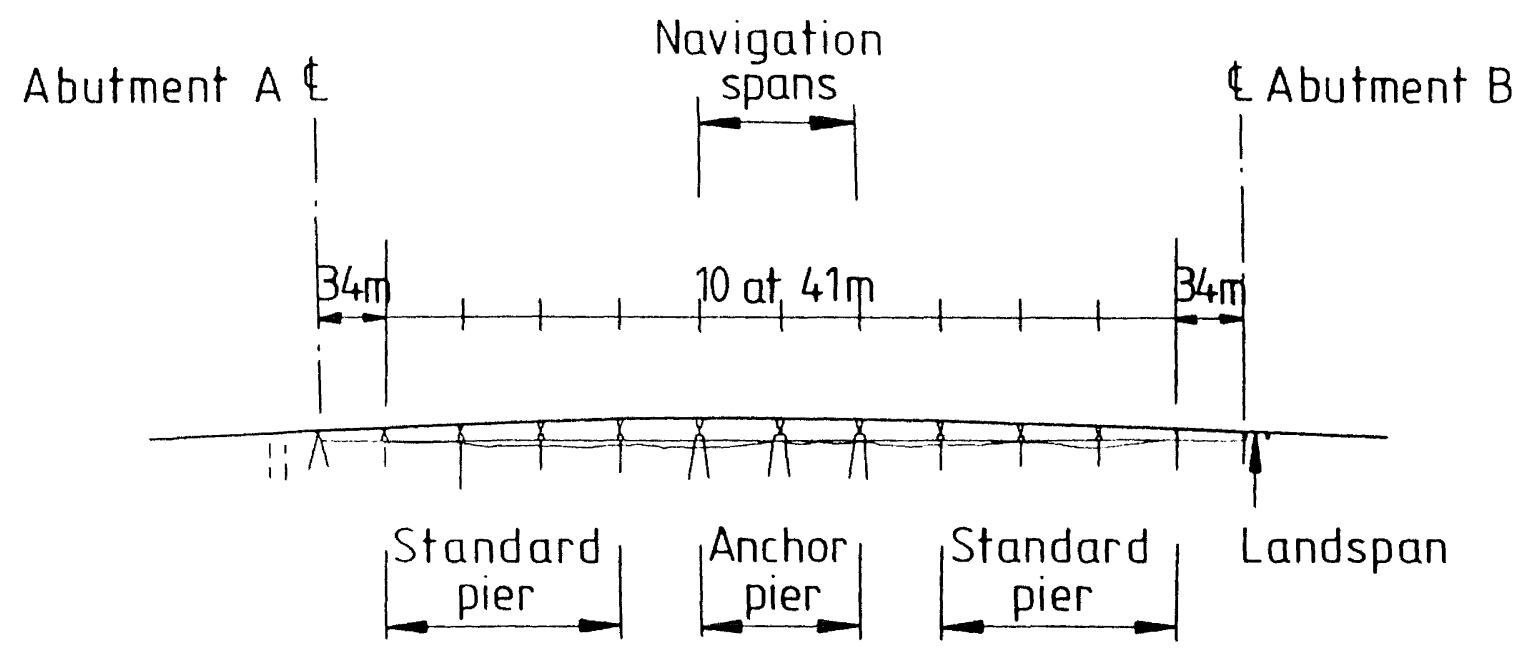

(a) BRIDGE ELEVATION

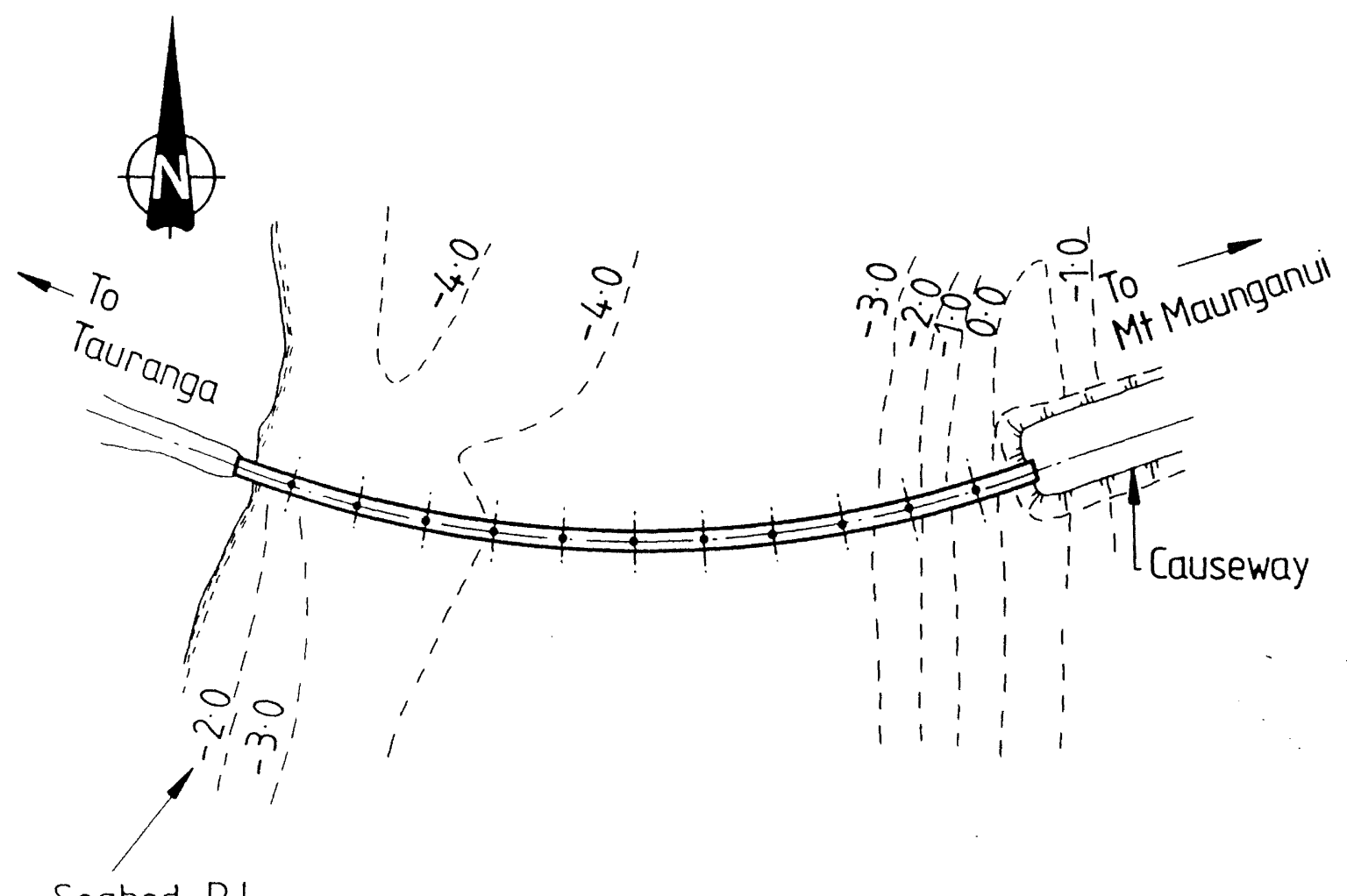

(b) PLAN 


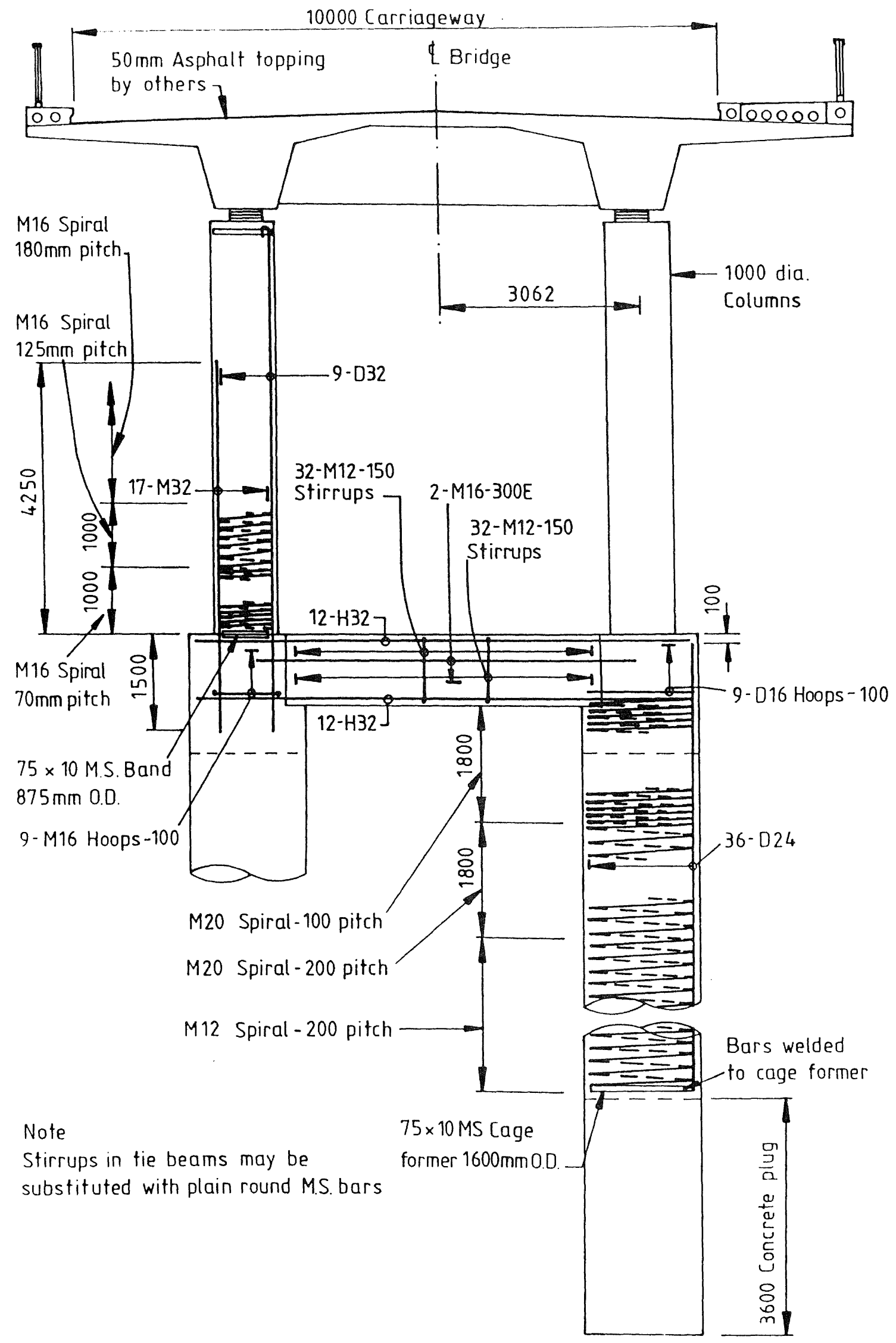

FIGURE 2.11 CROSS-SECTION OF BRIDGE B. 

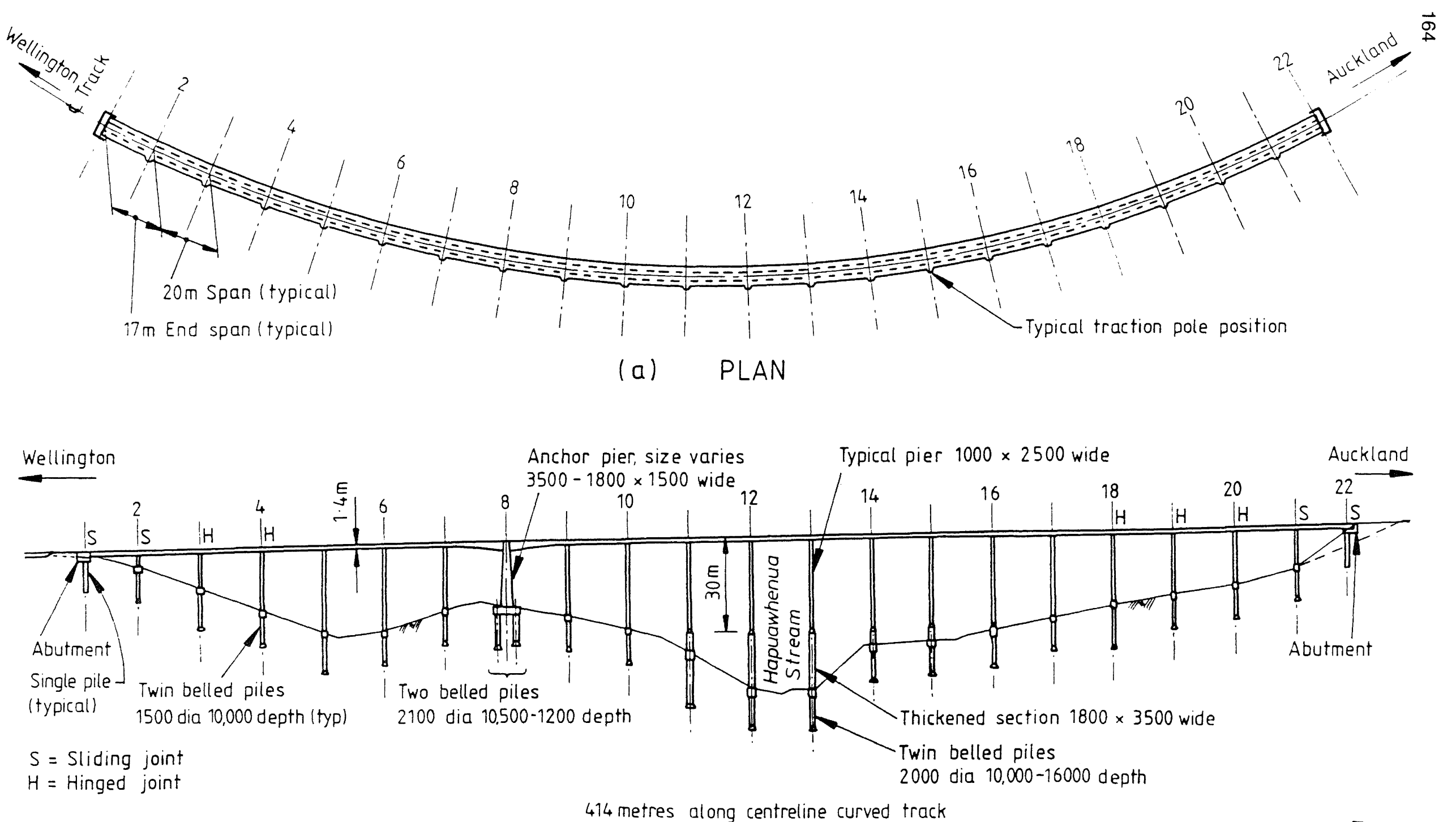

(b) ELEVATION

FIGURE 2.12 GENERAL ARRANGEMENT OP RAILTAY BRIDGE C. 


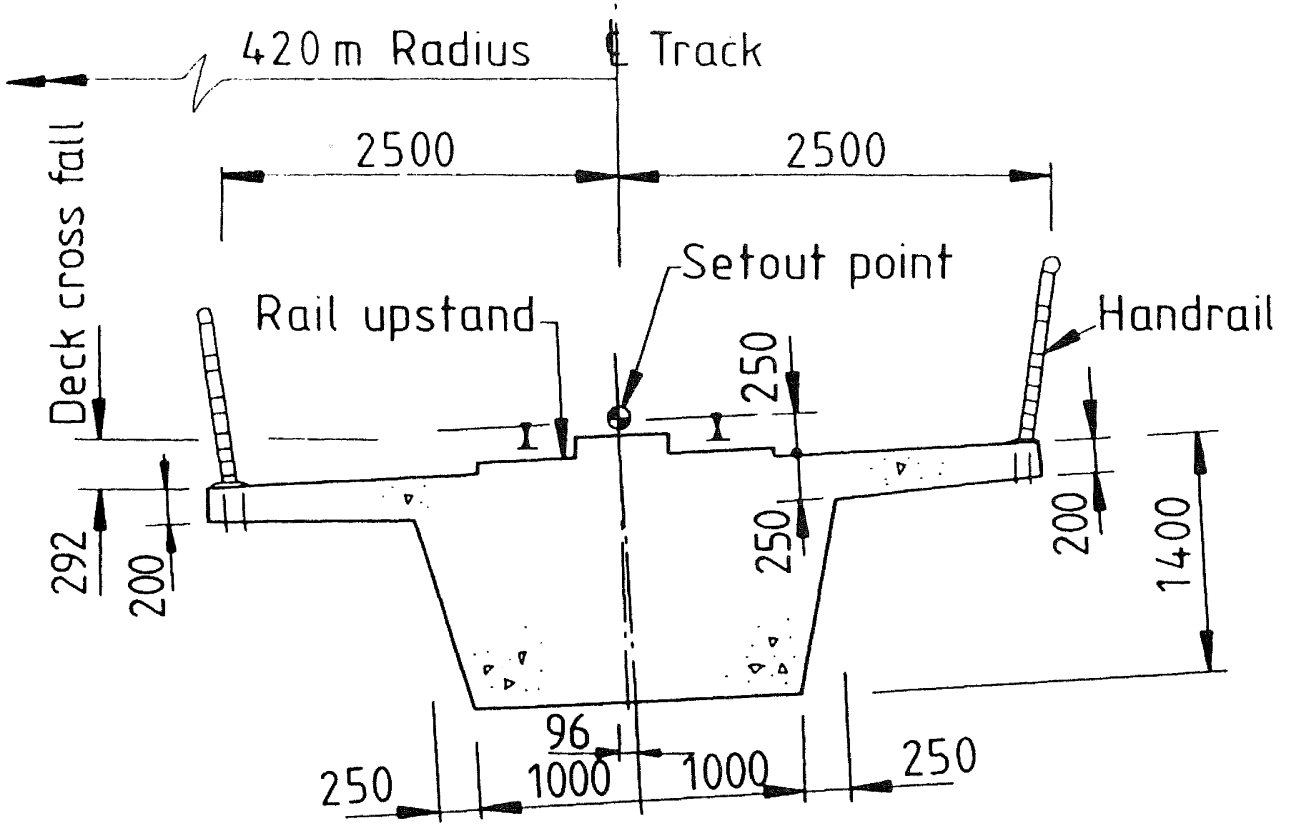

(a) TYPICAL DECK SECTION

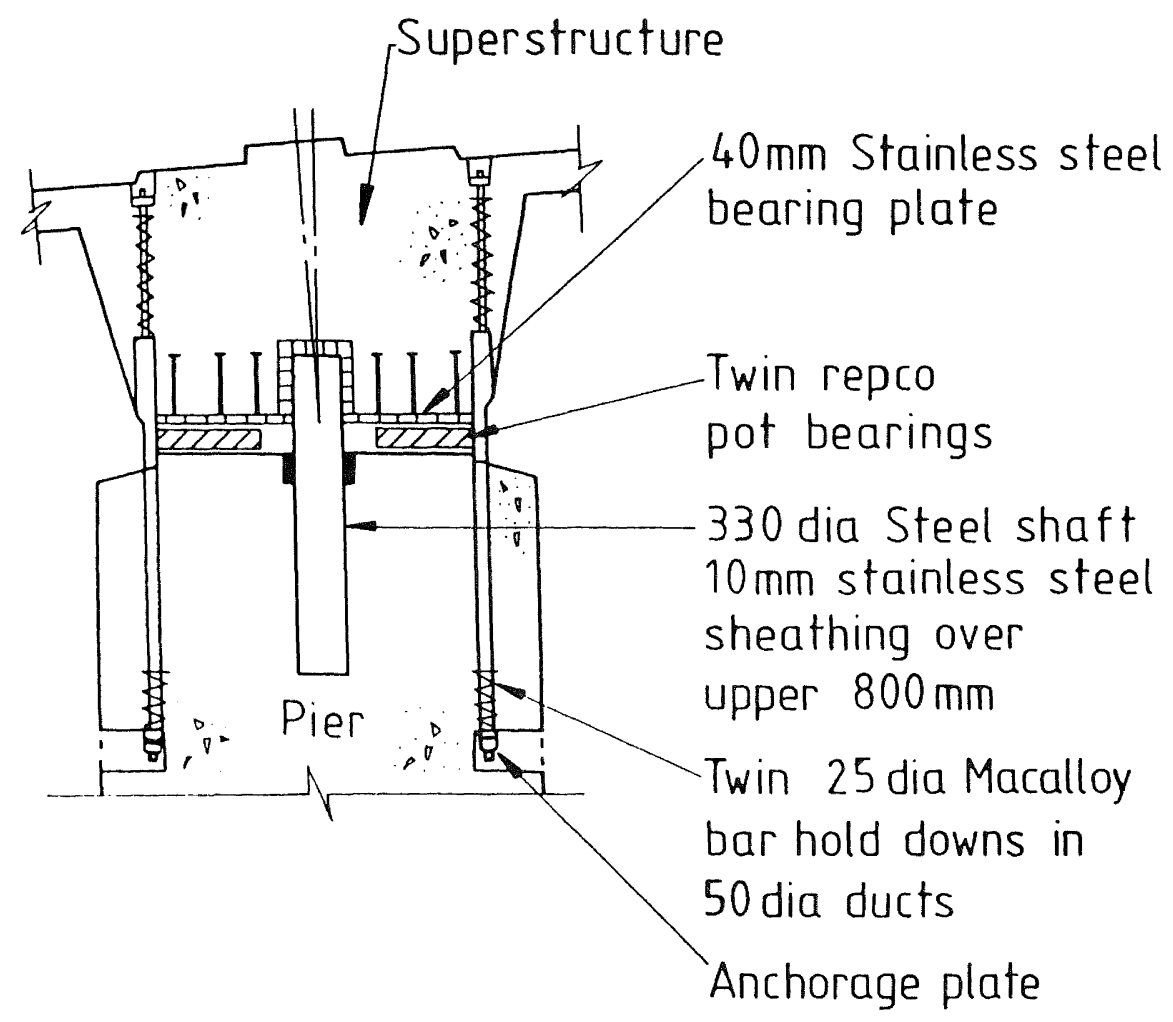

(b) PIER-DECK PINNED CONNECTION

FIGURE 2.13 CRO8B-8ECTIONS OF BRIDGE C. 
Transactions Vol. 15, No. 1/CE, March 1988, pp $16-23$.

2.7 "Guide Specification for Seismic Isolation Design of Highway Bridges", in preparation AASHTO, 1990.

2.8 TYLER R G, "Tapered steel Energy Dissipators for Earthquake Resistant structures", Bulletin, NZ structural Society for Earthquake Engineering, Vol. 11, No. 4, December 1978, pp $282-294$.

2.9 BLOXAM M J, NORTH P J, "Tauranga Harbour Crossing, Stella Passage Bridge Seismic Design", Bulletin, NZ National Society for Earthquake Engineering, Vol. 23, No. 3, September 1990, pp $220-$ 230 .

2.10 JURY $R$, HOLLINGS $J$ $P$ and CATLEY $T$, "Design of a Curved $414 \mathrm{~m}$ Long Continuous Concrete Railway Bridge to Resist Earthquake Motions", Bulletin, New Zealand National Society for Earthquake Engineering, Vol. 22, No. 1, March 1989, pp $50-56$.

APPENDIX 2.1

NEW ZEALAND CONCRETE DESIGN CODE (NZB 3101 , 1982) BEISMIC DESIGN PROVIBIONB FOR TRANBVERBE REINFORCEMENT IN COLUMNB AND PIERB FOR CONFINEMENT OF CONCRETE AND LATERAL SUPPORT OF LONGITUDINAL REINFORCEMENT [2.2]

\section{(a) LENGTH OF POTENTIAL PLABTIC hINGE REgION TO BE CONFINED}

The potential plastic hinge regions in columns and piers are considered to be the end regions adjacent to moment resisting connections over a length from the face of the connection as follows :

(i) When $P \leq 0.3 \phi f^{\prime} A$, the potential plastic hinge region is taken as not less than the larger column section dimension in the case of a rectangular section or the diameter in the case of a circular section, or where the moment exceeds 0.8 of the maximum moment at that end of the member, and

(ii) When $P_{e}>0.3 \phi f_{c}^{\prime} A_{g}$, the potential plastic hinge region is increased by $50 \%$,

where $\mathrm{P}_{\mathrm{f}}=$ column load in compression due to the design gravity and seismic loading, $\phi=$ strength reduction factor $=0.9$ for confined members, $f_{c}^{\prime}=$ lower characteristic compressive cylinder strength of concrete, and $A_{9}=$ gross area of column cross section.
2.11 PRIESTLEY $M J N$ and PARK $R$, "Strength and Ductility of Bridge Substructures" Bulletin 71, Road Research Unit, National Roads Board, Wellington, 1984, p 120.

2.12 PARK $\mathrm{R}$ and PAULAY $\mathrm{T}$, "Strength and Ductility of Concrete Substructures of Bridges", Vol. 1: RRU Bulletin 84, Bridge Design and Research Seminar, Transit New Zealand, 1990, p 170.

2.13 MANDER J B, PRIESTLEY $M J ~ N$ and PARK $R$, "Seismic Design of Bridge Piers", Report 84-2, Department of Civil Engineering, University of Canterbury, February 1984, p 483 .

2.14 ZAHN $F$ A, PARK $R$ and PRIESTLEY $M \quad J \quad N$ "Design of Reinforced Concrete Bridge Columns for strength and Ductility" Research Report 86-7, Department of Civil Engineering, University of Canterbury, March 1986, p 402.

2.15 WATSON $S$ and PARK $R$, "Design of Reinforced Concrete Frames of Limited Ductility", Report 89-4, Department of Civil Engineering, University of Canterbury, January 1989, p232.

The increase in length of potential hinge regions at high axial load levels is because tests $[2.11-2.15]$ have shown that at high axial load levels the flexural strength at the critical section is significantly enhanced by the larger confining steel content. Thus flexural failure could occur in the less well confined adjacent regions of column unless the confining steel is spread over a longer length of column.

Figure A.2.1 illustrates these requirements for a single column bridge pier when $P_{e} \leq 0.3 \phi f_{c}^{\prime} A_{g}$. Note that levels of $P_{e}$ exceeding $0.3 \phi f^{\prime} A$ are uncommon for bridge piers designed in New Zealand.

\section{(b) BPACING OF REINFORCEMENT IN POTENTIAL PLABTIC HINGE REGIONS}

For both circular and rectangular shaped transverse reinforcement, the centre to centre spacing in the longitudinal direction of the column in potential plastic hinge regions is required not to exceed the smaller of one-fifth of the least lateral dimension of the cross section, six longitudinal bar diameters or $200 \mathrm{~mm}(7.9 \mathrm{in})$. For rectangular hoops the centre to centre spacing between hoop legs or cross ties across the column section is required not to exceed $200 \mathrm{~mm}(7.9 \mathrm{in})$.

It is also required that longitudinal bars be spaced not further apart between centres than $200 \mathrm{~mm}(7.9 \mathrm{in})$. 


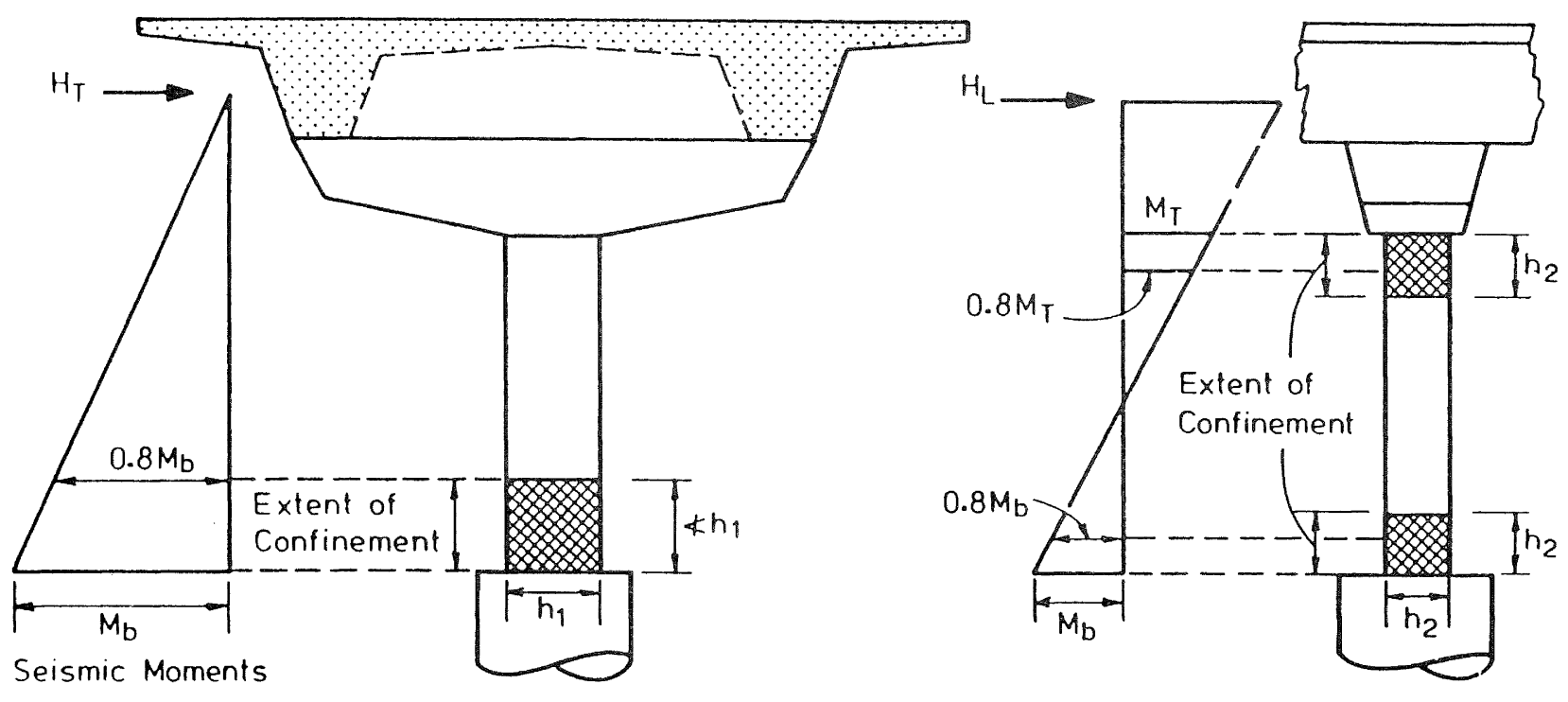

(a) Transverse Response

(b) Longitudinal Response

FIG.A.2.1 REGIONB TO BE CONFINED FOR A TYPICAL SINGLE COLUMN BRIDGE PIER WEN $P_{e} \leq 0.3 \phi F_{c}^{\prime} A_{g}$

Also for rectangular hoops, each longitudinal bar or bundle of bars is to be laterally supported by a corner of a hoop having an included angle of not more than $135^{\circ}$ or by a cross tie, except that longitudinal bars are exempted from this requirement if either :

(i) they lie between two bars supported by the same hoop where the distance between the laterally supported bars does not exceed $200 \mathrm{~mm}(7.9 \mathrm{in})$ between centres, or

(ii) they lie within the concrete core of the column section centred more than $75 \mathrm{~mm}$ $(3.9$ in) from the inner face of the hoop.

In addition, for rectangular hoops the yield force in the hoop bar or cross tie is to be at least one-sixteenth of the yield force of the longitudinal bar or bars it laterally restrains, including the contribution by any bar or bars exempted above from the direct support.

with regard to the limits on longitudinal spacing of transverse reinforcement, the onefifth of the least column lateral dimension requirement is to ensure that the bars are close enough to effectively confine the compressed concrete. The six longitudinal bar diameter requirement is to ensure that premature buckling of longitudinal reinforcing bars does not occur when they yield in compression during cycles of seismic load reversals. Tests $[2.11-2.15]$ have shown that a spacing of transverse reinforcement in excess of six longitudinal bar diameters may lead to excessive buckling of the longitudinal steel followed by premature strength degradation due to low cycle fatigue fracture of those bars.

\section{(c) MAXIMUM COMPRESSIVE LOAD LEVEL}

For both circular and rectangular columns, the column load in compression due to the design gravity and seismic loading $P$ is not permitted to exceed $0.7 \phi \mathrm{f}_{\mathrm{c}}^{\prime} \mathrm{A}$ unless it can be shown that $\mathrm{P}_{e}$ is less than $0.7 \phi \mathrm{P}_{0}$, where $\phi=$ strength reduction factor $=0.9$ for confined columns, $f_{c}^{\prime}=$ lower characteristic compressive cylinder strength of concrete, $A_{g}$ $=$ gross area of column section, and $\mathrm{P}_{0}=$ axial load compressive strength when the load is applied with zero eccentricity.

This upper limit on column load is placed because for very heavily loaded sections the available ductility is doubtful, even with large amounts of confining steel.

(d) QUANTITY OF TRANSVERSE REINFORCEMENT
REQUIRED FOR CONFINEMENT IN POTENTIAL PLABTIC HINGE REGIONS

\section{(i) Columns wth eircular section}

The quantity of transverse reinforcement of circular shape for confinement is expressed in terms of $\rho_{s}$, which is the ratio of the volume of spiral or circular hoop reinforcement to the volume of the concrete core. Therefore

$$
\rho_{s}=\frac{A_{s p} \pi d_{s}}{s \pi\left(d_{s} / 2\right)^{2}}=\frac{4 A_{s p}}{d_{s} s}
$$

where $\AA_{s p}=$ area of spiral or circular hoop bar, $d_{s p}=$ diameter of spiral or circular hoop, and $s=$ centre to centre spacing of spiral or circular hoop bar.

In potential plastic hinge regions the volumetric ratio of spiral or circular hoop reinforcement is required to be not less than 


$$
\rho_{s}-0.45\left(\frac{A_{g}}{A_{c}}-1\right) \frac{f_{c}^{\prime}}{f_{y h}}\left(0.5+1.25 \frac{P_{e}}{\phi f_{c}^{\prime} A_{g}}\right)
$$

or

$$
\rho_{s}=0.12 \frac{f_{c}^{\prime}}{f_{y h}}\left(0.5+1.25 \frac{P_{e}}{\phi f_{c}^{\prime} A_{g}}\right)
$$

whichever is greater, where $A_{g}=$ gross area of column cross section, $A_{c}=$ area of concrete core of section measured to outside of peripheral transverse steel $f^{\prime}=$ lower characteristic compressive cylinder strength of concrete, $f_{y h}=$ lower characteristic yield strength of transverse reinforcement, $P_{0}=$ column load in compression due to the design gravity and seismic loading, and $\phi=$ strength reduction factor $=0.9$ for confined columns.

\section{(ii) Columns with rectangular section}

In potential plastic hinge regions when rectangular hoops with or without cross ties are used, the total area of transverse bars $A_{\text {th }}$ in each of the transverse directions within spacing $s_{h}$ is required to be

$$
A_{s h}-0.3 \mathrm{sh}_{h} h^{\prime}\left(\frac{A_{g}}{A_{c}}-1\right) \frac{f_{c}^{\prime}}{f_{y h}}\left(0.5+1.25 \frac{P_{e}}{\phi f_{c}^{\prime} A_{g}}\right)
$$

or

$$
A_{s h}=0.12 S_{h} h^{\prime \prime} \frac{f_{c}^{\prime}}{f_{v h}}\left(0.5+1.25 \frac{P_{e}}{\phi f_{c}^{\prime} A_{g}}\right)
$$

whichever is greater, where $h^{\prime \prime}=$ dimension of concrete core of the section measured perpendicular to the direction of the hoop bars to the outside of the perimeter hoop, and the other symbols are as for circular columns.
The amount of transverse reinforcement required by the above equations for $\rho_{s}$ and $A_{s h}$ increases with the axial load level $\mathrm{p}_{\mathrm{e}} / \phi \mathrm{f}_{c}^{\prime} \mathrm{A}_{\mathrm{g}}$ because a higher axial load means a larger neutral axis depth which in turn means that the flexural strength of the column is more dependent on the contribution of the compressive stress block. Thus the higher the axial load level the more important it becomes to maintain the strength and ductility for the concrete, therefore leading to a greater quantity of transverse steel.

\section{(e) QUANTITY OF TRANSVERSE REINFORCEMENT REQUIRED OUTBIDE POTENTIAL PLABTIC HINGE REGIONB}

Over the length of column or pier adjacent to the potential plastic hinge region and equal in length to the potential plastic hinge region the centre to centre spacing of transverse reinforcement is required to be not more than twice that in the potential plastic hinge region and the quantity of transverse reinforcement is required to be not less than one-half that required in the potential plastic hinge region.

\section{(f) ANCHORAGE OF CONFINING REINFORCEMENT IN POTENTIAL PLAgTtC hINGE REgIONB}

The transverse steel is required to be anchored by at least a $135^{\circ}$ hook around a longitudinal bar. The extension at the free end of the transverse bar into the core concrete is required to be at least eight transverse bar diameters for plain round transverse bar or six transverse bar diameters for deformed transverse bar. Alternatively, the ends of the transverse bars shall be welded.

\section{(g) SPLICES IN LONGITUDINAL REINFORCEMENT}

Lap splices of longitudinal reinforcement are not permitted in the potential plastic hinge regions of columns.

and for the longitudinal direction is

$$
\mathrm{V}_{0 r}-\frac{\phi_{0}\left(M_{\mathrm{b}}+M_{t}\right)}{L_{c}}
$$

where $\phi_{0}=1.25$ is the overstrength factor, $M_{0}$ and $M_{t}$ are the ideal flexural strengths of the bottom and top sections of the column, respectively, calculated using the lower characteristic strengths of the materials and $L$ and $L_{c}$ are the column heights from the foundation to the centre of mass and to the bottom of the column cap, respectively.

For New Zealand manufactured Grade 300 and Grade 430 reinforcement, an overstrength factor of $\phi_{0}=1.25$ is used. This $\phi_{0}$ value allows for the probability of the actual yield strength of the steel being higher than 


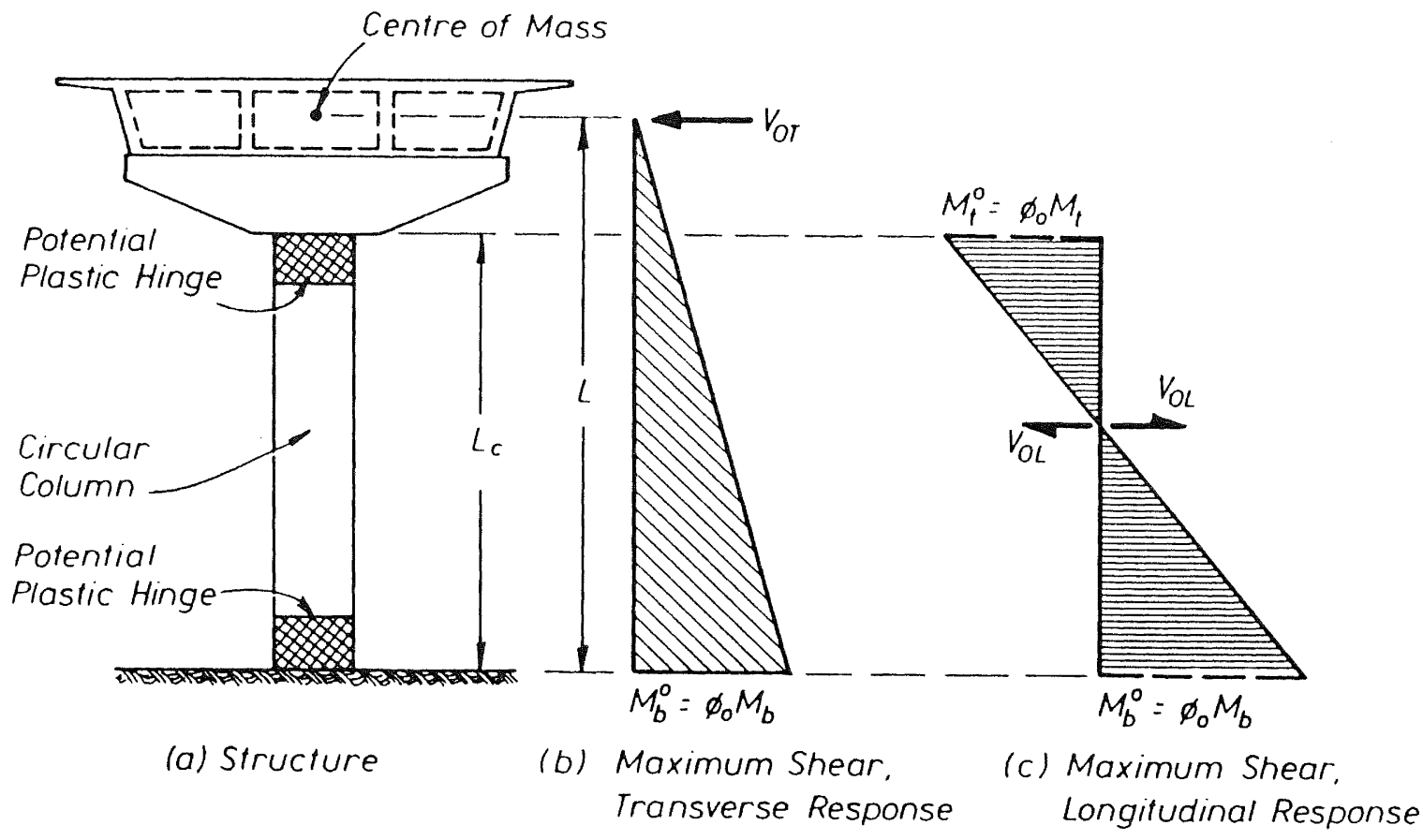

FIG. A.2.2 CAPACITY DESIGN PROCEDURE FOR DESIGN SHEAR FORCE FOR A BINGLE COLUMN BRIDGE PIER

the lower characteristic yield strength and for the additional steel strength due to strain hardening.

\section{(b) DESIGN BHEAR STRENGTH}

The ideal shear strength of the column is given by

$$
v_{i}=v_{c}+v_{s}
$$

where $V_{c}$ is the shear resisted by the concrete mechanisms of aggregate interlock and across the compression zone, and $\mathrm{V}_{\mathrm{s}}$ is the shear resisted by the transverse reinforcement.

\section{(i) shear Resisted by the concrete Mechanisms}

The shear resisted by the concrete mechanisms is given by

$$
\mathrm{v}_{\mathrm{c}}=\mathrm{v}_{\mathrm{c}} \mathrm{b}_{\mathrm{w}} \mathrm{d}
$$

where $v_{c}$ is the nominal shear stress resisted by the concrete, $b_{4}$ is the width of the column or diameter of a circular column, and d is the effective depth. For circular columns, $d$ need not be taken as less than the distance from the extreme compression fibre to the centroid of tension reinforcement in the opposite half of the section. If the longitudinal reinforcement is uniformly distributed around a circle of diameter $D^{\prime}$ in a column of gross diameter $D$, this results in

$$
d=0.5 D+0.318 D^{\prime}
$$

For large diameter columns, d may be approximated as $0.8 \mathrm{D}$.
Different expressions for $v_{c}$ apply between plastic hinge regions and in plastic hinge regions. The values for $v_{c}$ are related to the basic shear stress $v_{b}$ given by

$$
v_{b}=\left(0.07+10 \rho_{w}\right) \sqrt{f_{c}^{\prime}} \leq 0.2 \sqrt{f_{c}^{\prime}}
$$

where

$$
\rho_{w}-\frac{A_{s}}{b_{w} d}
$$

and $A_{s}=$ area of tension reinforcement = onehalf of the total area of reinforcement for a circular column.

Between the plastic hinge regions, for a column subjected to axial compressive load $\mathrm{P}_{\mathrm{e}}$

$$
v_{c}-\left(1+\frac{3 P_{e}}{f_{c}^{\prime} A_{g}}\right) v_{b}
$$

In the plastic hinge regions, where $\mathrm{P}_{\mathrm{e}} \leq$ $0.1 \mathrm{f}_{c}^{\prime} \mathrm{A}_{\mathrm{g}}, \mathrm{v}_{\mathrm{c}}$ is taken as zero because shear transfer within the compression zone and aggregate interlock are likely to be undependable when wide flexural cracks occur under reversed cyclic inelastic displacements. For axial compression load levels of $P_{e}>0.1 f_{c}^{\prime} A_{g}, v_{c}$ is given by

$$
v_{c}=4 v_{b} \sqrt{\frac{P_{e}}{f_{c}^{\prime} A_{g}}-0.1}
$$


which assumes that the concrete shear resisting mechanisms are enhanced with increase in axial load level.

(ii) shear Resisted by the Transverse Reinforcement

For rectangular sections the shear resisted by the transverse reinforcement is given by

$$
v_{s}-\frac{A_{v} f_{y h} d}{s}
$$

where $\mathbf{s}$ is the vertical spacing of shear reinforcement layers with total area $A_{v}$ parallel to the direction of the shear force, and $f_{y h}$ is the yield strength of the shear reinforcement.

For circular column sections the shear resisted by spirals or circular hoops is given by

$$
V_{s}-\frac{\pi}{4} A_{v} f_{y h} \frac{D^{\prime}}{s}
$$

which is found by summing the components in the direction of the shear force, of bar forces from spirals or circular hoops intercepted by a $45^{\circ}$ crack.

\section{APPENDIX 2.3}

THE REAL FLEXURAL STRENGTH OF REINFORCED CONCRETE COLUMNS

Previously summarized experimental research conducted at the University of Canterbury [2.11] has indicated that the measured flexural strengths of confined reinforced concrete columns was greater than the flexural strength predicted by the conventional code approach.

Fig.A.2.3 shows the plotted $M_{\max } / M_{\text {code }}$ ratio for columns tested [2.11] at various axial load levels, where $M$ is the maximum measured moment in the tests and $M_{\text {code }}$ is the flexural strength calculated by the code procedure on the basis of a rectangular compressive stress block with a mean stress of $0.85 f^{\prime}$, an extreme fibre concrete compressive strain of 0.003 , the measured material strengths $f^{\prime}$ and

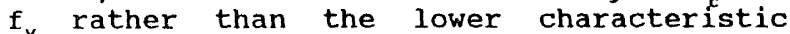
values, and assuming a strength reduction factor of $\phi=1$.

The conservative prediction of the flexurai strength by the code approach is mainly because the transverse reinforcement provided to improve the ductility of the columns also results in an enhancement of the concrete strength due to confinement. In addition, strain hardening of the longitudinal reinforcement causes strength enhancement.

The measured flexural strength enhancement shown in Fig.A.2.3 is strongly dependent on the axial load ratio. This follows because a high axial load means a large neutral axis depth, which in turn means that the flexural strength of the column is more dependent on the contribution of the concrete compressive stress distribution. The columns tested had amounts of confining reinforcement which were close to the New Zealand code recommended quantities, which increase with the level of axial load. Hence for a high axial load the effect of the increase of the strength of the concrete due to confinement is greater.

Economies would result from design based on the real flexural strength of confined columns, since a reduction in the quantity of longitudinal reinforcement necessary in columns would result.

Also, an accurate estimate of the probable overstrength in flexure of columns is necessary in order to calculate the maximum shear force acting on the columns, and the maximum moments imposed by the column on the adjoining structural members, when plastic hinges develop in the columns. To calculate the column overstrength in flexure, the effect of the actual yield strength of the reinforcing steel and the compressive strength of the concrete being generally greater than the lower characteristic values of $f_{y}$ and $f^{\prime}$ needs to be taken into account. This would mean multiplying the mean observed $M_{\max }$ values found from Fig.A.2.3 by about 1.15 .

It could also be noted that the enhanced flexural strength of confined sections of columns means that flexural failure could occur in less heavily confined regions away from the section of maximum bending moment. Hence the concrete design code requires columns which carry relatively large axial compressive loads to have a longer confined length than columns which carry relatively light axial compressive loads. 


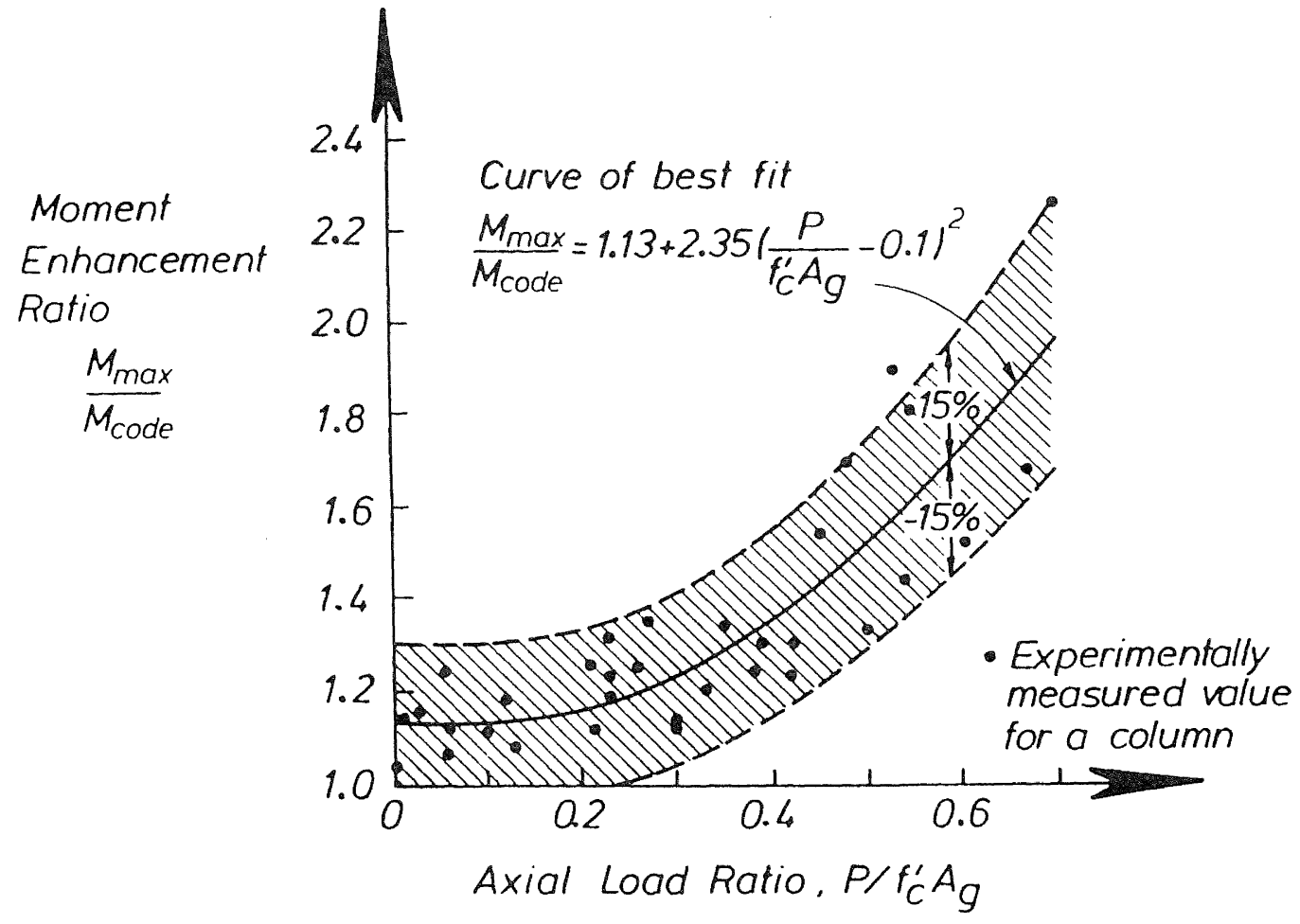

FIG.A.2.3 MAXIMUM MEABURED MORENTS FOR CONFINED REINFORCED CONCRETE COLUMNG RELATED TO FLEXURAL STRENGTH PREDICTED BY CODE APPROACH [2.11]

\section{APPENDIX 2.4}

REFINED DEBIGN PROCEDURE FOR BRIDGE COLUMNS INVOLVING CHARTS FOR FLEXURAL BTRENGTE AND DUCTILITY

\section{(a) REBULTS OF ANALY8ES}

Previous research conducted at the University of Canterbury has resulted in new design charts, derived by zahn et al [2.14], to relate the available curvature ductility factor of reinforced concrete bridge column sections to the magnitude of the confining stress applied by transverse spiral and hoop steel and to determine the flexural strength of those confined sections. The design charts were derived from theoretical studies of the cyclic moment-curvature behaviour of reinforced concrete column sections, using a computer analysis program that includes the cyclic stress-strain relationships for confined and unconfined concrete and the longitudinal reinforcing steel and takes into account the accumulation of strain energy in the transverse confining steel. The cyclic stress-strain relationships used for confined concrete, due to Mander et al [2.13], included the effect of the quantity and arrangement of the transverse confining reinforcement.

In the analysis, the yield curvature $\phi_{y}$ is obtained by extrapolating the secant elastic stiffness up to the ideal flexural strength. The ultimate curvature $\phi_{u}$ is obtained by imposing four identical cycles of bending moment to peak curvatures of equal magnitude in each direction. The available ultimate curvature is considered to have been reached when one of the following limit conditions is reached :

(i) The peak moment resisted in the last cycle has reduced to $0.8 M_{i}$, where $M_{i}$ is the ideal flexural strength of the section.

(ii) The strain energy accumulated in the confining reinforcement at the end of four cycles has become equal to its strain energy capacity and that steel fractures.

(iii) The tensile strain in the longitudinal reinforcing steel has reached that at the ultimate tensile strength.

(iv) The compression strain in the longitudinal reinforcing steel has reached that when significant inelastic buckling occurs.

The first of these limit conditions to be reached defines the available ultimate curvature $\phi_{y^{\circ}}$ Generally either limit condition (i) or (ii) was found to govern. These two limit conditions, (i) and (ii), are illustrated in Figs. A.2.4 and A.2.5. 


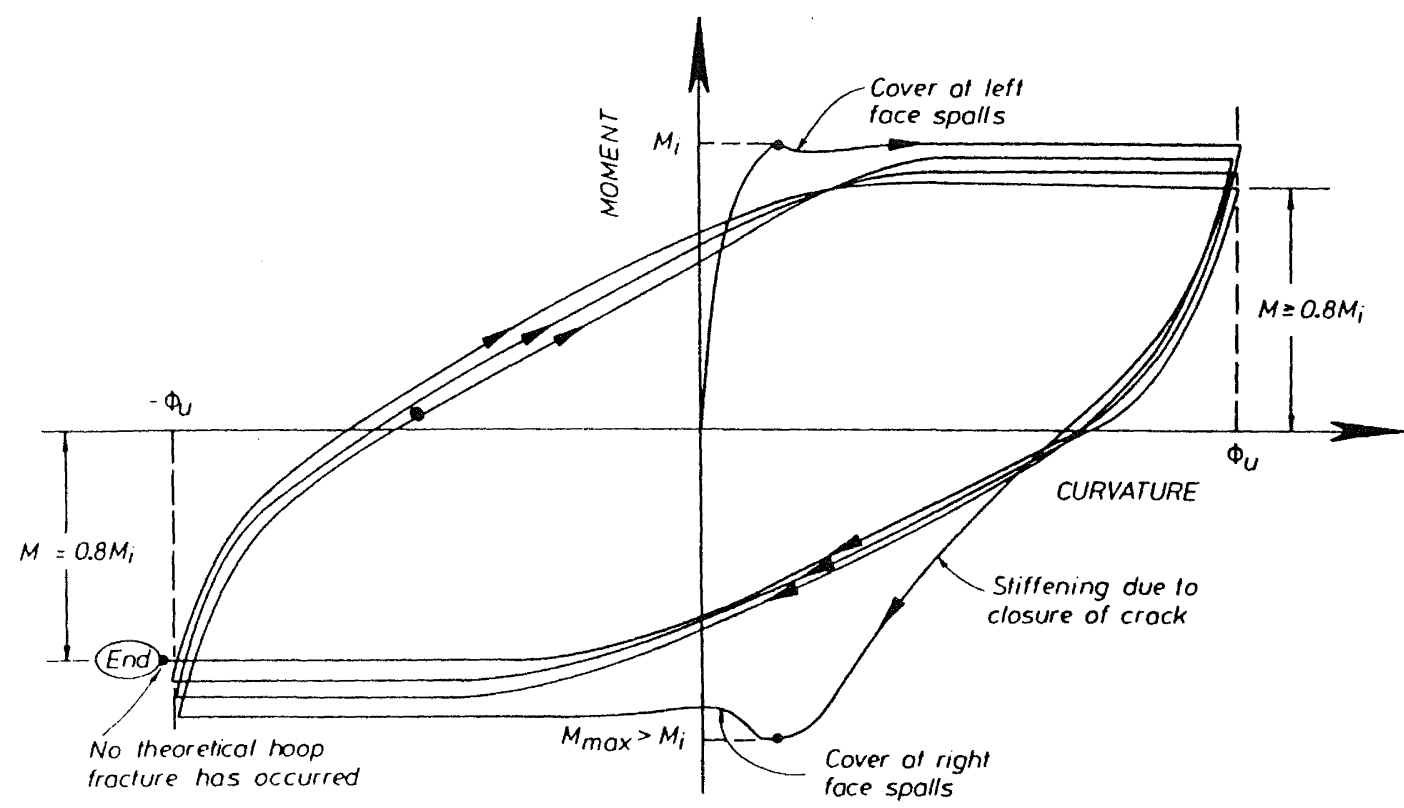

FIG. A.2.4 THEORETICAL MOMENT-CURVATURE RELATIONS FOR A REINFORCED CONCRETE COLUMN BECTION ILLUSTRATING THE CASE WHERE MOMENT DETERIORATION GOVERNB THE AVAILABLE ULTIMATE CURVATURE $[2.14]$.

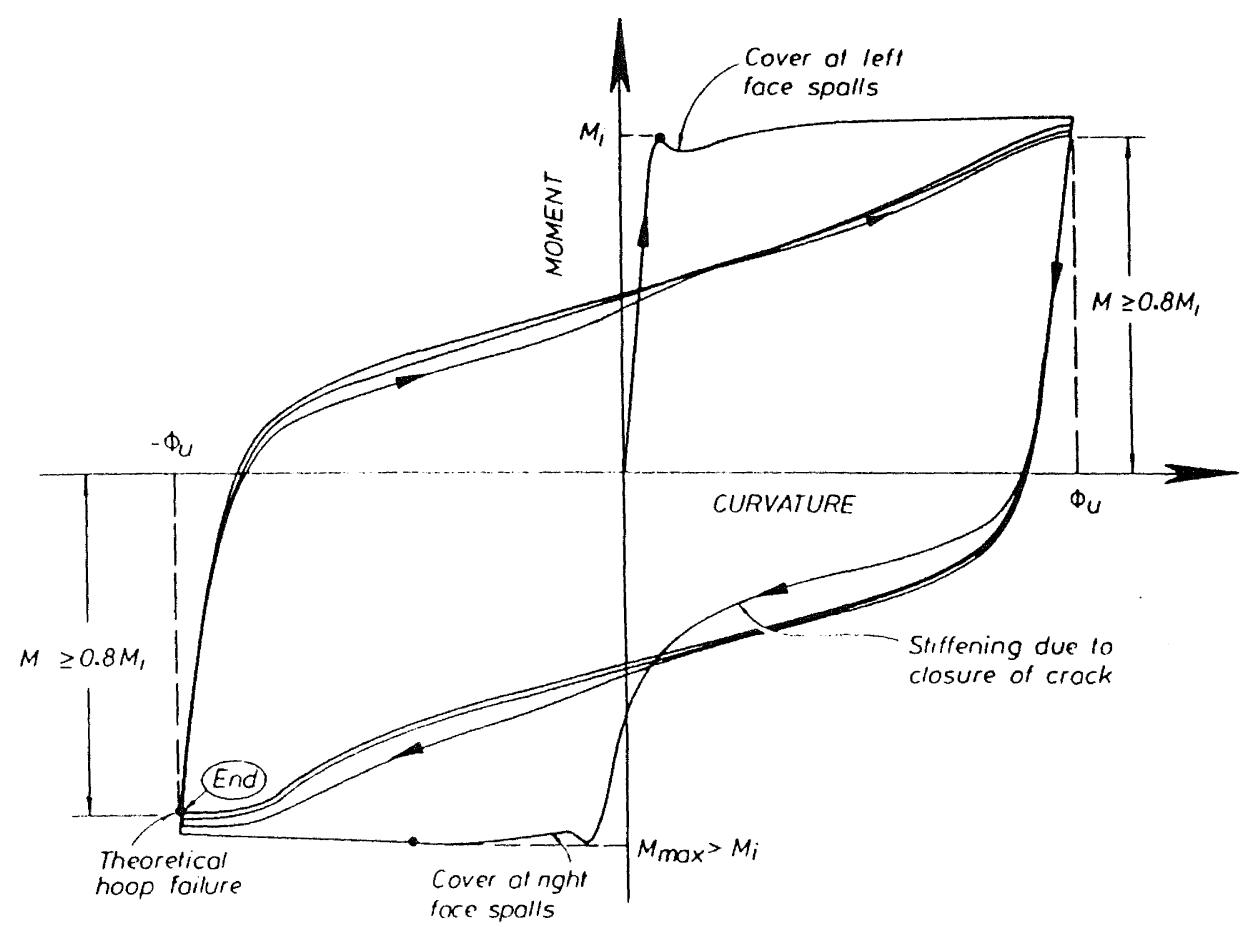

FIG.A.2.5 THEORETICAL MOMENT-CURVATURE RELATIONS FOR A REINFORCED CONCRETE COLUMN BECTION ILLUSTRATING THE CASE MHERE HOOP FRACTURE GOVERNB THE AVAILABLE ULTIMATE CURVATURE [2.14] 


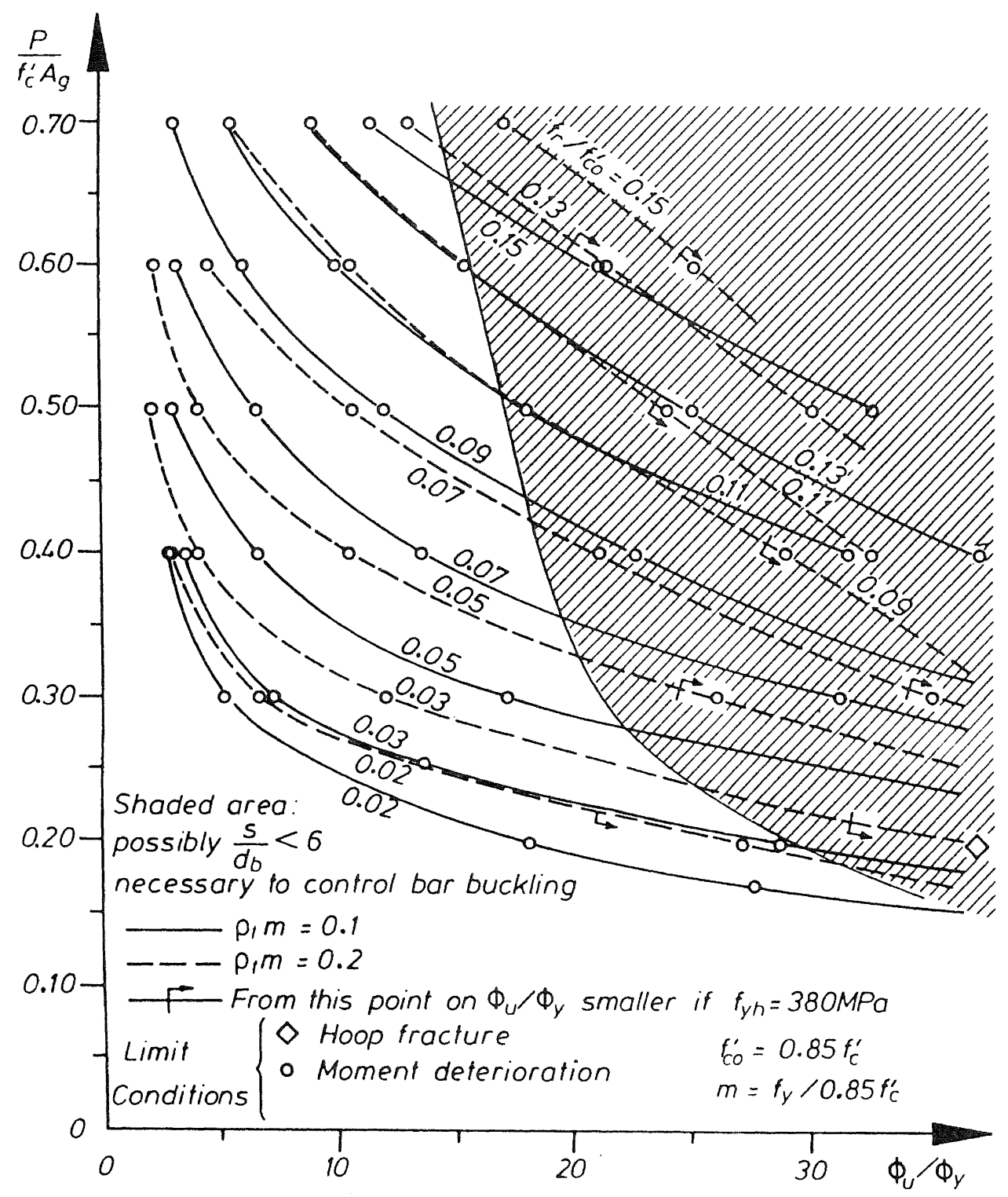

FIG.A.2.6 TYPICAL DESIGN CHART FOR CURVATURE DUCTILITY FACTOR FOR A CIRCULAR REINFORCEMENT CONCRETE COLUMN [2.14]

An example of a design chart derived for the available curvature ductility factor $\phi_{u} / \phi_{y}$ of a circular column is shown in Fig.A.2.6. The chart plots axial load ratio $P / f A$ against curvature ductility factor $\phi_{u} / \phi_{y}$ for various ratios of effective lateral confining stress to concrete compressive strength $f_{r} / f^{\prime}$ and for various $\rho_{t} \mathrm{~m}$ values where $\rho_{p}$ is the longitudinal steel ratio and $m=\mathrm{f}_{\mathrm{y}} / 0.85 \mathrm{f}_{\mathrm{c}}^{\prime}$. The effective lateral confining stress is dependent on the spacing, area and yield strength of the spiral bars. A range of charts for circular and rectangular columns have been derived [2.14].

Design charts were also derived to determine the flexural strength of column sections including the influence of the increase in the concrete compressive strength and ductility due to confinement. An example of a typical design chart for the flexural strength enhancement of a circular column is shown in Fig.A.2.7. The chart plots $M_{i} / M_{\text {code }}$ against $P / f_{c}^{\prime} A_{g}$ for various values of $f_{r} / f_{c o}^{\prime}$ [2.14].

The theoretical moment-curvature analyses and resulting design charts showed that :

(i) The quantity of transverse confining steel requirement to meet a curvature ductility factor demand in the order of 15 to 20 is less than that calculated using the New Zealand code equations for axial compression load levels $P / f_{c}^{\prime} A g$ $\langle 0.35$, but may be greater for $P / f A\rangle$ 0.35 , where $\mathrm{P}=$ axial compression load, $\mathrm{f}^{\prime}=$ concrete compressive cylinder strength and $A=$ gross area of the column. Fig. A.2.8 shows comparisons of quantities of transverse spiral reinforcement for a circular column required for a curvature ductility factor $\phi_{u} / \phi_{y}$ of 16 compared with quantities specified by New Zealand and North American codes. 


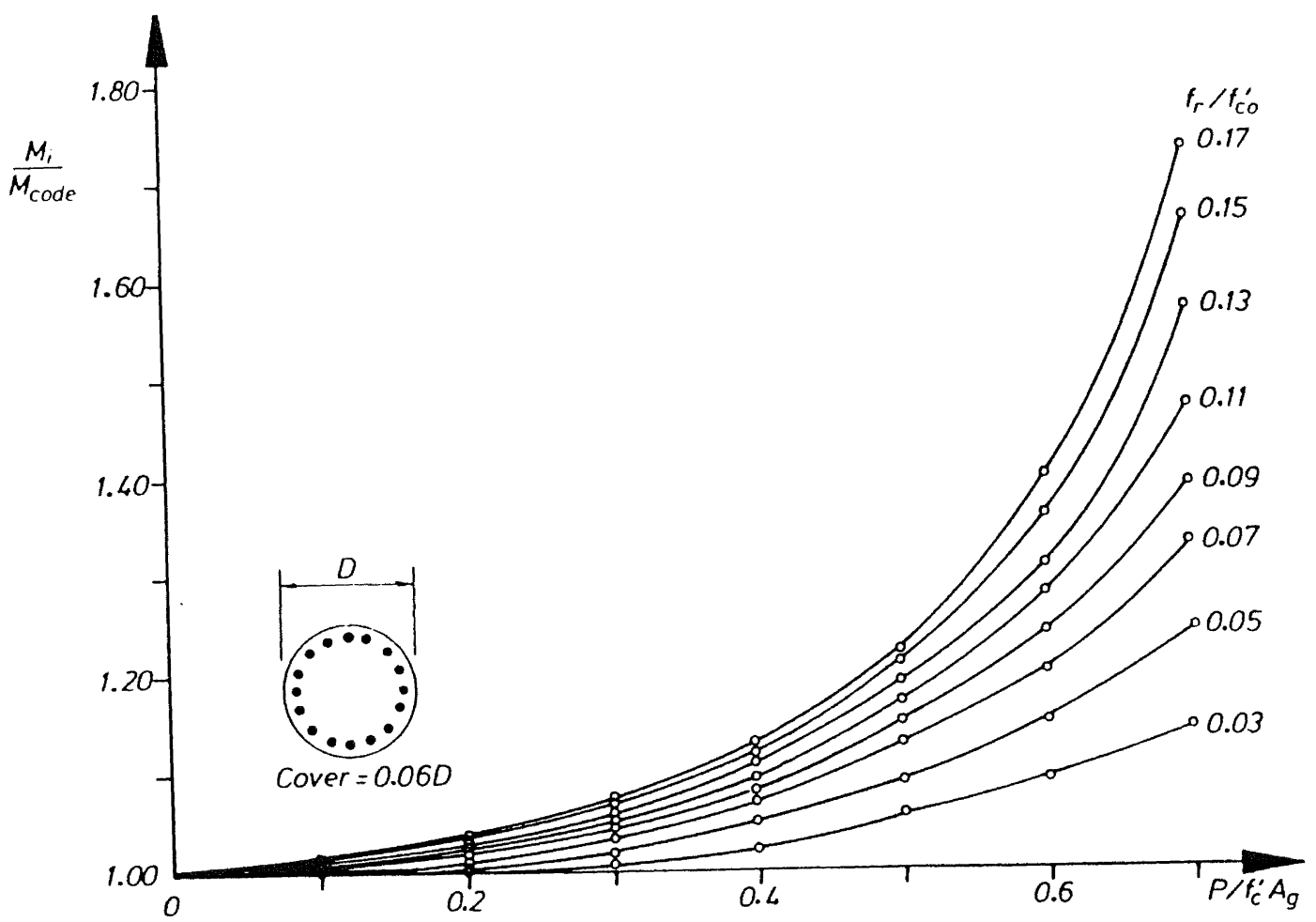

FIG. A.2.7 TYPICAL DEBIGN CHART FOR FLEXURAL BTRENGTH ENHANCEMENT FACTOR DUE TO CONCRETE CONFINEMENT FOR A CIRCULAR REINFORCED CONCRETE COLOMN BECTION [2.14]

(ii) The quantity of transverse confining steel required to meet any particular curvature ductility factor demand increases with decrease in flexural steel content and with increase in relative cover thickness.

(iii) Due to confinement of concrete, there is a substantial increase in the flexural strength of columns above that calculated using the code approach when the axial compression load level $\mathrm{P} / \mathrm{f}_{\mathrm{c}}^{\prime} \mathrm{A}_{\mathrm{g}}$ is greater than about 0.3 . For smaller compression loads this increase is small for typical amounts of confining steel (see Fig.A.2.7).

(iv) The design charts derived for reinforced concrete bridge columns are part of a comprehensive seismic design procedure which enables the determination of the quantities of longitudinal and transverse reinforcement required for adequate strength and ductility, as described below.

(b) PROCEDURE FOR DEBIGNING REINFORCED CONCRETE COLUMNB OF BRIDGE BUBSTRUCTURES FOR FLEXURAL BTRENGTH AND DUCTILITY

Zahn et al [2.14] have suggested the following step by step design procedure for reinforced concrete columns of bridge substructures using the design charts :
1. Choose a design displacement ductility factor, $\mu$, and member sizes for the substructure.

2. Use an appropriate inelastic design spectrum for the design earthquake loading, corresponding to the chosen $\mu$ value, to determine the horizontal seismic design base shear force $\mathrm{H}$ for the estimated period of vibration of the substructure.

3. Decide on the required locations of the plastic hinges in the substructure. Then using an appropriate method of analysis, calculate the plastic hinge moments $M$ necessary to resist the horizontal design load $\mathrm{H}$.

4. Choose the lower characteristic concrete compressive strength $f_{c}^{\prime}$ and the lower characteristic yield strength of the longitudinal steel $f_{y}$. Then calculate the required area of longitudinal steel in the column section so that $\phi M_{i}=M_{p}$, where $\phi$ is the strength reduction factor and $M_{i}$ is the ideal flexural strength of the column section. A value of $\phi=0.9$ is used. When calculating $M_{j}$ the flexural strength enhancement due to the confinement of the compressed concrete by the transverse reinforcement should be included. Design charts can be used to determine the flexural strength enhancement factor. Fig.A.2.7 shows typical chart. With the calculated area of longitudinal reinforcement, and the $f$ and $f_{y}$ chosen, go back to step 2 and 


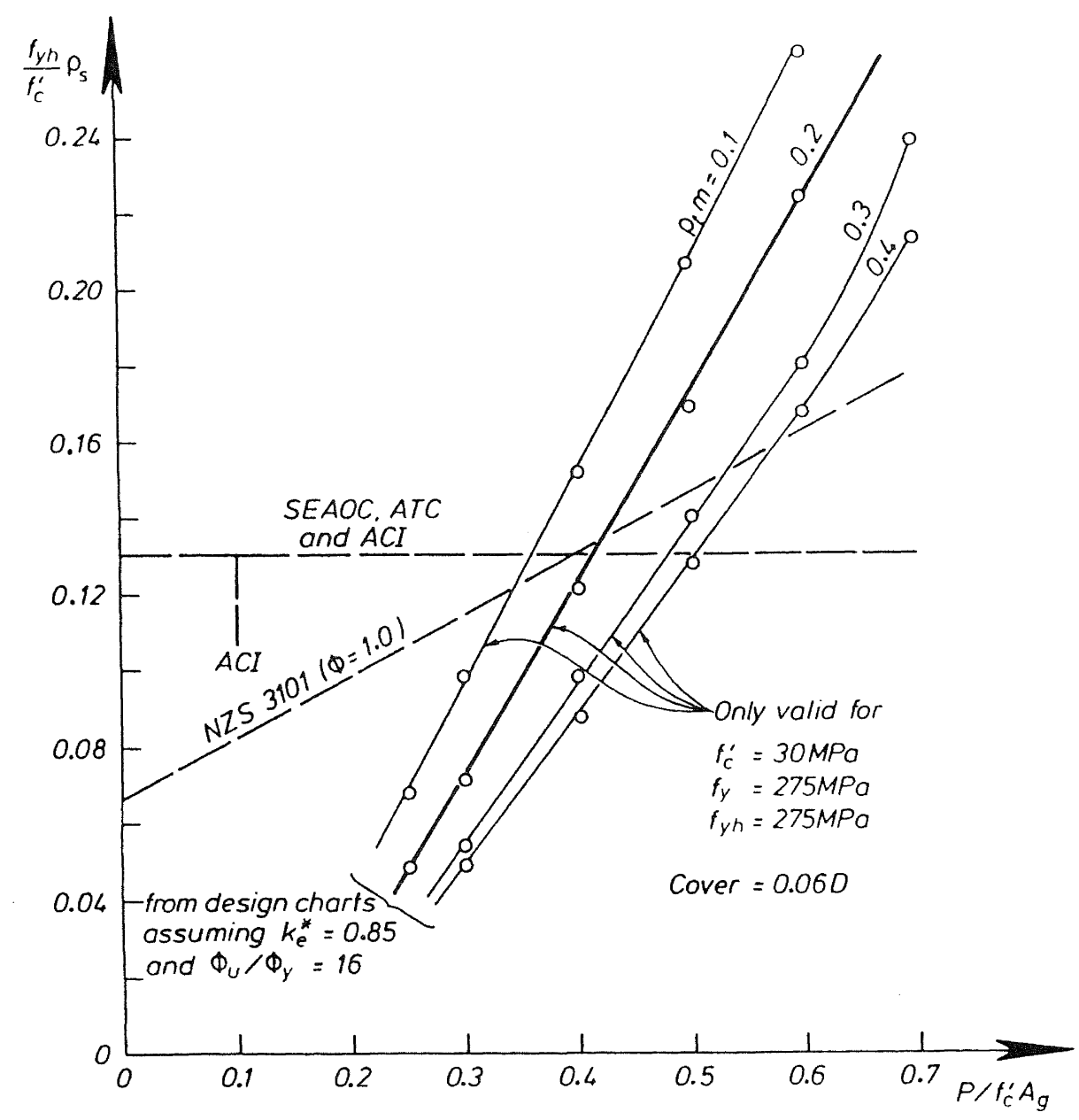

FIG.A.2.8 REQUIRED AMOUNTS OF TRANBVEREE SPIRAL REINFORCEMENT FOR DUCTILITY IN PLABTIC HINGE REGIONB OF TYPICAL CIRCULAR COLUMNB AS OBTAINED FROM MOMENT-CURVATURE ANALYSIS AND AS BPECIFIED BY THE NEW ZEALAND CODE AND NORTH AMERICAN CODES [2.14]

recalculate the effective flexural stiffness and then the period of vibration. check whether the new corresponding lateral force $\mathrm{H}$ can still be resisted. If necessary repeat steps 2 to 4 until a satisfactory solution is found.

5. For the chosen displacement ductility factor $\mu$ calculate the required curvature ductility factor $\phi_{\max } / \phi_{y}$ of the plastic hinges, where $\phi_{y}=$ curvature at first yield and $\phi_{\max }=$ maximum required curvature. In this calculation a value for the equivalent plastic hinge length $\mathrm{L}_{\mathrm{p}}$ must be assumed. For example for a cantilever column, let $\mathrm{C}=$ ratio of the total horizontal deflection due to the flexibility of the foundation (translation and rotation) and of the elastomeric bearings (between the columns and the superstructure) to the horizontal deflection due to column flexibility, and $L=$ vertical distance from the top of the foundation to the centre of mass of the bridge superstructure. Then for the cantilever column the required curvature ductility factor is given as (see section 1.6.2)

$$
\frac{\phi_{\max }}{\phi_{y}}-1+\frac{C(\mu-1)}{3 \frac{L_{p}}{L}\left(1-0.5 \frac{L_{p}}{L}\right)}
$$

Note that in some cases where $c>1$ the required curvature ductility factor may be too large to be achievable with a reasonable amount of confining steel. It is then necessary to accept a reduced ductility level and hence to redesign the structure for a higher base shear force. In that case it is necessary to return to step 1 .

6. Once the required curvature ductility factor $\phi_{\max } / \phi_{y}$ has been found, the level of confinement necessary from the transverse reinforcement to provide for that ductility factor can be determined as follows

$$
\frac{\phi_{\max }}{\phi_{y}} \leq \frac{\phi_{u}}{\phi_{y}}
$$

where $\phi_{u} / \phi_{y}$ is the available curvature 
design ductility factor, found from design charts derived to include the axial load ration $\mathrm{P} / \mathrm{f}_{\mathrm{c}}^{\prime} \mathrm{A}_{\mathrm{g}}$, the confining stress ratio $f_{r} / f_{c}^{\prime}$ where $f_{r}=$ effective confining stress from the transverse reinforcement, the longitudinal steel ratio $\rho_{t}$, the concrete compressive strength ' $f$ ', the yield strengths of the longitudinál and transverse reinforcement $f_{y}$ and $f_{y h !}$ and the ratio of concrete cover thickness to column depth. Fig.A.2.6 shows a typical design chart. To find the level of confinement necessary, determine the required $f_{r} / f$ for the needed $\phi_{y} / \phi_{y}$ and level of axial load $P / f_{c}^{\prime} A_{g}$. For multi-column bridge piers the equation for $\phi / \phi_{y}$ given in step 5 needs to be modified. If the resulting $f / f_{c}^{\prime}$ is considered to be uneconomically high, it is necessary to go back to step 1 , and to design for a lower level of ductility.

7. With the $f_{r} / f_{c}^{\prime}$ value obtained in step 6 , go back to Step 4 and check whether $\phi M_{j}=$ $M_{p}$. If not, determine a new estimate for $\rho_{t}$ (provided that $M_{p}$ is governed by the seismic load case), in the same manner as described in step 4. Recheck the period of vibration and confirm that $H$ can be resisted by the structure when $M_{R}$ has developed in the plastic hinge regions. with the new $\rho_{\text {t }}$ repeat steps 5 to 7 until $\phi M_{j}=M_{p}$ and $\phi_{\max } / \phi_{y} \leq \phi_{y} / \phi_{y}$ are both satisfied.

8. Once the final value of $f_{r} / f_{c}^{\prime}$ has been found, decide on the arrangement of the longitudinal and transverse reinforcement. Having chosen the diameter of the longitudinal bars, determine the spiral or hoop spacing $s$ or $s_{b}$ from the ratio $s / d_{b}$ or $s_{h} / d_{b}$. Then the area of the transverse reinforcement may be determined from the effective confining stress $f_{r}$, for a chosen arrangement of transverse reinforcement and yield strength of the transverse steel.

9. Design the shear reinforcement for the column and all elements resisting the plastic hinge moments, assuming that the plastic hinges have developed their overstrength moment, $M_{0}$, where $M_{0}$ may be taken as $\mathbf{M}_{i}$.

\section{(c) REFINED DEBIGN EOUATIONB FOR THE QUANTITIEB OF TRANBVERBE REINFORCEMENT REQUIRED FOR FLEXURAL DUCTILITY}

Watson and Park [2.15] have used the design charts for ductility derived by Zahn et al [2.13] to obtain refined design equations for the quantities of transverse confining reinforcement required in the potential plastic hinge regions of concrete columns. Typical ranges of the axial load ratio $P / f^{\prime} A$, the concrete compressive strength $f_{c}^{\prime}$ ' the mechanical reinforcing ration $\rho_{t} m$, and the cover ration $\mathrm{c} / \mathrm{h}$ for square and rectangular columns or $c / D$ for circular columns, were considered. The $95 \%$ upper-tail values of of $/ f^{\prime}$ obtained from the design charts and a regression analysis were used to obtain the best-fit equations by the least squares method. The derived equations were as follows

For square or rectangular sections :

$\frac{A_{s h}}{S_{h} h_{c}}\left\{\frac{A_{g}}{A_{c}} \frac{\left\{\left(\phi_{u} / \phi_{y}\right)-33 \rho_{t} m+22\right\}}{111} \frac{f_{c}^{\prime}}{f_{r h}} \frac{P}{\phi f_{c}^{\prime} A_{g}}\right\}-0.006$

For circular sections:

$\rho_{s}=\left\{1.4 \frac{A_{g}}{A_{c}} \frac{\left\{\left(\phi_{u} / \phi_{y}\right)-33 \rho_{t} m+22\right\}}{111} \frac{f_{c}^{\prime}}{f_{y h}} \frac{p}{\phi f_{c}^{\prime} A_{g}}\right\}-0.008$

where $A_{\text {sh }}=$ area of transverse bars in direction under consideration within centre to centre spacing of hoop sets $s_{h}, h_{c}=$ dimension of core of column at right angles to direction of transverse bars under consideration, $A_{0}=$ gross area of column, $A_{c}$ $=$ core area of column, $\phi_{u} / \phi_{y}=$ curvature ductility factor, $\rho_{\mathrm{t}}=\mathrm{A}_{\mathrm{st}} / \mathrm{A}_{\mathrm{g}}, \mathrm{A}_{\mathrm{st}}=$ total area of longitudinal column reinforcement, $m=$ $f_{y} / 0.85 f_{c}^{\prime}, f_{y}=y$ ield strength of longitudinal steel, $f_{y h}=$ yield strength of transverse steel, $f=$ concrete compressive cylinder strength, $\mathbf{P}=$ axial compressive load on column, $\phi=$ strength reduction factor and $\rho_{\mathrm{s}}$ = ratio of volume of transverse circular hoop or spiral steel to volume of concrete core of column.

The refined design equations give only the transverse reinforcement required for concrete confinement. The transverse reinforcement provided must also be checked to ensure that the tie requirements for preventing premature buckling of longitudinal compression bars, and the requirements for shear reinforcement, are satisfied. 


\title{
SECTION 3 EXAMPLES OF APPLICATION
}

\author{
(Principal Author: LG Cormack)
}

\subsection{DESIGN PHILOSOPHY}

The design philosophy of the examples of application presented, has been to provide high levels of flexibility and ductility, as in this manner it is considered that cost effective design is generally best achieved. This is because $\mathrm{NZ}$ experience is that flexible ductile structures often require little extra strength to resist seismic loads than is required to resist traffic loads. This approach does however call for greater attention to important matters of detail. In particular:

- making sure there is adequate ductility with all joints being well detailed and constructed;

- performing a "capacity design" to make sure that when earthquake shaking develops the full strength of the structure the plastic hinges form at predicted locations. The full strength needs to be calculated by allowing for possible overstrength of materials. strain hardening of the steel, and for the enhancement of bending strength caused by lateral confinement provided by the steel ties.

These factors may combine to give substantial increases in loads, which must be allowed for when assessing probable member strengths, column buckling and bar cut off points;

- providing adequate clearance and/or ties at all connections including abutments so that the earthquake induced displacements can be accommodated without loss of support to structural elements or unexpected damage.

With this approach however, it would be considered good practice to adopt design concepts that have significant redundancy (ie portal frame systems rather than cantilever columns) with a minimum of joints so that instability effects are minimised and the maximum number of potential plastic hinges are incorporated.

The basic philosophy is that the zones where plastic hinging and therefore damage is expected to occur in a major shaking must be determined at the outset, and reinforced to provide the required ductility. This involves not only an adequate amount of lateral steel, but also care with:

- spacing of ties so that main bars do not buckle;

- spacing of main bars so that the concrete core is well confined.

Detailed design rules [3.1] have been developed from extensive testing so there is confidence in this aspect of design. In addition, it is not uncommon to provide an inner helically reinforced core over the part of those columns that are designed to develop plastic hinges. This spiral core is designed to carry, at a low factor of safety, the dead load of the bridge so that should major damage occur then repair can be effected to the main column reinforcing without fear of collapse.

In multistorey buildings it is normally bad practice to design for plastic hinging in columns except near the foundations. This approach is rarely possible with bridges because of the strength and importance of the bridge deck structure. provided the columns are well detailed and constructed as summarised above, the "column sway" mechanisms that building engineers try hard to avoid can be safely accommodated.

\subsection{PARAMETERS UPON WHICH THE DESIGN EXAMPLES ARE BASED}

The following design parameters and standards have been adopted for each of the design examples.

\subsubsection{Design standards}

Design has been performed in accordance with the NZ Concrete Design Code $[3.1]$. This code has been developed from the approach outlined in the well known American Concrete Institute (ACI) codes.

\subsubsection{Concrete strength}

Concrete strength for the columns in the worked examples has been taken as $30 \mathrm{MPa}$ (measured on standard cylinders at 28 days). This strength is considered to be economically achievable on all bridge sites throughout New Zealand.

\subsubsection{Reinforcing steel}

Longitudinal steel in columns is deformed with a minimum characteristic strength of $430 \mathrm{MPa}$.

This grade of steel is selected as it is able to be rebent in case of construction damage and because its upper yield strength and increase in strength under the effects of strain hardening are controlled and are comparatively small. When checking the structure to confirm its reliability when yielding develops, the overstrength factor for this steel is taken as 1.25 .

Lateral or binding steel is plain (undeformed) bars of $300 \mathrm{MPa}$ design strength. 


\subsubsection{Foundation concept}

The approach adopted in the design examples is to provide a single large diameter pile under the pier. The diameter of the pile and the amount of reinforcing within it, is such that, with the soil conditions quoted, the plastic hinging can be expected to take place in the pier just above ground level and not in the pile. In consequence, there should be good access to the pier hinge zone after a shaking so that repairs can be relatively easily effected. In this case the maximum design displacement ductility figure and the correspondingly minimum design load permitted in the Bridge Manual [3.2] may be adopted.

\subsubsection{Importance Category}

Three different importance categories are listed in the Bridge Manual [3.2]. Because the bridge is designed as a 3 lane freeway it will certainly carry more than 2,500 vehicles per day, which places it in the top category of importance.

\subsection{6 soil conditions}

The soil conditions quoted would come in the category of "normal soil". (Note that the Bridge Manual [3.2] requires higher design loads for "soft soils" than for "normal soils" except for very rigid structures).

\subsubsection{Design Loads and strength Calculations}

The assessment of minimum horizontal seismic base shear force has been performed in accordance with the Bridge Manual [3.2]. Note that this method (refer clause $5.2 .1(a))$ requires the minimum seismic shear force to be no less than $0.05 \mathrm{~W}$ where $\mathrm{W}$ is the total dead weight. This limit of $0.05 \mathrm{~W}$ will control design for all longer pexiod ductile structures irrespective of seismic zone or importance, i.e. it will apply for a maximum ground acceleration of $0.25 \mathrm{~g}$ as well as $0.40 \mathrm{~g}$.

This lower bound limit is somewhat arbitrary and worthy of discussion.

Research has shown [3.3] that confinement of columns will enhance flexural strength, therefore this enhancement has been allowed for when assessing the pier reinforcement.

The flexibilities of the bridge examples considered are sufficiently large that the second order bending moments caused by pier axial load and the displacement of the piers (the so called P-delta effect) is significant.

There are no agreed rules in the $\mathrm{NZ}$ code for this quite complex dynamic situation and the preferred analytical treatment is a series of non-linear time history studies using large earthquake records. These studies must include the modelling of the p-delta effect.

In the absence of time history studies the design approach recommended is to add the second order P-delta moments produced at the maximum expected displacement to the calculated first order earthquake induced moments and to design the reinforcing steel accordingly.

This approach is considered to be conservative provided at the maximum expected displacement the second order Pdelta moment is less than one half of the probable strength of the piers; so that the restoring force is greater than the opposing P-delta effect.

The bigger displacements that are likely to be produced by a very big shaking should be within the probable strength of the piers when the additional strength caused by the strain hardening of the reinforcing steel and the actual material properties are taken into account.

\subsubsection{Bummary}

In summary therefore the following specific design parameters have been adopted for all examples studied:

- concrete strength (cylinders) $30 \mathrm{MPa}$

- main steel characteristic strength $430 \mathrm{MPa}$

- tie steel characteristic strength $300 \mathrm{MPa}$

Type of structure Ductile

Importance category $R$ 1.3

Soil condition

Normal Soils

\subsection{BRIDGE TYPES BELECTED}

\subsubsection{Case 1}

The first alternative was selected to have square piers (refer Fig 3.1). The top beam which will support the bridge deck has been taken as 1.2 metre deep so that, in the transverse direction, strong ground shaking will cause hinging in the piers just below this beam and just above the junction of the square columns with the 1200 diameter reinforced concrete piles.

The second alternative is a hammerhead pier (refer Fig 3.2). It has been assumed the bridge is pin jointed to the top of the hammerhead so that there will be only one hinge per pier in a strong shaking, located in the $1400 \mathrm{~mm}$ diameter pier just above its junction with its $1650 \mathrm{~mm}$ diameter reinforced concrete pile.

\subsubsection{Case 2}

The selection of bridge alternatives, even for given spans, soil conditions, and ground cross sections, is of course influenced by many factors. The most important of these are:

- stability of the slopes

- ease of access to all piers

- aesthetics

- constructor experience

- abutment concept. 


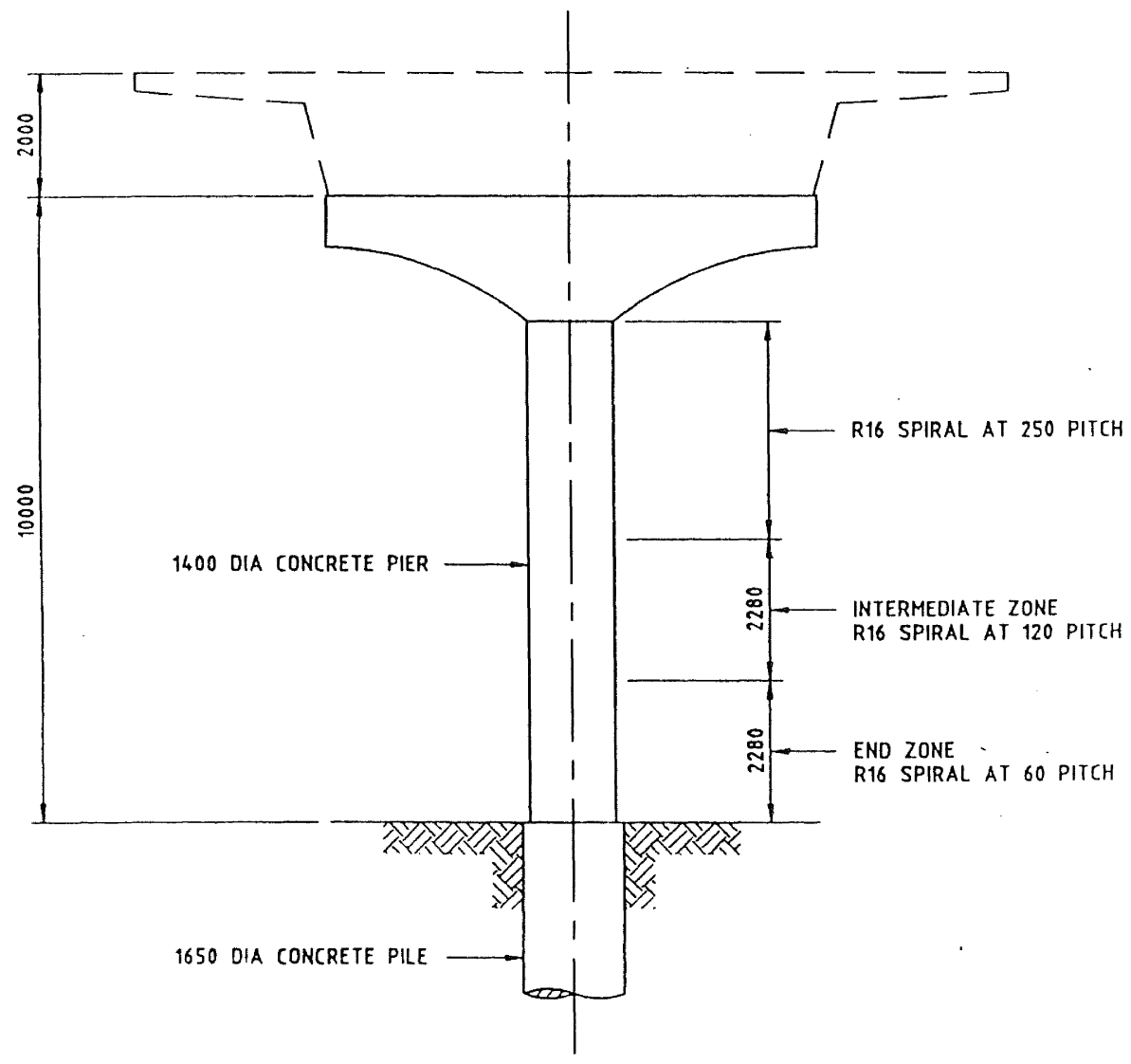

FIGURE 3.1 CABE 1 - RECTANGULAR PIERS

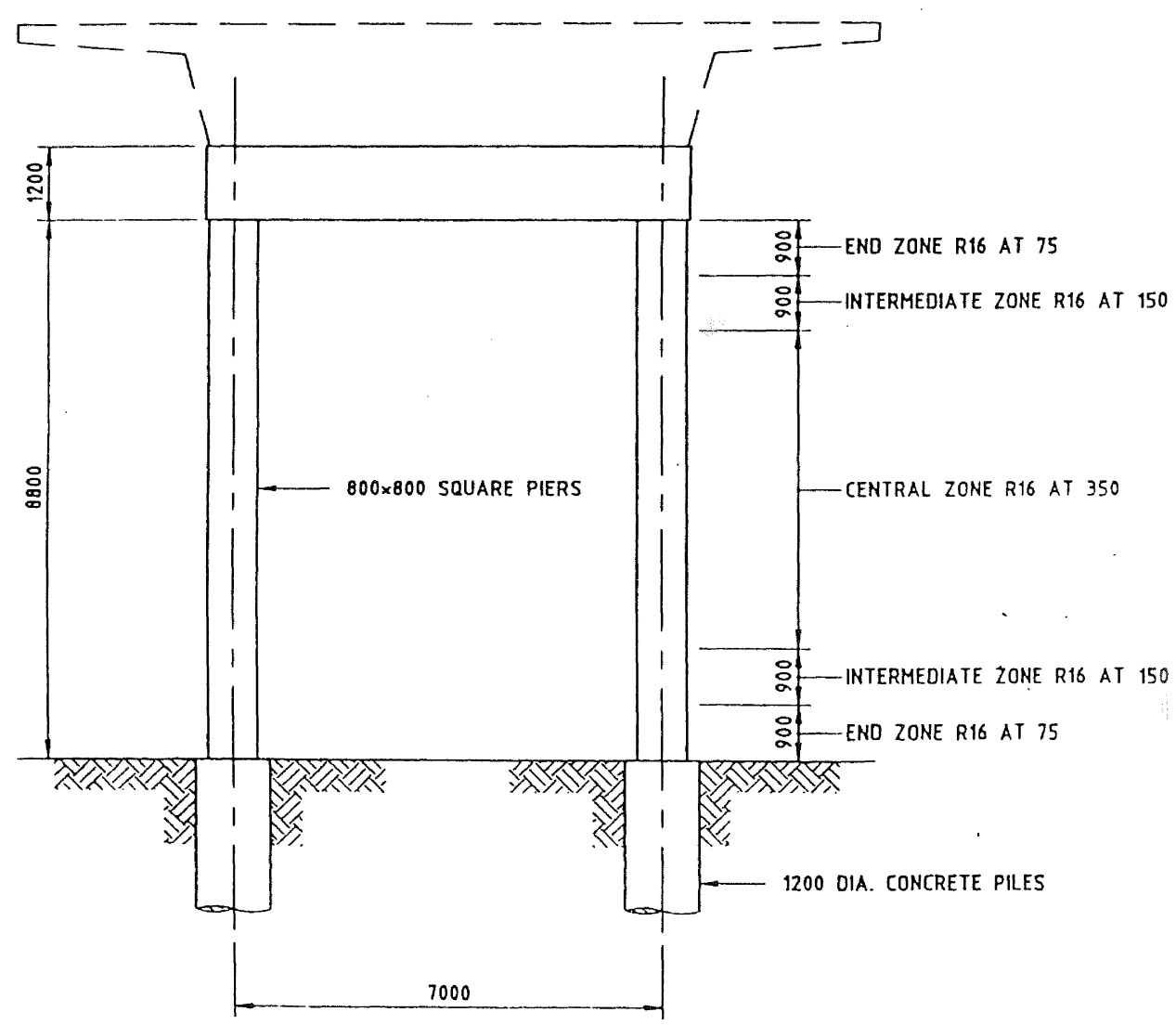

FIGURE 3.2 CA8E 1 - CIRCULAR PIERB 
Two alternatives have been selected for this study as being representative of bridge types that have been successfully used in $\mathrm{NZ}$ conditions (see Figs 3.3 to 3.5 ).

Alternative 1 is a cast in-situ prestressed concrete deck which is constructed span by span. It is built in to be continuous at all piers.

In the longitudinal direction hinging will occur in the pier tops immediately beneath the longitudinal beams and above the transverse beams and just above the piles.

In the transverse direction the hinging will occur in the pier tops immediately below the transverse beam and just above the piles.
The transverse beam has been set down by 1.5 metres from the top of the pier for two reasons. Firstly, to provide sufficient depth and support for the launching girder. and secondly to simplify the detailing of the reinforcing connecting the piers to the longitudinal beams.

Alternative 2 is a "push bridge" whereby the bridge is cast sequentially at one abutment and jacked out from pier to pier. A launching nose is provided to reduce construction stresses. Bearings are provided at the piers along with a steel shear connection which permits small movement at the pier top but effectively ensures the bridge is securely attached to the piers in the event of earthquake shaking.
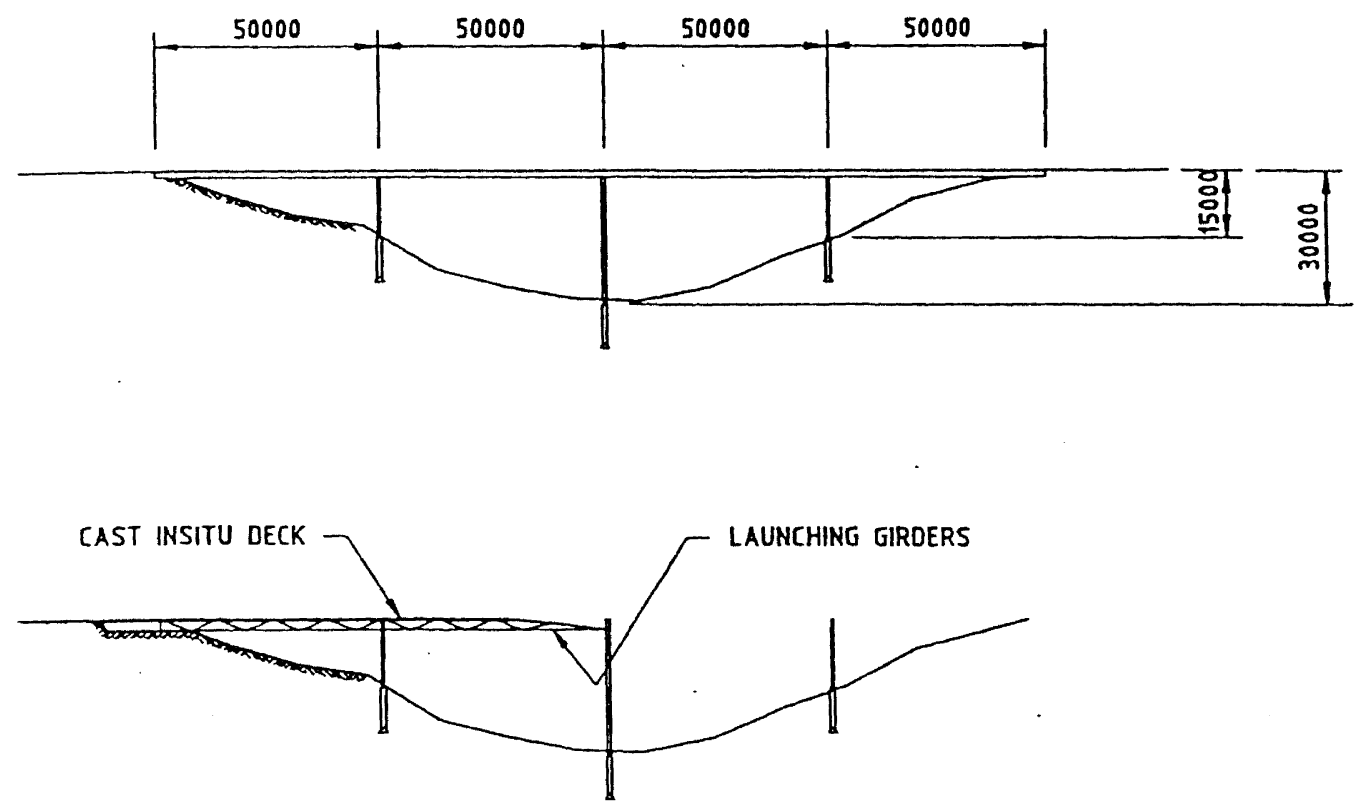

ALTERNATIVE 1

LAUNCHING GIRDER CONSTRUCTION

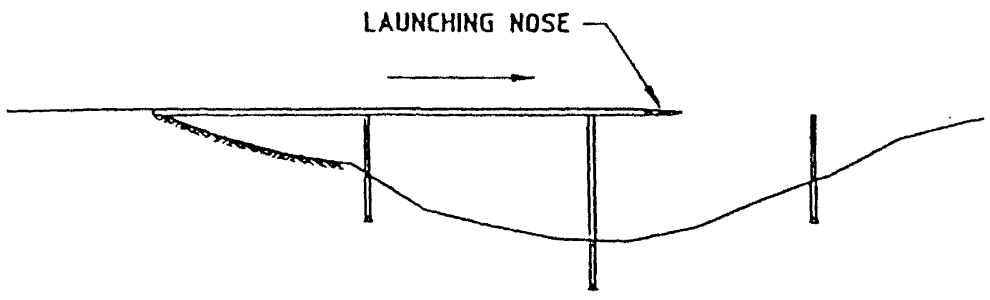

ALTERNATIVE 2

PUSH BRIDGE CONSTRUCTION

FIGURE 3.3 CABE 2 - ALTERNATIVES 


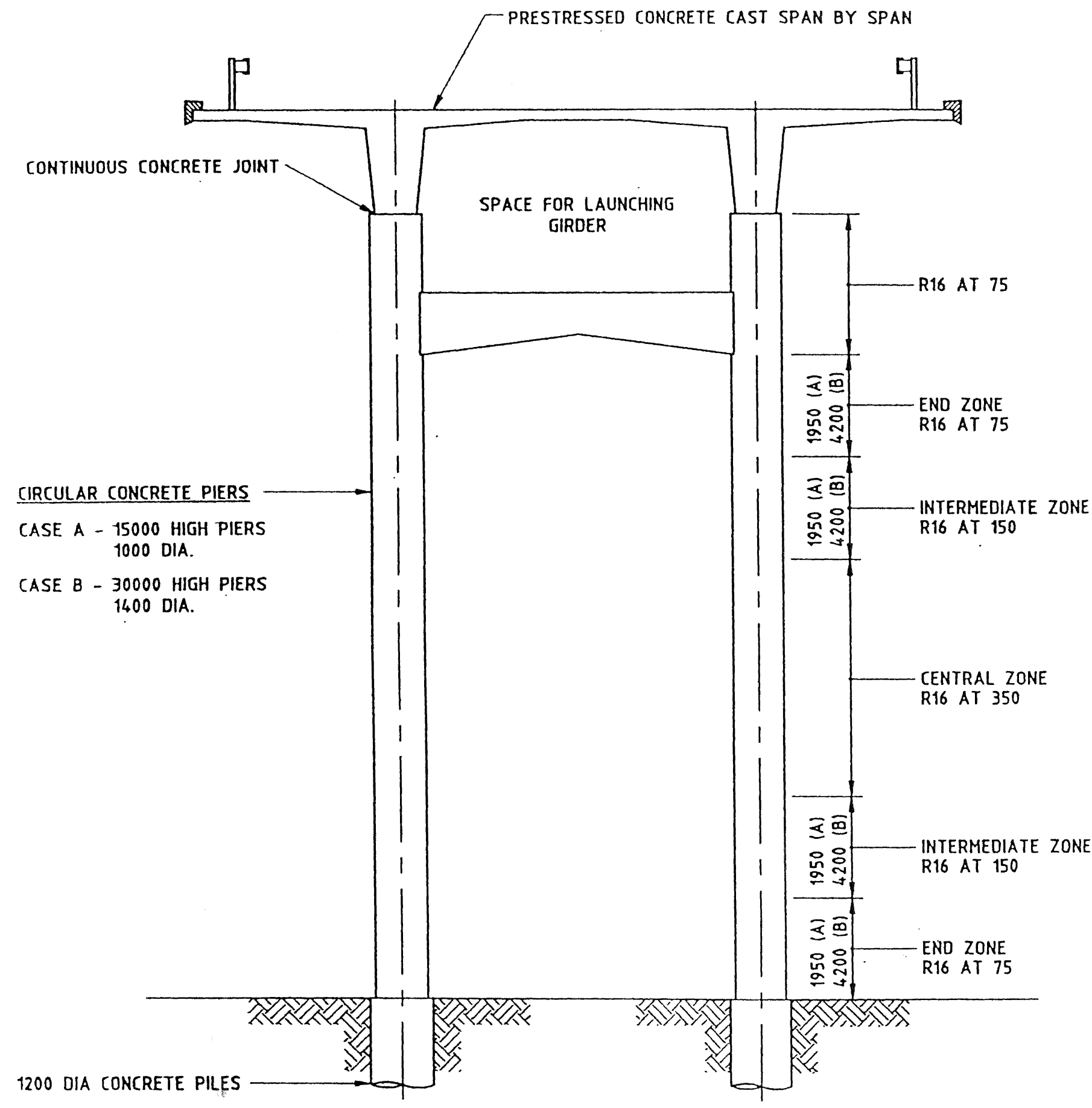

FIGURE 3.4 ALTERNATIVE 1 - DOUBLE PIERS

Note that a single bearing is provided at each abutment as opposed to two at each pier. This is so that in a major shaking the rotation of the box girder caused by the rotation of the bridge hammerhead piers, will not be restrained by the abutment. The box girder must of course be designed to accommodate this single central bearing point both for the torsion that eccentric traffic loads will produce and for the end diaphragm flexures and shears. The abutment bearing is designed to resist transverse loads.
In Alternative 2 therefore the pier is a hammerhead pier and all hinging in both the longitudinal and transverse directions will occur at the base of the $1500 \mathrm{~mm}$ pier just above the junction with the $1750 \mathrm{~mm}$ reinforced concrete pile below.

Circular piers have been adopted for both alternatives as this permits the least volume of lateral steel and better resistance to buckling loads than rectangular piers of the same area. 


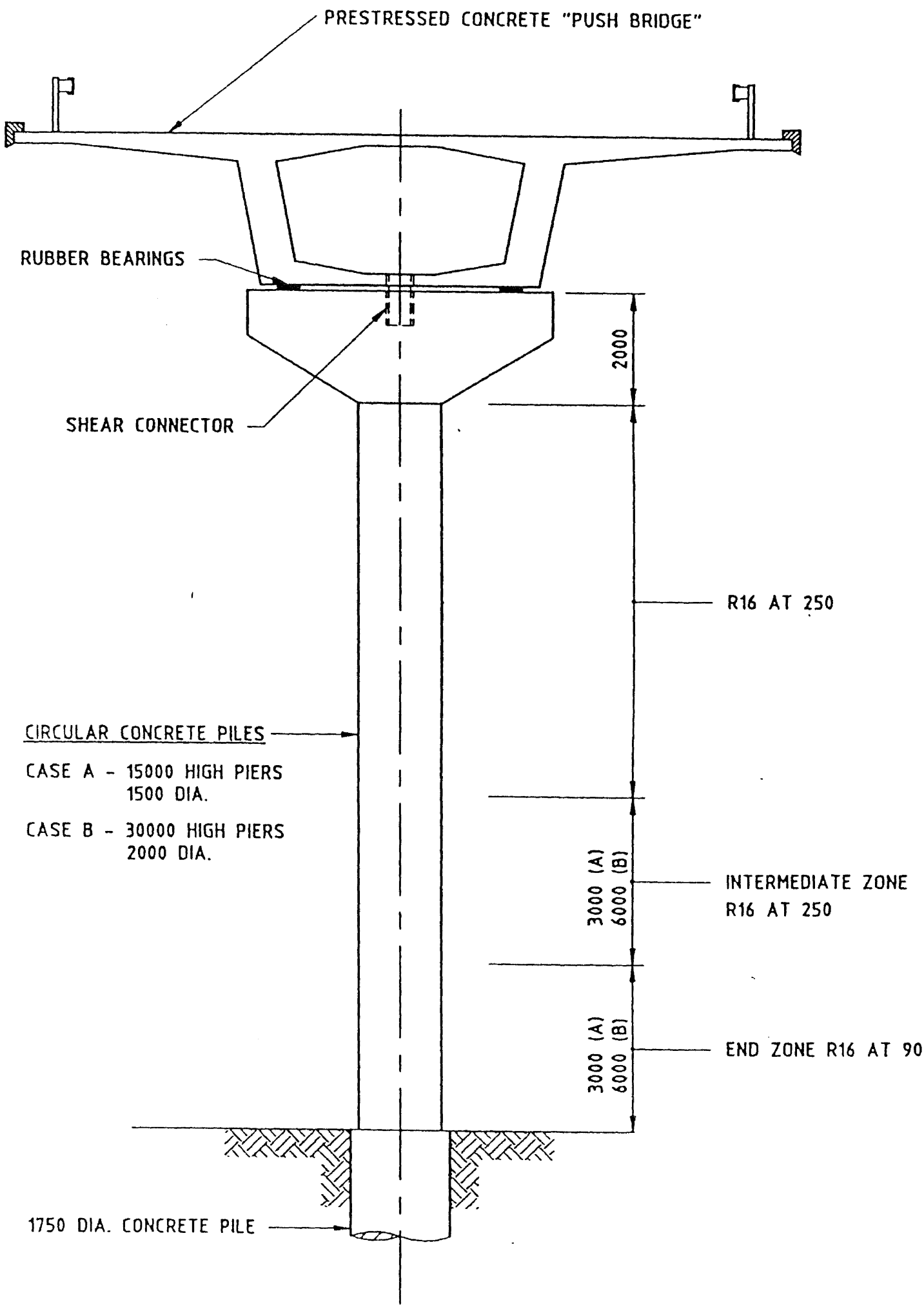

FIGURE 3.5 ALTERNATIVE 2 - SINGLE PIERB 
The abutment concept for Alternatives 1 and 2 is to seat the bridge on rubber bearings that are capable of withstanding the temperature, creep and shrinkage movements of the bridge deck plus the displacements caused by small more frequent earthquakes.

The stiffness of the bearings is such that quite considerable forces will be imparted to the abutments for which forces they must be designed. Because of the length of the bridge the displacements caused by creep and concrete shrinkage will be considerable. It will be uneconomical to design the bearings for these displacements and they will have to be compensated for, either by placing temporary bearings initially, or after some months of service jacking the end spans up off their bearings to relieve their stresses. This will mean that the displacements for which the bearings are designed are those caused by temperature, earthquake and a small fraction of the total creep and shrinkage induced movements.

The bearings would be designed to withstand small more frequent earthquakes without damage but might need replacement in the event of a major shaking.

The abutment concept for these bridges is an important matter because with rubber bearings a considerable portion of the load is transferred to them. This concept is only economic therefore if the abutments are located in competent material. Often there will be limited stability at abutment slopes, in which case this concept would not be appropriate.

The design requirements are for the abutment bearings to provide:

- longitudinal stability during erection

- resistance to traction loads

- resistance to lateral loads

- sufficient flexibility to accommodate creep, shrinkage and temperature induced movements.

Many possibilities are available and some of these are discussed in section 2. Each need consideration for the particular case understudy. For Alternatives 1 and 2 lead rubber bearings are not favoured as they are stiffer than simple rubber bearings, thereby attracting even more load to the abutments: and the increased damping potential they offer is shown by calculation not to be necessary.

A combination of sliding bearings and flexural energy dissipators would be possible but complicated and quite costly to construct.

This matter has not been analysed exhaustively, as to do so would require study of the design alternatives for the abutment. However the solution given here is considered to be realistic for the purposes of this study. Certainly it would be considered an uneconomic concept not to rely on the abutments to take a large proportion of the seismic loads provided the abutment soil conditions are favourable.

The clearance to be provided at the abutments is determined from the analysis. This should be sufficient to permit the bridge to develop its maximum expected displacement. For even greater movements than this the bridge must still be restrained so that it cannot separate from its abutments. Holding down bolts would not be employed for these bridges.

\subsection{METHODS OF ANALYSIS}

The ETABS (CSI) computer package was used to carry out a full response spectrum analysis using the acceleration response spectrum given in Reference 3.2 (Fig $5.2(\mathrm{a})$ ). For the $0.25 \mathrm{~g}$ case the response spectrum was scaled by $0.25 \div 0.40$ or 0.625 . This analysis includes the calculation of P-delta instability effects.

The piles are modelled as concrete members restrained by springs whose stiffnesses match the soil stiffnesses quoted.

The stiffness of piers, the top $5 \mathrm{~m}$ of the piles and the cross beams for Alternative 1 , case 2, were taken as $75 \%$ of the gross concrete stiffness to allow for cracking effects.

The mass of the deck structure was assumed to be in two parts, both located $500 \mathrm{~mm}$ below the top of the deck. Each part was one half of the total mass located 3.5 metres on either side of the centre line of the bridge. This was to allow for the effects of superstructure and hammerhead rotational inertia in generating additional moments in the piers.

For the case II studies a three dimensional ETABS study was carried out for the full bridge structure.

At the abutments the bridge was assumed to be supported on elastomeric bearings with no other restraint to longitudinal or transverse displacement.

Non-linear time history studies were performed for Case 2 to check its ability to resist a very big earthquake.

\section{$3.5 \quad$ RESULTS}

\subsubsection{Results for case 1}

The results are presented on Figs 3.1 and 3.2 and in Table 3.1 .

For both alternatives the period of the piers is sufficiently long that even when the ground shaking is $0.40 \mathrm{~g}$ the horizontal base shear is controlled by the quoted minimum of $5 \%$ of total dead weight. Therefore the same design horizontal base shear force applies to both cases of $0.40 \mathrm{~g}$ and $0.25 \mathrm{~g}$ ground shaking.

For the case of the single circular pier the pier design is dominated by eccentric traffic loads. Note that during the 
TABLE 3.1: CABE 1 REgULTS

\begin{tabular}{|c|c|c|}
\hline & DOUBLE PIER & SINGLE PIER \\
\hline 1. Pier Dimensions (mm) & $800 \times 800$ & 1400 \\
\hline 2. First Mode Period (secs) & 1.8 & 3.1 \\
\hline $\begin{array}{l}\text { 3. Total peak seismic moment } \\
\text { including p-delta design } \\
\text { ductility factor ( } \mathrm{kN}-\mathrm{m})\end{array}$ & 1767 & 5600 \\
\hline 4. Peak reinforcing & $16 \underset{\text { dia }}{\text { bars }} 32 \mathrm{~mm}$ & $\begin{array}{l}52 \text { bars } \\
\text { dia }\end{array}$ \\
\hline
\end{tabular}

earthquake action it was assumed in accordance with the code that no traffic load would be present.

The effect of hammerhead rotational inertia was found to be negligible.

For the purpose of assessing p-delta effects the maximum expected displacement was taken as six times the elastic deflection (i.e. deflection at first yield) caused by the design earthquake for Alternative 1 (the double pier).

For Alternative 2, the single pier, the design code indicates that the likely maximum ductility factor for a structure of 3.1 second period designed for a basic acceleration coefficient of $0.05 \mathrm{~g}$ will be 3 . Therefore the design P-delta moment was based on a deflection of 3 times the elastic deflection.

It should be emphasised that these two alternatives do not represent a real bridge case, because they relate to one pier only; whereas bridges are more complex involving the interaction of perhaps many piers and the abutments. They are presented therefore only to illustrate how the N.Z. codes would be interpreted. In particular, real design of a cantilever pier should, because of the lack of structural redundancy, address the possible deflection in a very big earthquake, and also the effect of eccentric traffic load acting in conjunction with the design earthquake.

\subsubsection{Results for Case 2}

The results are presented on Figs 3.4 and 3.5 and Table 3.2. Again the controlling horizontal design base shear is $0.05 \mathrm{x}$ the total dead weight. Therefore the same design results for $0.40 \mathrm{~g}$ or $0.25 \mathrm{~g}$ ground shaking.

As before, eccentric traffic load controls the design of the single pier flexural steel.

The abutment bearings take a significant part of the horizontal forces so care will be required with their design and installation and with the design of the abutments.

Under the design earthquake the maximum displacement at the abutments was $130 \mathrm{~mm}$, which is within the expected shear capacity of the bearings. For the shear force to be transmitted by friction between the rubber bearing and the concrete abutment a friction coefficient of 0.15 must be mobilised. This is within the reliable dynamic friction for elastomer on concrete.

For the assessment of P-delta effects the

TABLE 3.2: CABE 2 RESULTB

\begin{tabular}{|l|c|c||}
\hline & $\begin{array}{c}\text { ALTERNATIVE 1 } \\
\text { DOUBLE PIER }\end{array}$ & $\begin{array}{c}\text { ALTERNATIVE 2 } \\
\text { SINGLE PIER }\end{array}$ \\
\hline 1. Pier diameter (mm) & 1000 & 1500 \\
2. 1st mode period (seconds) & 3.7 & 4.1 \\
3. Reinforcing at pier base for & 30 bars $24 \mathrm{~mm}$ \\
15 piers & dia & $\begin{array}{c}50 \text { bars } 32 \mathrm{~mm} \\
\text { dia }\end{array}$ \\
4ercentage of earthquake load & & \\
carried & & \\
Abutments & $54 \%$ & $75 \%$ \\
longitudinal & & \\
transverse & $53 \%$ & $22 \%$ \\
15 pier & & $32 \%$ \\
longitudinal & $43 \%$ & \\
transverse & $43 \%$ & \\
\hline
\end{tabular}


code indicates that a displacement ductility of 3 be should be allowed for, and this displacement should be within the capability of the rubber bearings.

Aesthetically the circular columns should appear slender and of pleasing form, however detailed studies on this important aspect have not been performed.

The abutment details adopted in $\mathrm{NZ}$ have been discussed in section 2. For alternatives 1 and 2 , unless time history studies are performed, it would be considered good practice to allow clearance greater than the design displacement ductility of 3 . Alternatively, ductile links, as discussed in Section 2, with lesser clearance would be acceptable. In this case the abutments must of course be designed for the increased loads they would then be asked to carry in a major shaking.

\subsection{NON-LINEAR TIME HISTORY BTUDIES}

The expectation is that bridges designed in accordance with the $\mathrm{NZ}$ Code will withstand, with acceptable amounts of damage, very big infrequent earthquakes. This is because:

- The effects of steel strain hardening and confinement will give member strengths significantly higher than the dependable strengths upon which design is required by code to be performed.

- The damping assumed in the design is $5 \%$ of critical, however with very big earthquakes greater movement will take place with corresponding likely increases in damping.

- Under the action of a very large earthquake extensive loss of concrete cover and steel yielding is likely. thereby lengthening the natural period of vibration and usually reducing structural response.

- with well detailed and constructed bridges the displacement ductility factors actually achieved may be significantly larger than those envisaged by the design code.

To test the theoretical performance of Case 2 , Alternative 1 , a series of time history analyses were performed to evaluate the longitudinal performance of the bridge in a very big shaking. In these studies:

- stiffnesses were based on $75 \%$ of the gross concrete section

- the earthquake record used was El centro May $181940 \mathrm{~N}-\mathrm{S}$ but scaled up to 1.5 times the original record. It was run for 20 seconds of earthquake.

- The analysis program was DRAIN2D, using a time step of 0.01 seconds. DRAIN2D allows P-delta effects to be modelled approximately by a modification to initial geometric stiffnesses.

- the strength of the piers was taken as $4442 \mathrm{kN}-\mathrm{m}$ which is the calculated "probable" strength of the piers. This strength allows for strain hardening and the likely overstrength of materials.

The results of these studies may be summarised as follows:

- With an assumed 5\% of critical damping the moments in the piers reached a maximum of $3000 \mathrm{kN}-\mathrm{m}$ and the bearing shear displacement was $237 \mathrm{~mm}$.

- As this displacement might be sufficient to make the abutment bearings slide, further analyses were made assuming freesliding or rolling bearings at the abutments.

This increased the period from 3.8 seconds to 6.0 seconds but only increased the displacement from 237 to $242 \mathrm{~mm}$.

- Because the corresponding pier forces were still short of the probable strength of the pier, indicating that damping might be less than 5\%, a further run was performed with $2 \%$ of critical damping. For this case the displacement increased to $341 \mathrm{~mm}$ and the peak moment in the piers was $3677 \mathrm{kN}-\mathrm{m}$.

These studies were not comprehensive and for real bridges a more extensive series of analyses using other and synthetic earthquake records as necessary, would be appropriate. However an interim conclusion is that:

The flexible nature of the bridge together with the $0.05 \mathrm{~W}$ minimum design load has produced a bridge that should suffer little damage in a major shaking.

The expected displacements of the bridge, even when the bearings are assumed to provide no restraint, are quite small so that P-delta effects and ductility demand are expected to be quite small.

\subsection{REFERENCES}

3.1 "Code of Practice for the Design of Concrete Structures, NZS 3101 Part $1: 1982^{\prime \prime}$

"Commentary on the Design of Concrete structures, NZS 3101:1982" and "Amendment No. 1 to NZS 3101: Parts $\& 2,1989^{\prime \prime}$

Standards Association of New Zealand, Wellington.

3.2 "Bridge Manual: Design and Evaluation" (Draft for Comment), Transit New Zealand, Wellington 1990.

3.3 Park, $\mathrm{R}$ and Paulay, T. "Strength and Ductility of Concrete Substructures of Bridges" Vol. 1: RRU Bulletin 84 Bridge Design and Research Seminar, Transit New Zealand, 1990, p.170. 


\section{SECTION 4 \\ RETROFITTING OF HIGHWAY BRIDGES}

(Principal Author: HE Chapman)

\subsection{INTRODUCTION}

\subsubsection{Backqround}

New Zealand is a lightly populated mountainous country. It has a well developed highway system with a total length of some $93000 \mathrm{~km}$, of which $11500 \mathrm{~km}$ are state highways.

The country's stock of highway bridges with spans exceeding 3 metres comprises approximately 2500 structures on the state highway network and approximately 8000 on the local authority highways. Much of the stock - 70 percent in the case of state highways - was built in the period 1930 to 1970, as illustrated in Fig. 4.1. The total length of bridging amounts to $300 \mathrm{~km}$, resulting in average bridge lengths of 50 metres and 20 metres on the state and local authority systems respectively. While a large proportion of the bridges comprise short single span structures, there are many multi-span bridges, with lengths up to 1750 metres.

The seismicity of the most active parts of the country is similar to that of California with a magnitude 6 earthquake or greater occurring on average every year and a magnitude 7 or greater every 10 years. New Zealand bridge design for earthquake resistance has advanced significantly since about 1970. In this period understanding of structural dynamic behaviour and of methods to attain ductility of concrete members has improved. Furthermore much effort has been spent in translating the results of research into a form readily usable by designers.

Before 1970 structural integrity was recognised as an important design consideration, especially as a result of the Napier earthquake in 1931 - a Richter magnitude 7.8 event in the north east of the North Island. A Public Works Department design instruction dated 1933 required that "wherever possible the structure should be made monolithic, and where this is not possible all parts of the structure should be well tied together". Such design practices are evident in structures built since 1933 and there are few where spans are not interlinked. A feature of these structures, however, is the absence of special detailing for member ductility, and of the application of capacity design procedures (see section 1), both of which are now considered to be important aspects of seismic design practice.

\subsection{2 past Policy on seismic Retrofitting of Highway Bridges}

Approximately $20 \%$ of the state highway bridge stock has been built since 1970 . This represents a period of significant

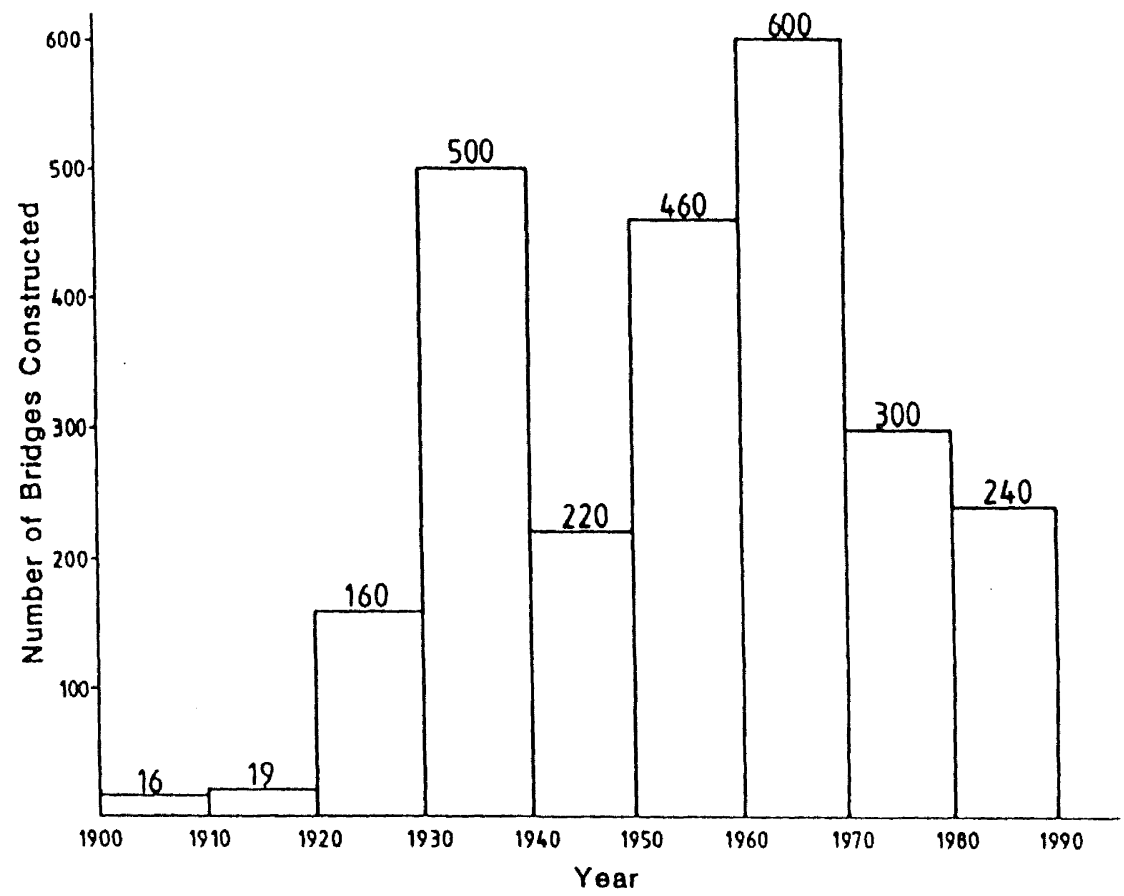


effort by the highways autnority to upgrade the geometric standards of the highways and to replace substandard bridges for structural (traffic load) or geometric (alignment or width) requirements. In addition urban motorway systems were developed in the main cities. During this period funding was allocated primarily to raising the service standards of bridging rather than to seismic retrofitting. In cases where improved seismic performance could be achieved at small cost by combining retrofitting with improvements for service purposes, this was done. Examples are discussed later in this paper. While there was an awareness that unacceptable seismic risk should be remedied, high risks of span collapse had generally been alleviated by the policy of interlinking spans from an early date.

\subsubsection{Current Pollcy on Beismie Retrofitting of Highway Briages}

Much of the new bridge construction necessary for service requirements is now complete and emphasis is moving towards maintaining the stock. With progressive traffic growth the consequential cost of disruption by earthquake is increasing and attention is focusing more closely on assessing these risks and taking appropriate action.

During 1990 the following steps were taken:

- A multi-disciplinary study "Lifelines in Earthquake" was sponsored by the centre for Advanced Engineering of the University of canterbury to examine the likely effects of a major earthquake on the capital city, Wellington. The transportation network was one of the lifelines studied. It is likely that this type of study will be extended to other cities in the future.

- A pilot study was carried out, for Transit New zealand (the national land transport authority), of the seismic resistance of five "typical" highway bridges. These were chosen as representative of the large number of structures built during the period 1930 to 1970 . More detailed follow-up studies arising from this work are now in hand to assess the need and justification for retrofitting. These include laboratory testing of structural specimens modelling some of the typical details identified as vulnerable.

- A preliminary study was made, for Transit New Zealand, of the seismic resistance of a motorway viaduct designed in the 1960 s. More detailed follow-up studies arising from this work are now in hand with respect to a number of specific features.

- Several seismic studies were undertaken of individual structures as part of more general considerations for renewal.

The retrofitting strategy being followed is to work in steps from the general to the specific:

- Identify the network structure vulnerability in general terms and evaluate the risk and consequences of structural seismic damage, initially in the most seismically active areas of the country.

- Assess the feasibility and cost of mitigation by retrofit.

- In appropriate cases undertake detailed assessment and retrofit of individual structures as required.

In addition specific structures which clearly justify immediate consideration are being assessed and the benefit/cost relationship for mitigation by retrofit being determined. Follow-up action with retrofit measures will depend on Transit New zealand's decision following their consideration of the conclusions of the investigation.

To date only the initial steps have been taken, as listed above. The methods used have comprised an office review of bridge details, approximate structural analysis and the use of judgement and experience. An advantage of this approach is that wide coverage can be achieved with a relatively low budget, and the need for subsequent more costly detailed work can be focused on the most appropriate areas.

\subsection{A8BESBMENT OF EXISTING STRUCTURES}

\subsubsection{Aspects studied}

In this section assessment of

- flexural strength

- flexural ductility

- shear strength

- beam/column joint shear strength

- foundation capacity

- compliance with capacity design principles

will be discussed by reference to a number of structures of different types which have been considered recently. A summary of main points will conclude the section. No mention is made in this review of the vulnerability of approach embankments to settlement or slope failure. Settlement is a common occurrence in strong shaking and is usually readily and quickly remedied to allow traffic to resume. The effects of slope failure due to instability or liquefaction are more serious and take longer to remedy, though are less common than settlement. None of the bridges reviewed is considered to have a high risk of slope failure but it is an aspect which should be considered when assessing an existing structure.

\subsubsection{Methods of Assessment}

The assessment of structural member capacities uses "as built" drawing records and the usual materials design codes, as referred to in section 1. An important feature of assessment is to adopt realistic values of material properties - in particular those for the reinforcing steel. It has been found by site sampling and testing that in structures built during the 1930 to 1970 period the reinforcement is 
likely to possess a characteristic yield strength 15 to 20 percent greater than the specified value. Two significant effects arise from this:

- the strength of the structure may more closely meet current specified strength values - a beneficial effect.

- the shear forces required in the structural members to induce a plastic mechanism in the structure are greater than would be calculated assuming the minimum specified yield value for the reinforcement - a detrimental effect.

\subsubsection{Bridge $A$}

This bridge was designed in 1936 and is a multi-span structure with a reinforced concrete $T$ beam superstructure and reinforced concrete pier columns supported on piles. The bridge has $90-12.2$ metre spans, with deck expansion joints and double piers at 5 span intervals. The critical structural element is the pier/pile assembly shown in Fig. 4.2.

The behaviour of the bridge under transverse loading (normal to the bridge centreline) is considered critical and the following conclusions were drawn:

- assuming the probable, rather than the specified minimum yield strength of the reinforcing steel, the pier columns would yield at a seismic loading of $0.3 \mathrm{~g}$, provided that the piles do not yield first and that the column reinforcement anchorages do not fail (see below).

- with the above structure yield strength an available structure displacement ductility of four is necessary to meet current design requirements for the most
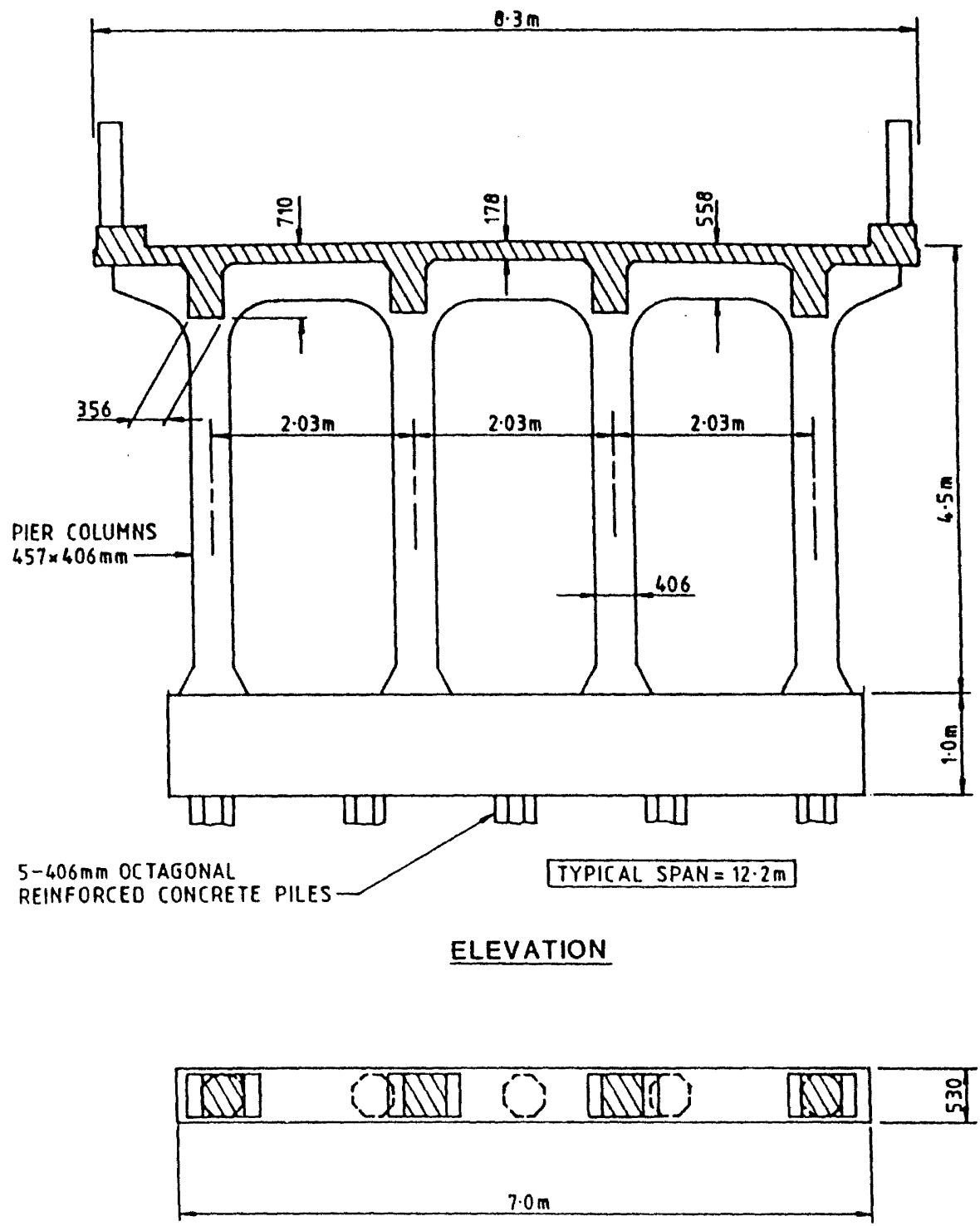

PLAN OF PILE CAP

FIGURE 4.2 TYPICAL DETAILS OF PIER - BRIDGE A 
important bridges in the most active seismic areas.

- the pier columns are unlikely to tolerate cyclic displacements much exceeding yield because:

- the rectangular hoops are widely spaced so that the column core concrete is poorly confined and the main reinforcement would be poorly restrained against buckling

- the capacity of the upper part of the column to resist shear forces necessary to develop a plastic mechanism is marginal

- the top anchorage length of the plain round column bars into the cross beam is approximately 50 percent of the current design code requirements, suggesting that bar anchorage failure would be likely.

- the piles are strong enough to resist the shear forces from the columns hinging, but would themselves hinge first in flexure if they are standing as columns with a free height of more than approximately 1.5 to 2 metres (such as in a river bed).

- under longitudinal seismic action the bridge is likely to be supported by the abutment approach fills and by interaction between sections of its length. Longitudinal behaviour is unlikely to be critical on firm ground as each span is monolithic with its supporting piers. On soft or sandy silts where soil liquefaction could occur pier/pile damage could result from individual longitudinal movements of the piles relative to the superstructure.

\subsubsection{Bridge B}

This bridge was designed in 1952 and is a 15 span structure, 208 metres long, with a reinforced concrete $T$ beam superstructure and reinforced concrete slab piers supported on reinforced concrete piles. The deck is divided into four lengths with three intermediate transverse joints (see Fig. 4.3). The behaviour of the bridge under both transverse and longitudinal seismic actions could be critical. Conclusions were as follows:

a) Under transverse effects:

- the critical flexural elements are the piles. Under "design earthquake" shaking the piles are unlikely to yield if they have less than 1 to 1.5 metres of free length between the pile cap and the gravel river bed, and the structure would perform elastically. With greater free pile lengths the piles would need to form plastic hinges for which they are not well detailed. Under severe cyclic motions the piles would almost certainly

$207.63 \mathrm{~m}$

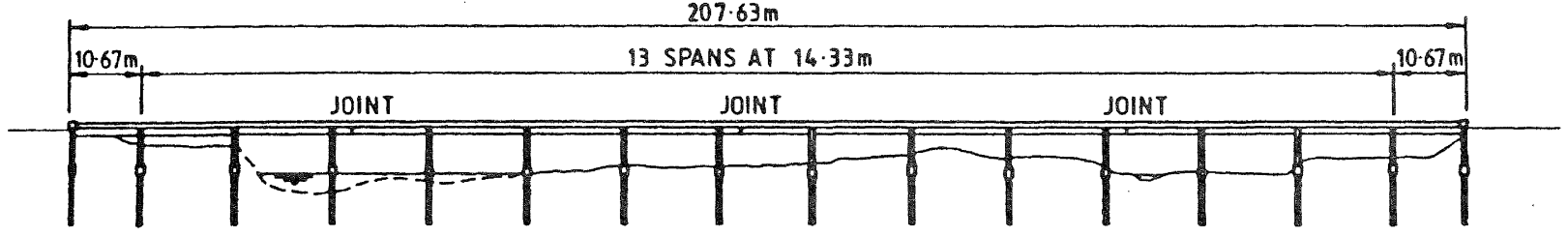

ELEVATION

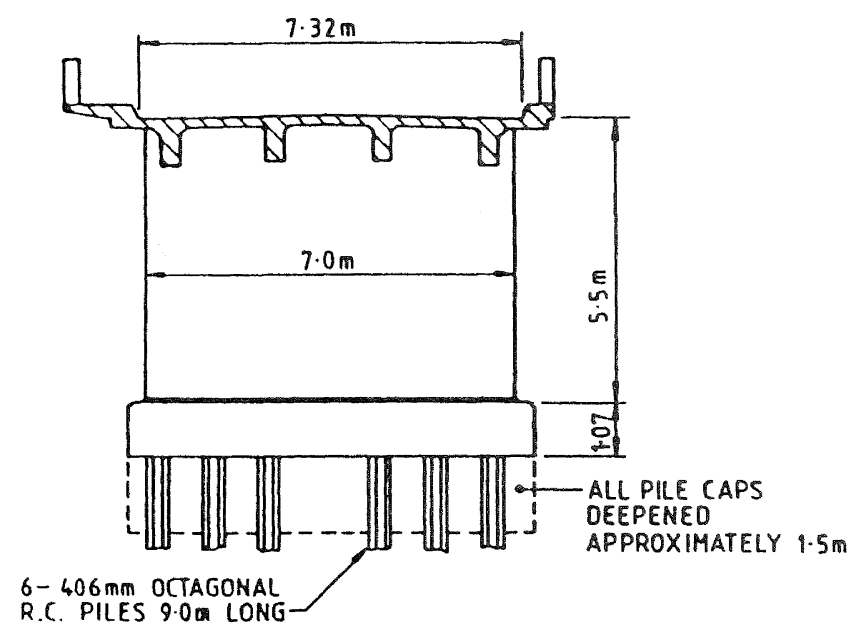

ELEVATION OF PIERS

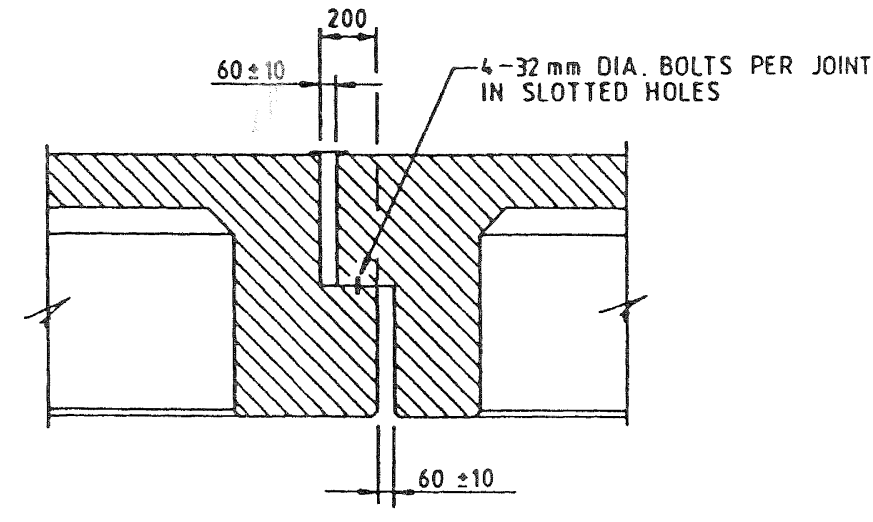

TYPICAL TRANSVERSE JOINT ACROSS DECK AND BEAMS 
suffer damage to the concrete core in the plastic hinge zones, with consequent loss of strength. While the shear strength of the piles is sufficient to resist pile flexural yielding, it depends on the shear contribution of the concrete. The concrete contribution diminishes significantly after multiple cycles of flexural yielding with poor confinement, and hence the piles as detailed would be a weak link in the structural chain.

b)

$$
\text { under longitudinal effects: }
$$

- features of the design of Bridge $B$ are the three intermediate transverse joints shown in Fig. 4.3. Surprisingly it was found that, in spite of normal practices previously referred to, these joints have no structural tie bars linking across the joints to inhibit excessive movement of the joints and loss of support. The piers are relatively flexible longitudinally. The joint support overlap is approximately $140 \mathrm{~mm}+/-10 \mathrm{~mm}$ (temperature movement) and the scope for individual joint closure is $60-/+10 \mathrm{~mm}$. Cumulative closure of two joints could lead to loss of support at the third one. Actions to rectify this detail are in hand.

\section{2 .5 Bridge C}

This bridge was designed in 1969 and is a 10 span structure 127 metres long. It has reinforced concrete piers and a concrete deck as shown in Fig. 4.4. The superstructure is tied down at each pier cap with 32 - $12 \mathrm{~mm}$ diameter bars and is discontinuous longitudinally between spans. The spans are interlinked with $18-16 \mathrm{~mm}$ bolts at each pier and have a $400 \mathrm{~mm}$ overlap over each pier cap. Due to the abutment

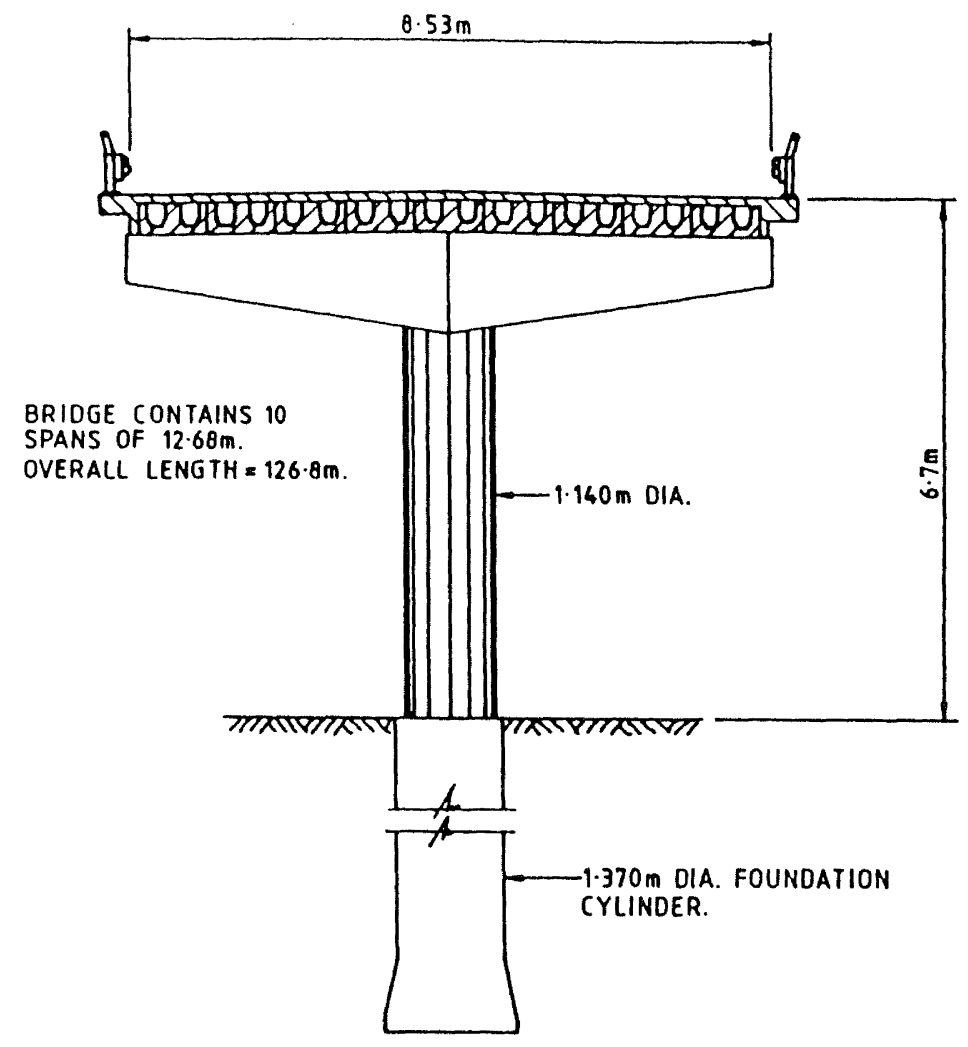

TYPICAL CROSS, SECTION

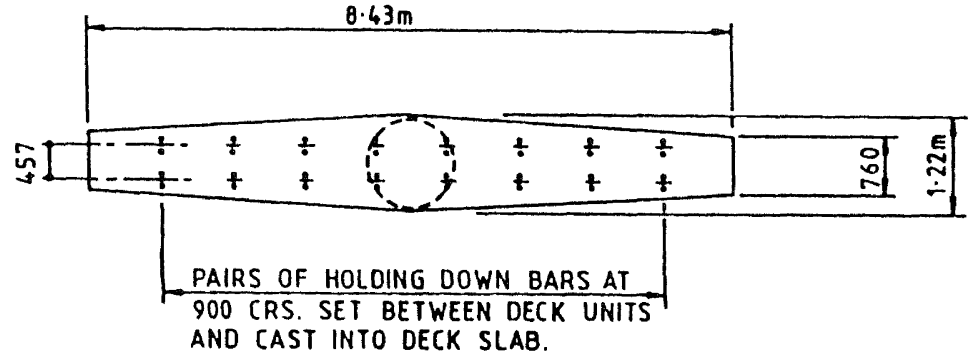

PLAN ON COLUMN CAP

FIGURE 4.4 PIER DETAILB - BRIDGE C 
details the critical direction of seismic motion is transversely. The shear, flexural and ductile capacities of the foundation cylinder and pier stem were analysed, and an assessment of the likely ductility demand on the pier was carried out. Conclusions were as follows:

- The spans are adequately interlinked longitudinally to consider transverse seismic response to be the governing case.

- The pier stems would yield at their bases at a seismic loading of $0.3 \mathrm{~g}$ and the foundation cylinders are strong enough to resist and focus the plastic hinging in the piers.

- To meet the current design requirements for a new bridge of importance category 1 in the most active seismic areas the piers would need to be capable of displacing up to 2 to 3 times the displacement at which yield first occurs.

- The shear capacity of the column concrete exceeds the shear demand from plastic hinging by a factor of 2. The shear capacity of the circular hoops is nominal, because they are of small diameter bars and are widely spaced. Furthermore it is unclear whether the ends are lapped or welded to provide a closed hoop. It is current design practice to provide welded hoops to resist all the shear forces within the length of a plastic hinge zone, because the concrete core is subject to large tensile strains in this zone. Loss of cover concrete can result in loss of anchorage of the ends of unwelded hoops. If this structure experienced strong shaking causing significant plastic hinge deformations, it would be mainly depending on the concrete within the

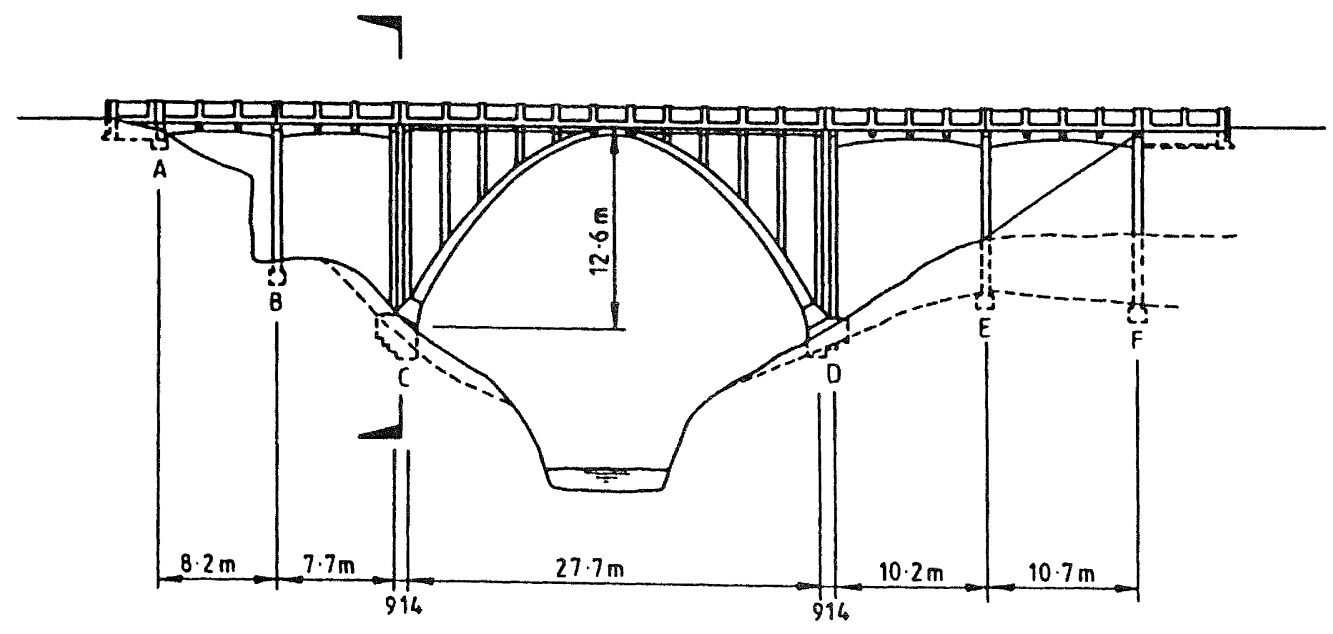

ELEVATION

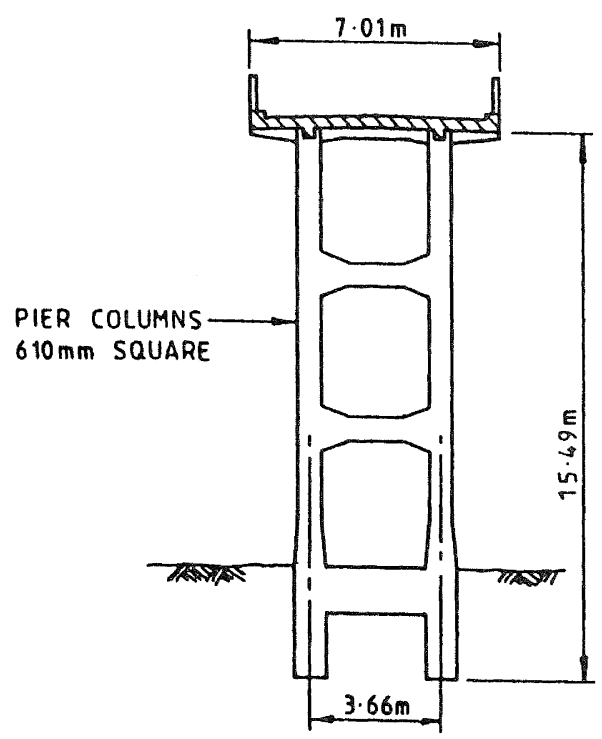

PIER C SECTION

FIGURE 4.5 BRIDGE D 
plastic hinge zone to resist the shear. There is some doubt as to the dependability of the concrete alone to perform adequately in these circumstances.

- If the piers experienced shaking to cause significant plastic hinging it is likely that:

- cover concrete would spall off experience local buckling because the confining hoops in the plastic hinge zone are widely spaced and of small diameter bars with limited anchorage to ensure hoop continuity

- some column core concrete would be damaged because of the nature of the confining hoops

- effectiveness of the anchorage of the pier reinforcement to the foundation cylinder reinforcement is likely to deteriorate during cyclic plastic hinge actions because the two sets of bars are lapped within the plastic hinging zone, and are not confined by closely spaced hoops. Tensile force transfer between the bars is therefore likely to be only partially effective, due to bar slip.

- In addition to the purely theoretical bending action of the pier stems cantilevering from their foundations, it is possible that they could be restrained against rotation at their tops by the deck stiffness. In this event the upper part of the pier could experience some damage in a strong earthquake, although to a lesser extent than at their bases.

\subsubsection{Bridge D}

This bridge was designed in 1935 and is of arch form (see Fig. 4.5). All members are of reinforced concrete construction. This example of arch bridge is in three independent structural sections $A-C, C-D$ and $D-F$. Each of the three structural sections is relatively well secured against longitudinal seismic loading and it is likely that transverse effects would most affect the bridge. of particular note are the two approach sections $A-C$ and $D-F$, and the effect of their structural form on their likely seismic response.

Transversely the main structural mass of each is supported by the transversely stiff abutment, the moderately flexible intermediate pier and the relatively more flexible high pier. Thus during transverse shaking the centre of mass of the deck is significantly eccentric to the centre of resistance. This would result in translation of the deck and also rotation of the deck about a vertical axis through the stiff abutments, leading to amplified displacement of the tall piers and dependence on the anchorages at the abutments. Approximate analysis of the tall pier columns indicates that the combination of tension and bending at their base would govern the seismic capacity and that the columns would yield under a transverse seismic loading of about $0.5 \mathrm{~g}$. This represents approximately $60 \%$ to $80 \%$ of the current design loading based on 58 critical damping, assuming the structure were designed to remain elastic (ie with no demand for ductile action). These approach

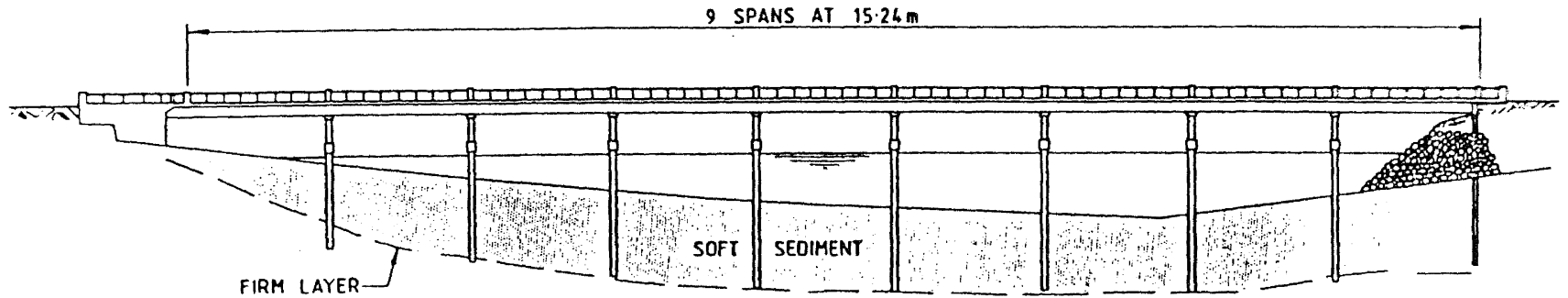

ELEVATION

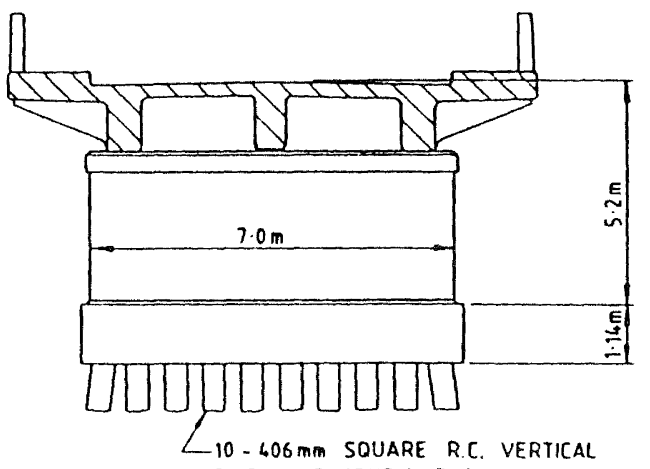

PILES ILENGTHS VARY

\section{ELEVATION OF PIER}

FIGURE 1.6 BRIDGE E 
structures are higher and probably less damped by soil/structure interaction than many typical structures, thus being likely to respond more vigorously than average structures.

Should the bridge be shaken by a major seismic event critical column locations would be required to undergo plastic deformations. As with other member details of this period the confining stirrups are widely spaced and the column core concrete would probably be damaged, losing serviceability.

\subsubsection{Bridge $\mathrm{E}$}

This bridge was designed in 1935 and is a 9 span structure 137 metres long. It has a reinforced concrete $\mathrm{T}$ beam superstructure and reinforced concrete slab piers supported on reinforced concrete piles, as shown in Fig. 4.6.

The bridge is well anchored to rock at one end longitudinally and its transverse action is considered critical. With solid slab piers the governing elements are the piles which are of differing free heights at different piers. The free heights vary from 2 to 8 metres and the thickness of the soft sediments into which they are drlven varies from zero at one abutment to exceeding 12 metres at mid-crossing. The anticipated seismic behaviour is similar to that described for Bridge $B$ with pile flexural yielding and damage being the governing factor. An important aspect affecting response is the varying depth of the foundation and its founding material. It is likely that significant redistribution of seismic loadings would occur on such a structure leading to greater local damage than might otherwise be expected. This must be considered during a detailed assessment.

\subsubsection{Conclusions from the Bridges studied}

on the basis that most older structures free to vibrate will need to experience plastic deformations during strong earthquakes the following points have been identified during the studies carried out:-

- Structural elements often possess as much lateral load resistance as today's codes require but they do not possess the necessary ductility.

- Potential plastic hinge zones contain insufficient confining hoops leading to: - poorly confined core concrete

- inadequate restraint of main bars against buckling during cyclic yielding

- inadequate member shear strength when the concrete shear strength decays in the plastic hinge zones.

- Transverse hoop anchorages may be inadequate, due to their being lapped and not welded in the cover concrete.

- Main member reinforcement may have inadequate anchorage lengths to develop bar yield forces. Older structures used plain round, rather than deformed, bars. increasing the risk of anchorage slip.
- Main member reinforcement may be lapped in potential plastic hinge zones, with a consequent risk of splice failure.

- The structural form may be such that plastic actions will occur in locations inaccessible for inspection and repair (eg in foundation piles). Often the elements are not appropriately detailed.

- structural forms and differing pier stiffnesses may lead to significant lack of symmetry of the structure and of its dynamic response. Such features as markedly differing free pile lengths or depths of soft foundation materials warrant special consideration during seismic assessments.

- The relative member strengths in both flexure and shear may lead to undesirable modes of ductile or brittle actions beyond the elastic range. The "capacity design" philosophy would not have been applied when older structures were designed.

- Attention should be paid to potential loss of support of spans due to lack of span linkages or inadequate seating lengths.

\subsection{OBBERVED BEHAVIOUR OF EXISTING BRIDGES}

\subsubsection{Backaround}

Records are held of bridge behaviour during three strong earthquakes in New Zealand since 1968. Some features of reported behaviour have been selected and are described below.

\subsubsection{Inangahua Earthquake 1968}

This Richter magnitude 7.0 earthquake occurred at a focal depth of $12 \mathrm{kilometres}$ on 24 May 1968,16 kilometres north of Inangahua township in New Zealand's South Island. Its effects on three quite large railway bridges and five small to medium sized highway bridges are described in References 4.1 and 4.2. Two particular aspects are of interest to the current topic:

(a) The response of large slab piers on calsson zoundations

The three railway bridges were all carried on piers of similar form (see Fig. 4.7). The bridges were all located in or close to Inangahua township where Modified Mercalli MMX intensity shaking was estimated. The piers of the two bridges in Inangahua suffered significant damage near to the connection betwen the rigid upper slab and the lower twin cylinders. In some cases the damage was consistent with axial tension developing at the cylinders due to 'stepping' of the large mass on the two cylinders due to transverse rocking motions. There was evidence that vertical $25 \mathrm{~mm}$ diameter reinforcing bars through the connection had been buckled and straightened by cyclic actions. In other cases damage showed diagonal tension failures through the pier web and into the cylindrical portion of the pier. 


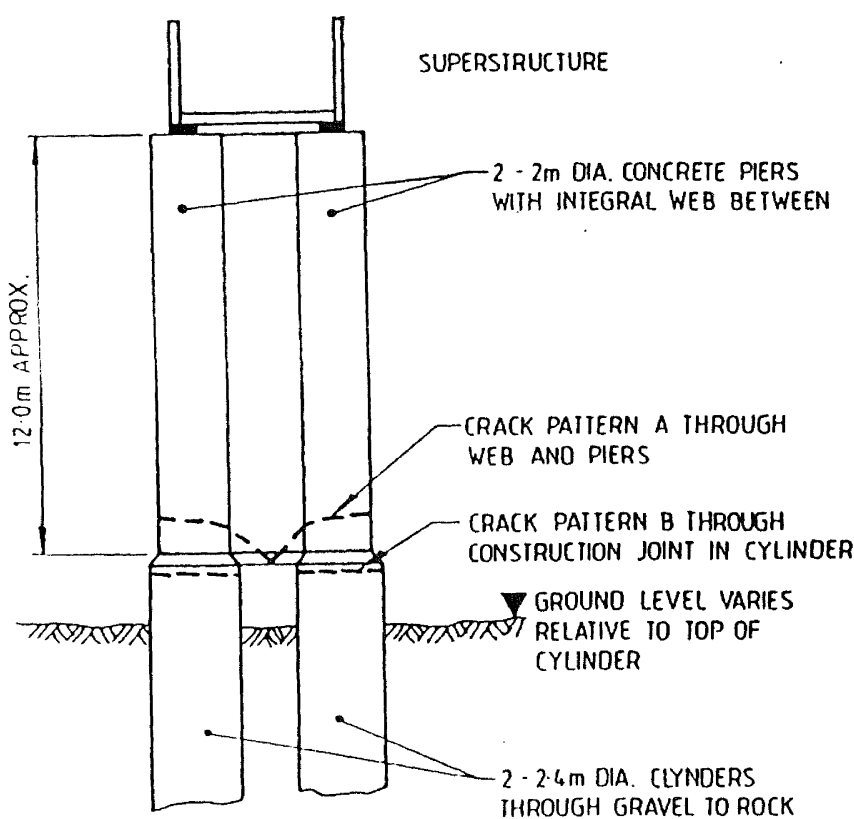

FIGURE 4.7 TYPICAL BRIDGE RIERS AT INANGAHUA

These failures indicate that the expected point of weakness is indeed attacked by strong shaking. Any reduction of seismic loading by suitable retrofit (such as base isolation - see 4.4.3) reduces the severity of such potential damage although the mass of the pier contributes significantly to the seismic load.

\section{(b) The settlement of approach embankments}

One of the rail bridge approach embankments settled up to 1.5 metres over a length of 30 metres. The embankment was 6 metres high overlying 13 metres of natural gravel. A second rail bridge's embankments both settled - one by a metre over a 30 metre length and the other more than a metre over hundreds of metres. These bridges, and presumably also the approaches, were built more than 50 years (and up to 80 years) ago.

The reports on the five highway bridges suggest that approaches settled on only one of them (built in 1956) - by up to $460 \mathrm{~mm}$ on a height of fill of approximately 4 metres.

It has been common practice since the 1960s, to install concrete approach slabs 1.5 to 2 metres long at each abutment and buried approximately a metre below road level. These reduce the effects of normal approach fill settlement and subsequent increased uneveness due to traffic impacts. They also reduce the likelihood of serious vehicle impact with the back of the abutment after seismic shaking and approach fill settlement.

\subsubsection{Edgocumbe Earthquake 1987}

This Richter magnitude 6.3 earthquake occurred on 2 March 1987 in the north east of the North Island. It produced strong local shaking (exceeding Modified Mercalli MMVIII) over an area of 900 square kilometres due to its shallowness $(8 \mathrm{~km})$ and the soft alluvial nature of the underlying materials. The townships of Edgecumbe and Te Teko experienced shaking of intensity MMIX. The duration of the strong shaking was approximately 10 seconds, which probably had a bearing on the limited bridge damage noted.

The performance of the eleven main highway bridges and two rail bridges in the area was generally excellent. Minor settlement of approach filling was almost universal, and serious transverse spreading of one embankment occurred adjacent to a river flood plain in which soil liquefaction was evident. The bridge structures showed very little distress except in one case. Due to a construction shortcoming, an elastomeric bearing was able to escape its retaining ring under extreme shear displacement. This resulted in reduced transverse restraint at the abutment of the 5 span bridge and consequent additional demand on the closest of the four piers. The pier acted in a ductile manner, as designed, with only some cover concrete spalling away and no loss of serviceability. The bridge was jacked and the bearing re-installed in a short time. The bridge showed little residual transverse displacement at the abutment. The other bridges all showed only superficial spalling and joint movements. All but two of these bridges were less than 90 metres long with flexible pier columns rather than wall piers. They had a length to width ratio of 10 or less and most had approach fills abutting the end deck diaphragms. It is felt that the abutment damping influence on the transverse response of relatively short structures such as these is likely to be significant, yet is not normally taken into account in determining seismic response for design purposes.

The piers of the two longer bridges - 240 and 260 metres long - have wall piers supported on piles. No major damage occurred to the piles - again possibly due to the relatively short duration of the shaking.

In summary the following general observations may be made from bridge behaviour during the Edgecumbe earthquake:

- the short duration of strong shaking (approximately 10 seconds) probably limited bridge member damage.

- the detailing of pier columns for ductile action in one important structure successfully prevented major pier damage.

- the damping effect of the abutment/approach interface apparently significantly reduces the transverse seismic response of shorter bridges (say with a length to width ratio up to 10 to 1). This damping effect is not usually taken account of in deciding the design seismic loading for the piers. 
- critical attention to the design and construction of important, though small, details is vital. Failure of the smallest link in a structural chain can have a major influence on a structure's seismic behaviour.

\subsubsection{Bouthern Hawkes Bay Earthquak 1990}

This Richter magnitude 6.5 earthquake occurred on 13 May 1990 in the south east of the North Island at a depth of approximately $30 \mathrm{~km}$. Strong shaking was experienced at Dannevirke where much damage occurred in older buildings. An inspection of bridges in the area showed only superficial settlements of approaches and minor cracking in some concrete. Abutment damping appears to have been evident in limiting substructure damage, as discussed in 4.3 .3 .

\subsubsection{General Comments}

The seismic assessment of structures described in 4.2 provides estimates of the yield strength of the structural members and the response accelerations at which yield would theoretically occur. Assessments are made using probable yield strengths of reinforcement, thus taking account of one common source of reserve strength. If the intensity of ground shaking necessary to cause structural yield response is estimated, it is often found to be a very low value -particularly for the short period, stiff structures which are common in the older designs - for example less than $0.1 \mathrm{~g}$.

In the 50 year life of many of the bridges in question it is very likely that such ground motion has occurred more than once, yet the structures remain undamaged - even the long ones where abutment interaction is unlikely to be a factor.

Column laboratory tests have shown that flexural yield to a small displacement ductility value (conservatively 2 but often more) produces no visible distress in the concrete, and the ground motion to induce this response is significantly greater than that to induce elastic limit response. It is considered therefore that the tolerance of most columns (even with minimal stirrups) to small ductile yielding, coupled with the short duration of lesser intensity shaking, results in a higher damage threshold than might be indicated by taking the elastic limit as the damage criterion. This aspect should be taken into account when assessing the probability of seismic structural damage.

\subsection{RETROFIT METKODS}

\subsubsection{General}

Two distinct approaches to retrofit are identified for possible use on New Zealand bridges:

- appropriately enhance the structural member properties. The most usual needs are for increased shear and ductility capacities as it is found that yield strengths are often similar to currently specified values. Attention to prevent bar anchorage or splice failure may also be required but is not always practicable.

- modify the structure's response by base isolation and energy dissipation techniques.

It is often not feasible to retrofit a structure to fully meet the current design philosophy of "capacity design" and ensure an intended mode of inelastic behaviour. In such cases compromises are necessary. Retrofit is used to raise the threshold of damage and to reduce to an acceptable level the consequences and probability of damage occurring.

\subsubsection{Member Property Enhancement}

Investigation of techniques for enhancement is proceeding in New Zealand and projects completed to date relate to concrete building members, as reported in Reference 4.3 .

Four reinforced concrete columns were tested by compression loading and cyclic lateral loading simulating a severe earthquake, to investigate repair and strengthening techniques. The original columns were 350 $\mathrm{mm}$ square and represented columns designed and constructed in New Zealand before the $1970^{\prime} \mathrm{s}$. Two columns were tested, repaired and strengthened by jacketing and retested. The other two columns were strengthened by jacketing and tested. The jacketing consisted of a $100 \mathrm{~mm}$ thickness of concrete and new longitudinal reinforcement placed through the floor slab. The test results showed that the original columns lacked adequate bond between the plain longitudinal bars and the concrete, and demonstrated low displacement ductility factor and energy dissipation capacities, and significant reduction of strength at the end of each testing. The jacketed columns showed significant increases in strength and lateral stiffness compared to those of the original columns, with improvements in the available displacement ductility factor and energy dissipation capacities.

Details of the original columns are shown in Fig. 4.8 and those of the repaired and the jacketed columns in Fig. 4.9. Typical test results for column $\mathrm{S} 1$ before and after repair by jacketing are shown in Fig. 4.10 . Comparison of the hysteresis loops for the four specimens suggested that the previous damage had little effect on the later performance of the columns which were tested, then repaired by jacketing. The column jacketing clearly makes an important contribution to the stiffness, strength and ductility of the column.

\section{The following conclusions were drawn:}

- The seismic load tests on two column units representing reinforced concrete columns designed and constructed in New zealand before the 1970 's showed that this type of column has very low displacement ductility capacity. The columns tested were $350 \mathrm{~mm}$ square. contained plain round longitudinal bars, and had transverse reinforcement consisting of $6 \mathrm{~mm}$ diameter hoops at 265 


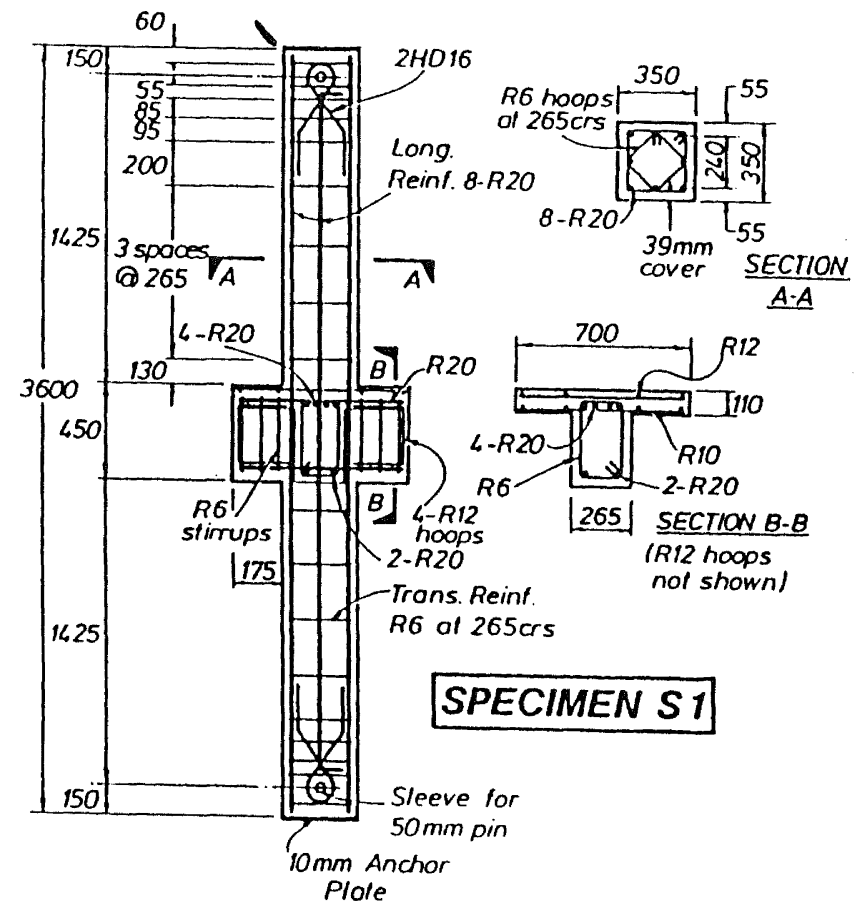
FIGURE 4.8 DIMENSIONS AND REINFORCEMENT DETAILS FOR THE ORIGINAL COLUMN
UNITS
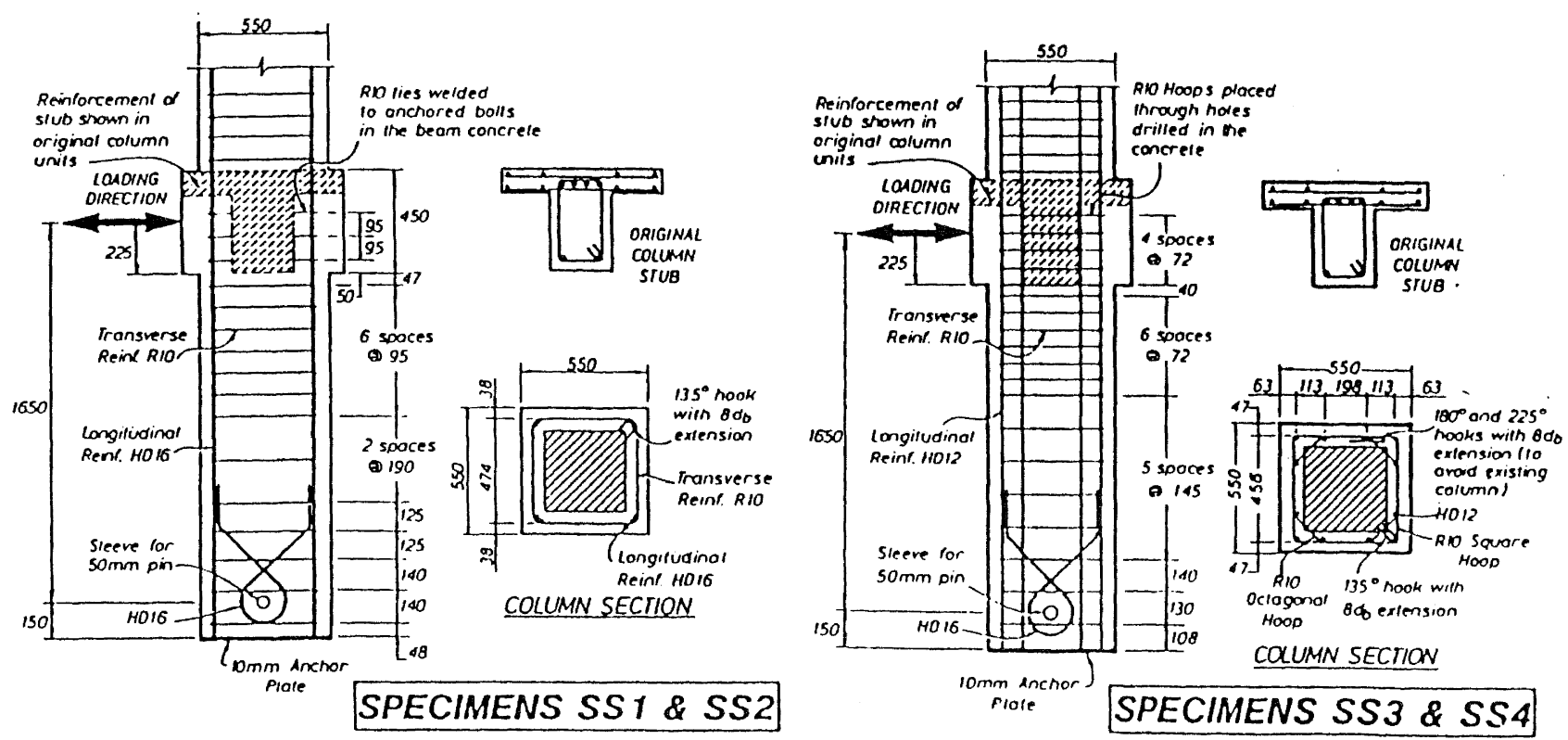

FIGURE 4.9 DIMENBIONB AND REINFORCEMENT FOR COLUMN UNITS 881 TO 884 
$\mathrm{mm}$ centres. Available displacement ductility factors of approximately 2 to 3 were found in these column units. Evidence of lack of bond between the plain round longitudinal bars and the surrounding concrete was also observed, which resulted in a softening of the lateral load-displacement relationship starting from about one-half of the measured lateral load strength. As a consequence, these column units had reduced energy dissipation capacity and a significant reduction of strength was observed at the end of the loading cycles to a nominal displacement ductility factor of 3 .

- Four reinforced concrete column units representing columns constructed in New zealand before the $1970^{\prime} \mathrm{s}$ were repaired and/or strengthened by jacketing with added longitudinal and transverse reinforcement. Two of the columns had been damaged by seismic loading before repair and strengthening; the other two columns were strengthened without being subjected to previous seismic loading. The other variable in this part of the investigation was the distribution of the new longitudinal reinforcement and the new transverse reinforcement in the concrete jacket. The new longitudinal reinforcement was placed bundled in the four corners of the jacket with single square hoops as transverse reinforcement. or distributed around the jacket with square and octagonal hoops as transverse reinforcement (see Fig. 4.9). Results of the seismic load tests on the jacketed columns showed that the strength and stiffness of the jacketed columns were up to 3 times those of the original columns. The measured hysteresis loops for the jacketed columns indicated good energy dissipation and limited reduction in strength up to the end of testing. cyclic lateral loading with nominal displacement ductility factors up to 6 were imposed on these specimens, and the corresponding available displacement ductility factors found ranged from 7 to 8. These tests also showed that the effect of previous damage to the original columns and the two different reinforcing details used in the jacketed columns had no significant influence on the overall seismic response of the jacketed columns.

- The results of this investigation indicate that the tested jacketing technique significantly improves the seismic behaviour of typical reinforced concrete columns constructed in NeW Zealand before the 1970's. However, as was found in this investigation, this technique of retrofitting is labour intensive.

A current project at the university of Canterbury is the testing of full scale models of column details from Bridge A referred to in 4.2 .3 above. It is intended to check the bar anchorage performance, shear, flexure and ductility capacities and to subsequently repair the specimens using added reinforcement and concrete jacketing. or steel jacketing to increase the ductility and shear strength without increasing the flexural strength. Close interest is also being maintained in progress on similar testing currently underway in other countries.

\subsection{Base Isolation of structures}

This retrofit technique has been used on a number of bridges in New Zealand, where the development of practical energy dissipating devices (in particular the lead/rubber bearing) provided the key to this cost effective protection for suitable structures. Much has been published on the technique for example References 4.4 and 4.5) and it is not intended to include details in this paper. New Zealand bridges retrofitted with base isolation are described in 4.6 .

\subsection{PRIORITIZING RETROFIT NEEDS}

As set out in 4.1 .3 above the strategy for determining justifiable retrofit is to work from the general to the specific. Activities have included a pilot study of typical bridges and some follow up actions on individual structures are planned or are in hand. Steps envisaged to follow may include considering a "typical" length of main highway in the most seismically active zone and the evaluation of the potential cost of bridge damage, loss of service, and repair in comparison with the cost of retrofit. This exercise would quantify the scale of existing risk and the costs involved in risk management.

\subsection{EXAPLLES OF RETROFTTTING}

The earliest major seismic retrofit work on a New Zealand state highway bridge was undertaken in 1973 when a new superstructure was bulit onto old existing piers. The 5 span bridge has a total length of 170 metres and comprises 4 steel trusses with a concrete deck. It was recognised the "design" elastic response of the bridge would severely overstress the piers, which are similar to those illustrated in Fig. 4.7 , and possess little ductility. In the absence of developed energy dissipators the superstructure was "base isolated" transversely by supporting it on PTFE/stainless steel sliding bearings and restraining it transversely by 3 double universal column sections at each pier. These are embedded into the pier tops and cantilever some 3.5 metres up to the deck soffit, where they engage in a longitudinal slot between downstand concrete corbels, which allow the deck to move longitudinally but not transversely. The superstructure is anchored longitudinaliy at one abutment. The compact structural steel sections provide the necessary ductility at each pier, while the sliding bearings limit the horizontal forces imposed on the piers during seismic movements.

The other significant seismic retrofitting undertaken in New Zealand to date involves eight bridges on state highway 35 in the East Cape region of the North Island. The work was carried out in $1983-7$ as part of a comprehensive structural upgrading involving concrete deck replacement and girder strengthening. 


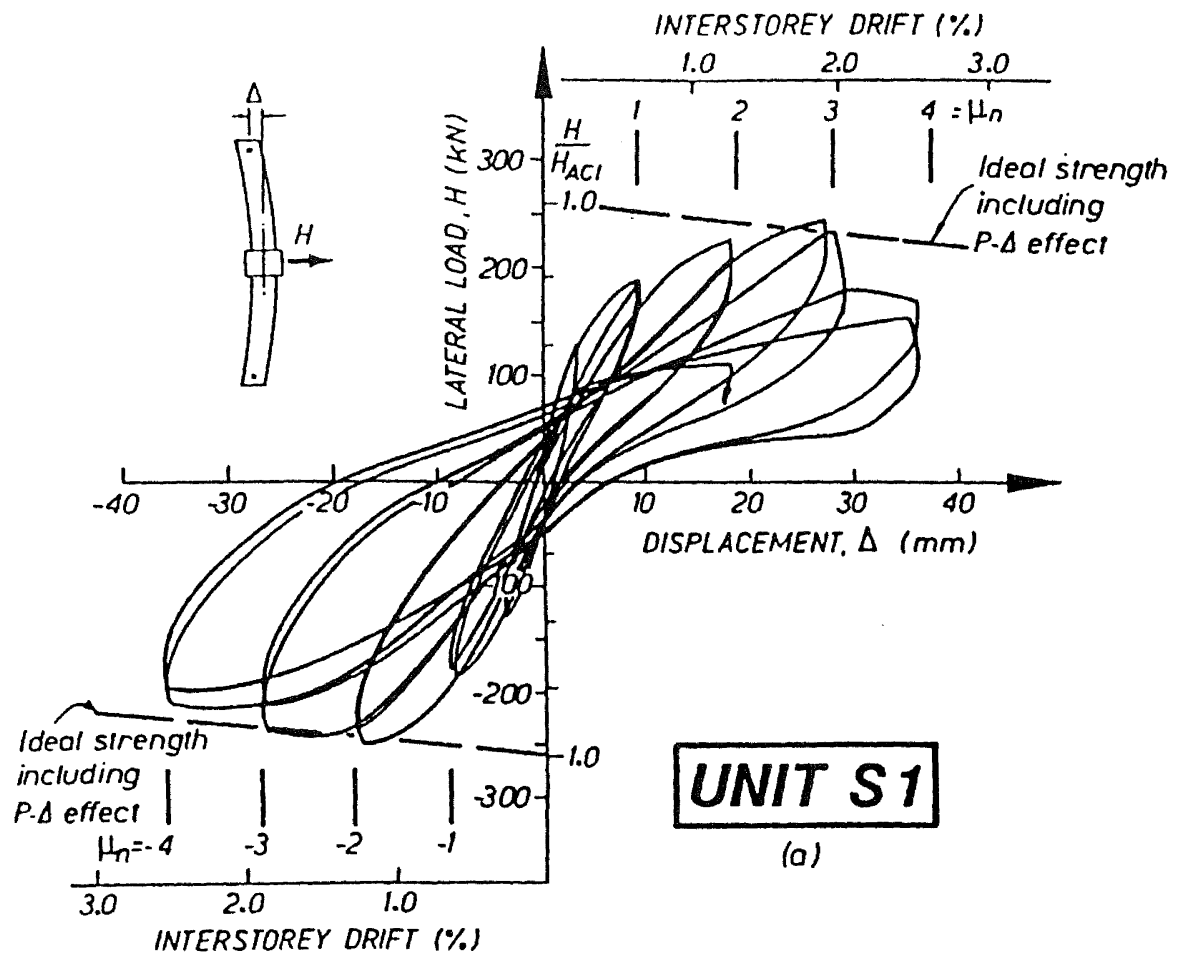

(a) Original Column

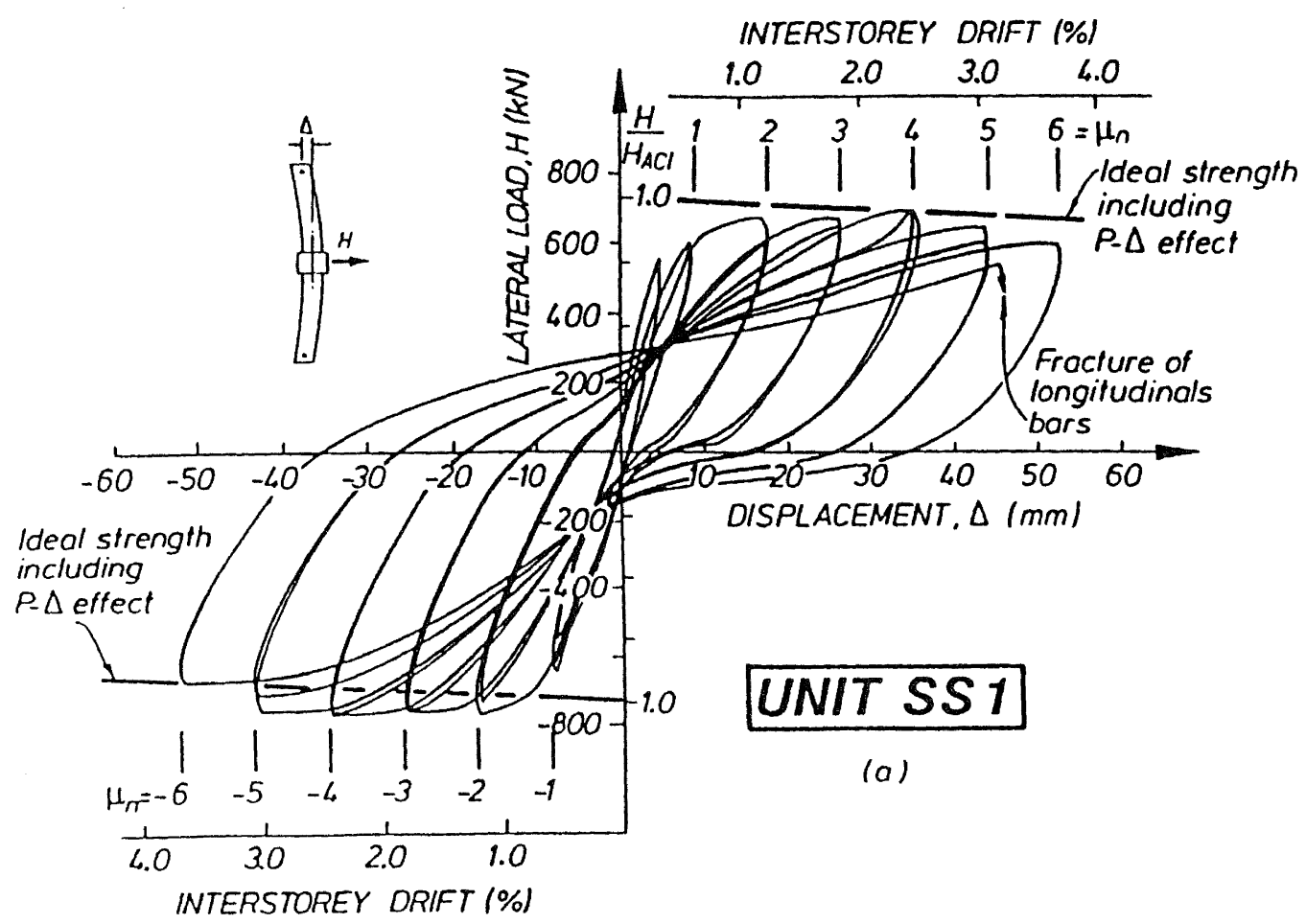

(b) Jacketed Column

FIGURE 4.10 EXPERIMENTAL LATERAL LOAD VERSUS DISPLACEMENT HYSTERESIS LOOPB (a) ORIGINAL COLUMN (b) JACKETED COLUMN 
All eight bridges, which were built between 1956 and 1962, consist of a conventional. arrangement of steel plate girders composite with a reinforced concrete deck slab and supported on reinforced concrete piers and abutments. The bridges were designed to the seismic design requirements of the 1956 Bridge Design Manual which specified a horizontal force of one tenth of the weight of the structure. Design live loading was to AASHO H20-S16 standard. A summary of span arrangements and pier types is given in the following table:

$\begin{array}{lll}\text { Bridge } & \text { Spans (metres) } & \text { Pier Type } \\ \text { Hikuwai 1 \& } 2 & 30.5-30.8-30.5 & \text { Frame } \\ \text { Hikuwai 3 } & 18.4-27.7-27.6 & \text { Frame } \\ \text { Hikuwai 4 } & 27.6-27.7-27.6 & \text { Frame } \\ \text { Makatote } & 21.5-21.6-21.6-21.5 & \text { Slab } \\ \text { Makarika 2 } & 15.4-15.5 .-15.4 & \text { Slab } \\ \text { Kopuaroa 1 } & 13.9-13.9 & \text { Slab } \\ \text { Kopuaroa 4 } & 13.9-14-14-13.9 & \text { Slab }\end{array}$

Fig. 4.11 shows the general arrangement of Hikuwai 2, which has tall slender open frame type piers typical of all four Hikuwai bridges. Seismic loads in the longitudinal direction are designed to be resisted at both abutments by an arrangement of eleven $405 \mathrm{~mm}$ octagonal reinforced concrete piles raked at $1: 3$. Transverse seismic design loads are designed to be resisted at all supports.

Fig. 4.12 shows the general arrangement of Makarika 2 which has low slab type piers typical of the remaining four bridges. The distribution of seismic design loads is the same as that in Hikuwai 2 bridge.

Extensive cracking was observed in all bridge decks soon after construction. The decks continued to deteriorate with use, with a substantial reduction in stiffness and progressive spalling of cover concrete from the underside of the decks being observed over the years. After a vehicle punched a hole through the deck on Hikuwai 1 in 1980 it was decided to replace the decks on all eight bridges. The girders required strengthening to carry the thicker replacement deck and current design live loads.

Analysis of the original raked piled abutments confirmed that they had considerable capacity to resist a high level of lateral loading without distress. On the other hand the piers, particularly the open frame type, were found to be lightly reinforced with little or no confining reinforcement in areas of potential plastic hinges. Studies showed that these bridges could be retrofitted for a small incremental cost, by isolating the superstructure with flexible elastomeric bearings and incorporating energy dissipators at the abutments, providing the work was carried out at the same time as redecking and girder strengthening.

The typical structural arrangement adopted for retrofitting on all eight bridges is shown in Fig. 4.13. The typical original and retrofitted details at the abutments and piers are shown in Figs. 4.14 and 4.15 respectively. Note the deck slab elements are linked together over the piers to enable the deck to act as a horizontal diaphragm spanning between the abutments.

Seismic retrofitting design loads for the four Hikuwai bridges were determined using the design charts developed by Blakeley in Reference 4.4. Lead/rubber energy

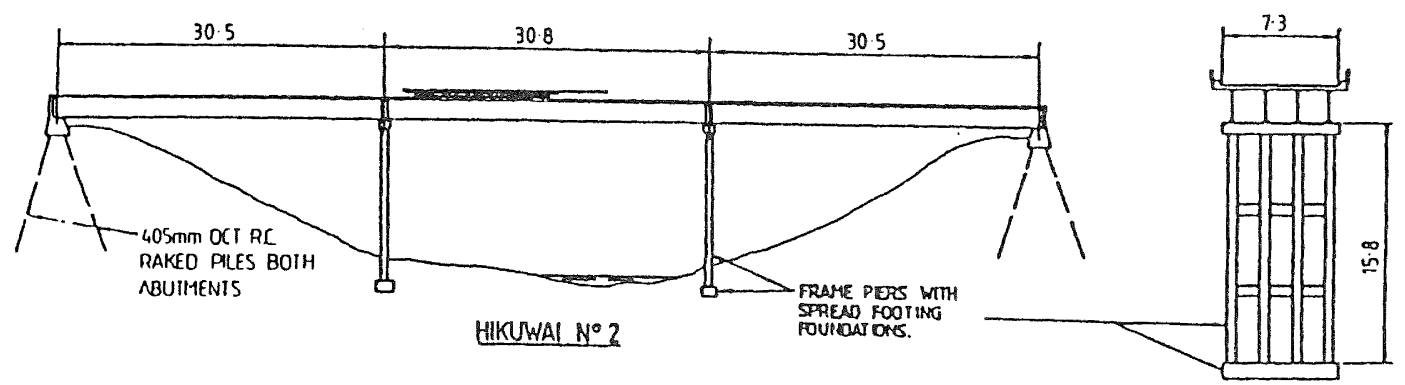

FIGURE 4.11 GENERAL ARRANGEMENT TYPICAL OF HIRUWAI BRIDGES WITH FRAME PIER8

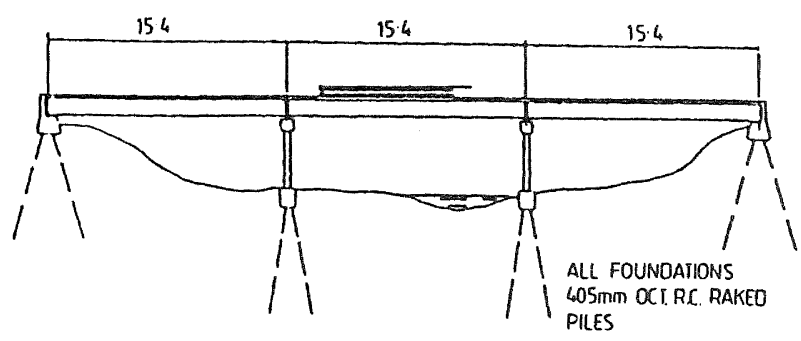

MAKARIKA N NO$^{\circ}$

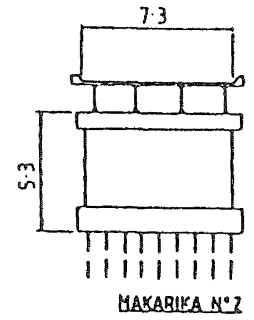

MAKABIEA Nי3

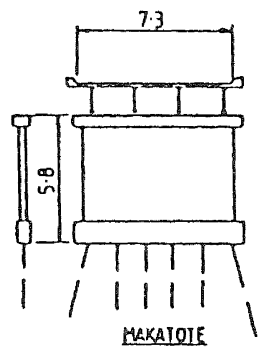




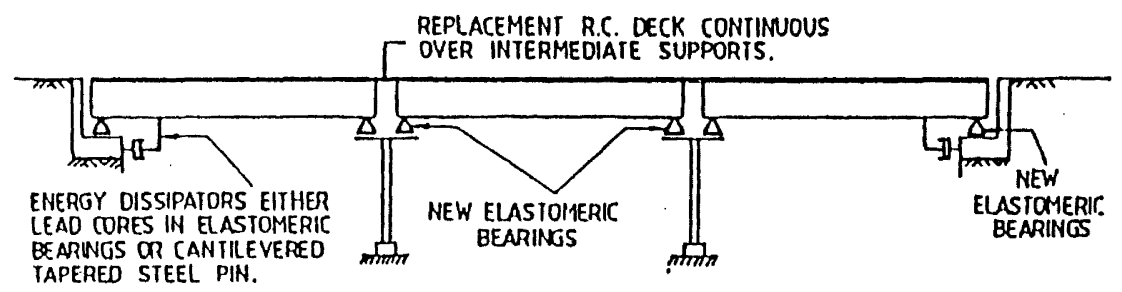

FIGURE 4.13 TYPICAL BTRUCTURAL ARRANGEMENT OF RETROFITTED BRIDGES

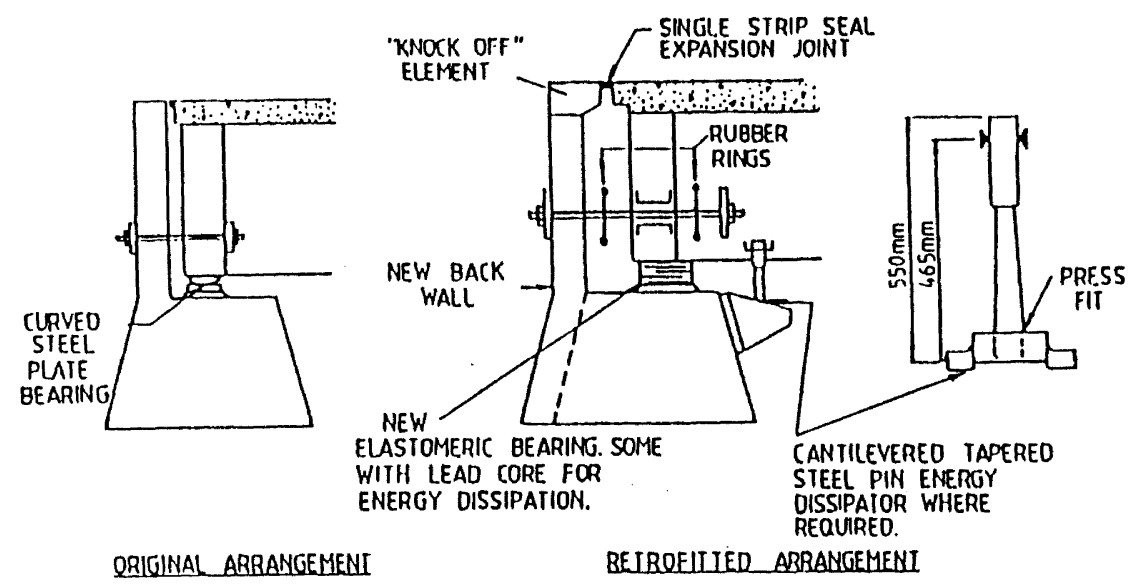

FIGURE 4.14 TYPICAL DETAILS AT ABUTMENTB
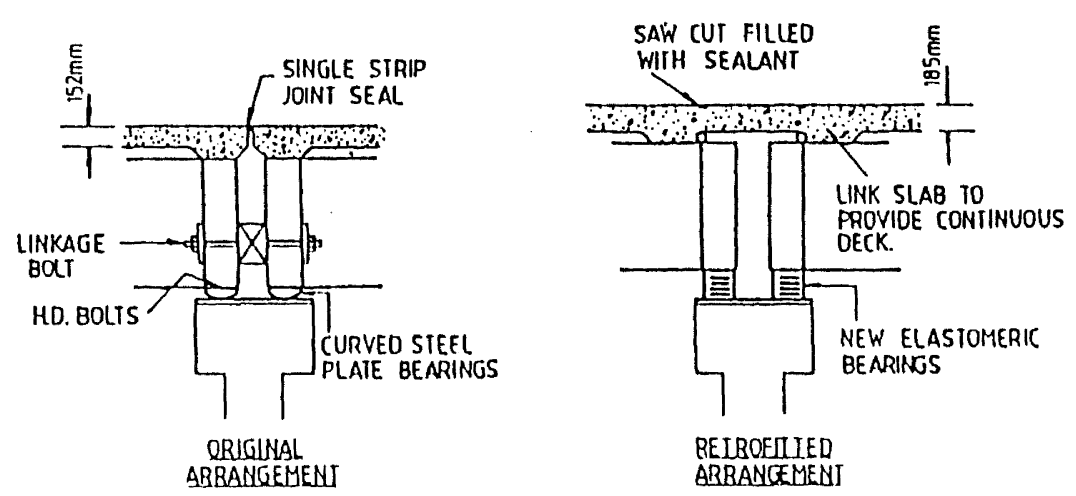

FIGURE 4.15 TYPICAL DETAILS AT PIERS 
dissipators were found to be suitable and were designed in accordance with Reference 4.4. However, for the remaining bridges with slab piers which have a substructure mass of the same order as the superstructure a specific dynamic analysis was carried out as recommended by Blakeley. The FEPLANE programme, which was developed at Berkeley, USA was used for the computer modelling and to establish design loads for retrofitting. Lead/rubber bearing energy dissipators were not considered suitable for Makarika, or for Kopuaroa 1 and 4 , as their dead load compressive stress would have been low and hence less effective in confining the lead core. Cantilever tapered steel pin energy dissipators, designed using Reference 4.6, were therefore used instead.

The retrofitted structures were analysed for both the corrected El Centro 1940 Accelerogram, and the Artifical $\mathrm{B} 1$ record. Maximum horizontal shear deflection on the elastomeric bearings for all bridges were about 60 to $75 \mathrm{~mm}$ for El Centro and 100 to $115 \mathrm{~mm}$ for B1. All substructures have sufficient "dependable strength" to resist El Centro and sufficient "probable strength" to resist $B 1$ shaking. The retrofitted structures can therefore be expected to sustain only minimal damage in a severe (MM8-9) earthquake, whereas before retrofitting they were likely to have sustained extensive damage in a modest (MM77.5) earthquake.

\subsection{ACKNOWLEDGEMENTS}

Due acknowledgement and thanks are made to Dr M. Rodriguez and Mr C. R. Stuart for their respective contributions as follows:

- 4.4.2 is extracted mainly from Reference 4.3 .

- 4.6 (State Highway 35 bridges) is reproduced mainly from Reference 4.7.

The agreement of the General Manager, Transit New Zealand, to publication of the information on state highway bridging is acknowledged with thanks.

\subsection{REFERENCES}

4.1 HOLLINGS J.P., FRASER I.A.N., "Earthquake Damage to Three Railway Bridges 1968 Inangahua Earthquake" Bulletin of New Zealand National Society for Earthquake Engineering, Vol 1 No 2 Dec 1968.

4.2 EVANS G.L., "The Behaviour of Bridges under Earthquake", Proceedings of New Zealand Roading Symposium 1971, Vol 2 pp 664-691, National Roads Board, Wellington 1972 .

4.3 RODRIGUEZ M., PARK R., "Seismic LOad Tests of Reinforced Concrete Columns strengthened by Jacketing" Proceedings of New Zealand Concrete Society Conference September 1990, pp 72 - 83, NZ Concrete Society, Wellington 1990.

4.4 BLAKELEY R.W.G., "Analysis and Design of Bridges Incorporating Mechanical Energy Dissipating Devices for Earthquake Resistance", Proceedings of a Workshop on Earthquake Resistance of Highway Bridges, January 1979, pp 313342, Applied Technology Council, ATC6, California USA, November 1979.

4.5 CHAPMAN H.E., KIRKCALDIE D.K., "Seismic Design of Base Isolated Bridges Incorporating Mechanical Energy Dissipators", Bridge Design and Research Seminar Volume 3 (43 pages and addendum), Transit New Zealand, Wellington 1990.

4.6 TYLER R.G., "Tapered Steel Energy Dissipators for Earthquake Resistant Structures", Bulletin of the New Zealand National Society for Earthquake Engineering, Vol 11, no 4, pp 282-294.

4.7 STUART C.R., "Seismic Retrofitting of Bridges in New Zealand", Proceedings of Second Joint US - New Zealand Workshop on Seismic Resistance of Highway Bridges, May 1985, pp 157-161, Applied Technology Council, ATC-12-1, california USA, 1986. 